\title{
On ultrastructure and gene expression during epiblast morphogenesis and axial differentiation in the prestreak embryonic disc of the pig
}

\author{
Dissertation \\ for the award of the degree \\ "Doctor rerum naturalium" (Dr.rer.nat.) \\ of the Georg-August-Universität Göttingen \\ within the doctoral program Biology \\ of the Georg-August University School of Science (GAUSS) \\ submitted by \\ Braah Harmoush
}

from Latakia, Syria

Göttingen, 2019 
Thesis Committee

Prof. Dr. E. A. Wimmer, Dept. of Developmental Biology GZMB, Georg-August-University Göttingen

Prof. Dr. C. Viebahn, Institute of Anatomy and Embryology, University Medical Center Göttingen

Members of the Examination Board

Reviewer: Prof. Dr. C. Viebahn

Second Reviewer: Prof. Dr. E. A. Wimmer

Further members of the Examination Board

Prof. Dr. A. Mansouri, Molecular Cell Differentiation Group, Max Planck Institute for Biophysical Chemistry

Prof. Dr. C. Wichmann, Molecular Architecture of Synapses Group, University Medical Center Göttingen

Prof. Dr. G. Eichele, Molecular Developmental Neurobiology Group, Max Planck Institute for Biophysical Chemistry

Prof. Dr. J. Wilting, Institute of Anatomy and Cell Biology, University Medical Center Göttingen

Date of the oral examination: October $15^{\text {th }}, 2019$ 
To those who never give up on me:

To my beloved Parents 


\section{Contents}

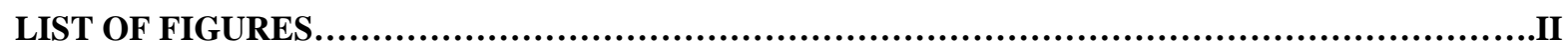

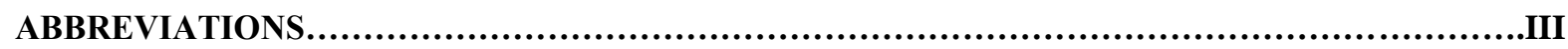

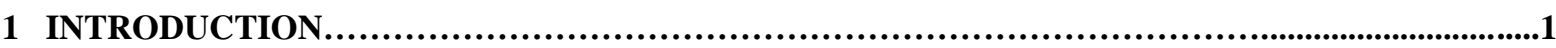

1.1 MORPHOGENESIS OF THE FLATTENED EPIBLAST AT THE PREGASTRULATION STAGES ......................1

1.2 THE EARLY ANTERIOR-POSTERIOR AXIS DIFFERENTIATION AND HOMEOBOX GENE GOOSECOID ............3

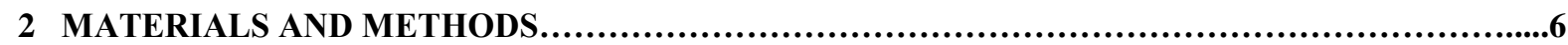

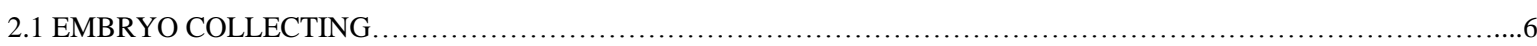

2.2 FIXATION AND EMBEDDING FOR LIGHT AND ELECTRON MICROSCOPY ......................................

2.3 HIGH RESOLUTION LIGHT AND TRANSMISSION ELECTRON MICROSCOPY ..................................

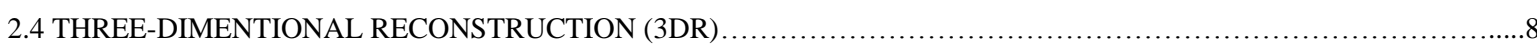

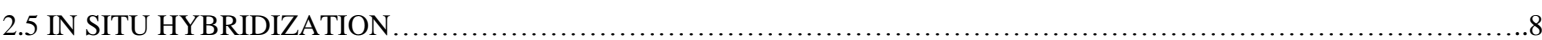

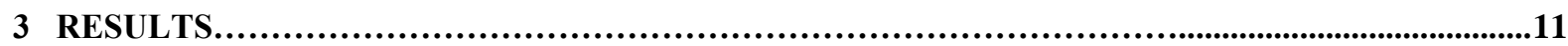

3.1 REFINED STAGING FOR THE MORPHOGENESIS OF THE EMBRYONIC DISC IN THE PIG.........................11

3.2 CHARACTERISTICS OF THE BALL-SHAPED EMBRYONIC DISC (STAGE 1-)................................13

3.3 THE FORMATION OF EPITHELIAL VENTRAL EPIBLAST (STAGE $1+$ ) ......................................... 14

3.4 3D RECONSTRUCTION AND TOPOGRAPHICAL CORRELATION DURING EPIBLAST EPITHELIALIZATION

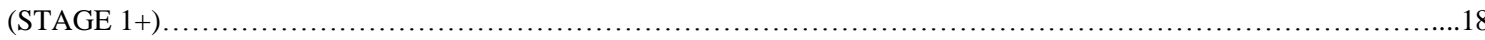

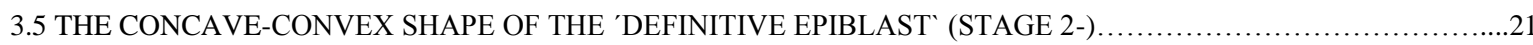

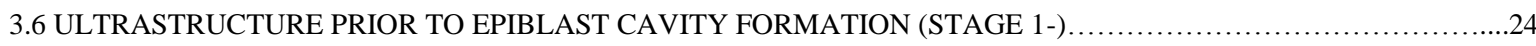

3.7 ULTRASTRUCTURE DURING THE DISINTEGRATION OF POLAR TROPHOBLAST AND DORSAL EPIBLAST

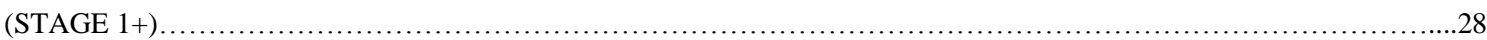

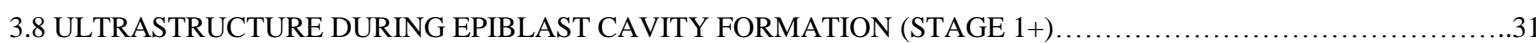

3.9 ULTRASTRUCTURE DURING THE FORMATION OF THE CONCAVE-CONVEX EPIBLAST SHAPE

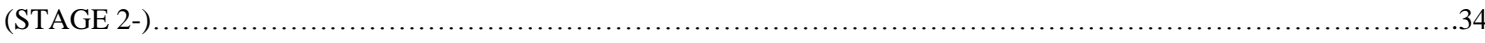

3.10 GOOSECOID EXPRESSION AT PREGASTRULATION STAGES 0, 1-, 1+, 2 AND STAGE 4+.......................36

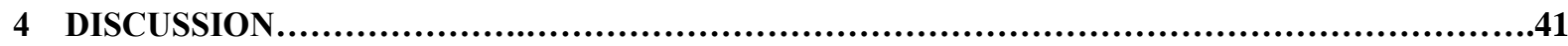

4.1 THE MORPHOGENESIS AND EPITHELIALIZATION PROCESS OF THE EPIBLAST BEFORE THE ONSET OF

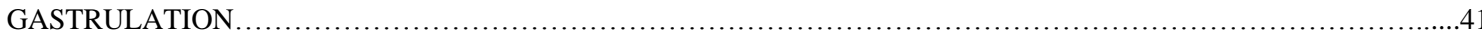

4.2 THE POLAR TROPHOBLAST PHAGOCYTOSIS, CELL DEATH AND THE FATE OF DORSAL EPIBLAST...........43

4.3 EARLY ANTERIOR-POSTERIOR AXIS DIFFERENTIATION AND THE PRECURSORS OF THE PRIMITIVE

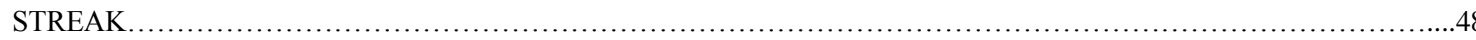

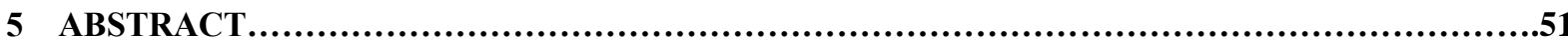

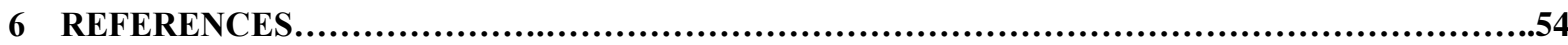

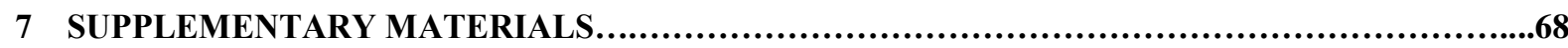

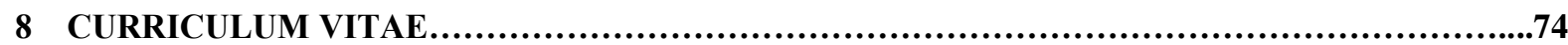




\section{LIST OF FIGURES}

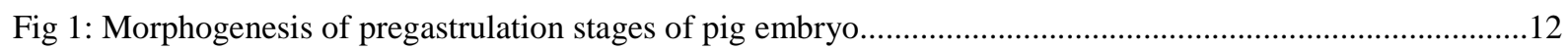

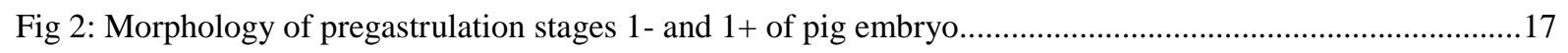

Fig 3: 3D reconstruction of pig embryonic disc at pregastrulation stage $1+$ of pig embryo .........................19

Fig 4: Schematic correlation of anterior-posterior axis with the morphological characteristics of stage 1+

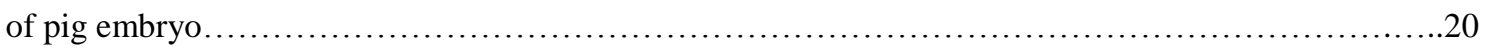

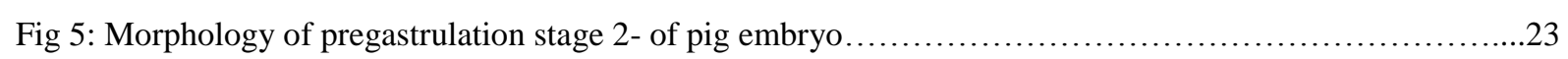

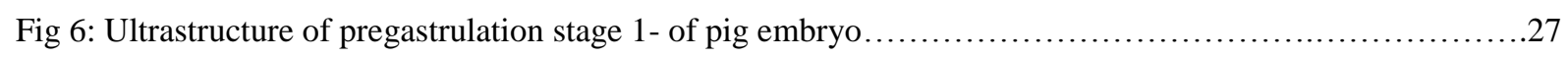

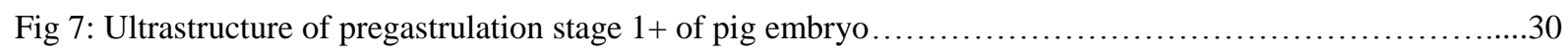

Fig 8: Ultrastructure of remnants of polar trophoblast and dorsal epiblast at pregastrulation stage 1+

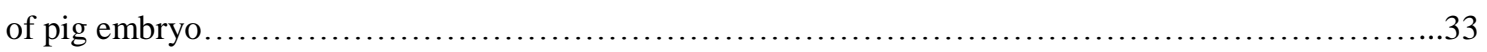

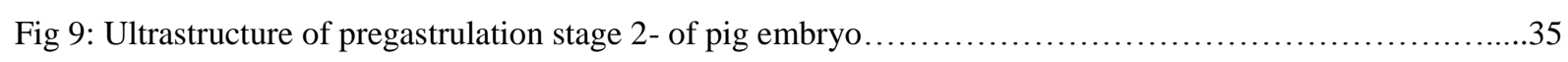

Fig 10: Goosecoid expression at pregastrulation stages $0,1-$ and $1+$ of pig embryo................................

Fig 11: Goosecoid expression at pregastrulation stage 2 and stage $4+$ of pig embryos......................... 40

Fig 12: Schematic correlation of the two goosecoid expression domains in the pig embryonic disc during epiblast development and gastrulation.

\section{Supplementary material figures}

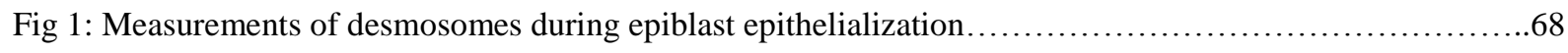

Fig 2: Comparison of lipid droplets in polar trophoblast, epiblast and hypoblast at stages 1 - and $1+\ldots \ldots \ldots \ldots . . .69$

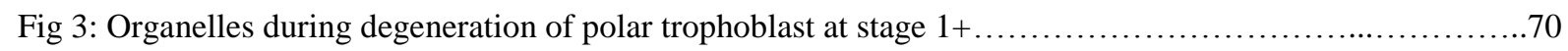

Fig 4: Organelles in the remnants of polar trophoblast cells at late stage $1+$ and $2-\ldots \ldots \ldots \ldots \ldots \ldots \ldots \ldots \ldots . \ldots 1$

\section{List of tables}

Table 1: Comparison of embryonic stages prior to gastrulation with age

Table 2: Measurements $(\mathrm{nm})$ of the special desmosomes during the epithelialization of the epiblast cells. 


\section{Abbreviations}

3DR three-dimensional reconstruction

AHB anterior hypoblast

AMC anterior marginal crescent

AP

anterior-posterior

AVE

anterior visceral endoderm

BMP4

bone morphogenetic protein 4

bp

base pair

cDNA

complementary deoxyribonucleic acid

dpc

day post coitum

EMT

epithelial to mesenchymal transition

GA

glutaraldehyde

gsc

goosecoid

h

hour

hCG

human chorionic gonadotropin

ICM

inner cell mass

Ml

milliliter

MET

mesenchymal to epithelial transition

mRNA

messenger ribonucleic acid

nm

nanometer

OsO4

osmiumtetroxide

PBS

phosphate buffer saline

PFA

paraformaldehyde

PMSG

pregnant mare serum gonadotropin

RER

rough endoplasmic reticulum

RT-PCR

reverse transcriptase polymerase chain reaction

$\mu \mathbf{m}$

micrometer

ZLDs

zipper like desmosomes 


\section{Introduction}

Gastrulation is well known as a critical period of embryonic development because it marks the beginning of the specific body plan and is defined for most multicellular animals. For the first time in development, the principal body axes are unequivocally visible and molecular interactions are confronted with a complex topographical arrangement of cells, not least due to the appearance of a principally new cell type by the mesoderm. In mammals and birds, gastrulation begins with the appearance of mesoderm cells in the primitive streak at the posterior pole of the embryonic disc (Mouse: Nakatsuji et al., 1986; Lawson et al., 1991; Human: Carlson. 2002; rabbit: Viebahn et al., 2002; Pig: Hassoun et al., 2009; Sun et al., 2013; Cow: Maddox-hyttel. 2003; Sheep: van Leeuwen et al., 2015), where mesenchymally differentiated cells are generated from the unilaminar epithelial epiblast in a process called epithelia-mesenchymal transition (EMT; Chuai et al., 2012; Bertocchini et al., 2013; Nakaya and Sheng. 2013).

\subsection{Morphogenesis of the flattened epiblast at the pregastrulation stages}

In contrast to most amphibian and fish species, where the pre-gastrulation epiblast (or ectoderm) is pseudostratified or only partially epithelialized (Nakaya and Sheng. 2008), establishing a unilaminar epithelial sheet always precedes gastrulation in amniotes, and planar cell movements within this epithelium are suggested to be a prerequisite for primitive streak formation (Sheng 2015; Halacheva 2011; Stankova 2015). In many mammals, the gradual epithelialization of the pregastrulation epiblast is also critical to ensure (1) the integrity and stability of the embryonic disc after the disappearance of the polar trophoblast (s. below) and (2) for permeability of nutrients (Barends et al., 1989; Williams and Biggers, 1990). The epiblast also provides the basis for the controlled growth of the embryonic disc and the distribution of signals for the formation of the primitive streak.

Flattening of the embryonic disc is the result of the inner cell mass (ICM) segregating into a pseudostratified (pluripotent) epiblast and a squamous or cuboidal (extraembryonic) hypoblast in most mammals (Luckett. 1975; Degrelle et al., 2005; Nakaya and Sheng. 2013; Posfai et al., 2014; Sheng. 2015), and in rodents this transition is thought to start with a mosaic distribution of presumptive epiblast and hypoblast cells (Rossant and Tam. 2009; Bedzhov and Zernicka-Goetz. 2014). Almost simultaneously the first signs of the anterior-posterior body axis appear in the hypoblast at the future anterior pole of the embryonic disc (s. Viebahn 
1999 for a review) and could be considered to be the first blueprint of the body axis. A second differentiation step accompanying the appearance of the flat embryonic disk is speciesspecific and occurs extraembryonically: the polar trophoblast (covering the inner cell mass) either degenerates and exposes the epiblast to the uterine cavity or it proliferates and contributes, instead of the mural trophoblast, to placenta formation. The post-hatching mouse blastocyst, for example, allows the polar trophoblast to proliferate (while adhering to the uterine wall) and to gives rise to the ectoplacental cone (while the previously flat epiblast transforms into an egg cylinder; Gardner et al., 1973; Dey et al., 2004). In most mammals except for higher primates, in contrast, the polar trophoblast disintegrates (Geisert et al., 1982; Betteridge and Fléchon. 1988; Williams and Biggers. 1990; Enders et al., 1988; Vejlsted et al., 2005; Blomberg et al., 2008) and the flat embryonic disk may still need to be established through transformation from a transitional ball-shaped mass of seemingly non-polarized epiblast cells (Sheng, 2015).

In contrast to the wide use of ungulates as domestic animals and, indeed, as historic model animals for human development, their regulative strategy and the successive differentiation steps leading to the transition from the ball-shaped epiblast into a flat disc shape, or the reorganization of the non-polarized epiblast cells into a polarized columnar epithelium, remain largely unknown. This also stands in strong contrast to the detailed description of the mosaic phenomenon in the mouse (Rossant and Tam. 2009; Bolton et al., 2016). The best formal description among ungulates can be found in the pig. Shortly after hatching from zona pellucida at day 7 (Barends et al., 1989) the epiblast is covered with a continuous layer of cuboidal polar trophoblast cells dorsally and a squamous epithelium of hypoblast cells ventrally (Hassoun et al., 2009; Hyttel et al., 2009). Polar trophoblast cells are connected to each other by many desmosomes and their upper surface contains short microvilli (Fléchon. 1978; Norberg. 1973). Soon thereafter the polar trophoblast is completely lost but in contrast to the morphological analyses available for the rabbit and the horse, where the polar trophoblast disintegration shows signs of apoptosis and phagocytosis by epiblast cells (Williams and Biggers. 1990; Enders et al., 1988), the mechanism behind polar trophoblast degeneration in the pig is yet to be determined. There is only rather a general description of the appearance of the multiple discontinuities between the polar trophoblast cells and extracellular spaces forming between epiblast cells (Barends et al., 1989) and that of the cattle (van Leeuwen et al., 2015). In addition, this process is reminiscent to the formation of the mouse blastocyst cavity after the fifth round of cell division when hundreds of small fluid- 
filled microlumens at cell-cell junctions have been shown to grow to form the blastocyst cavity (Dumortier et al., 2019) and formation of the mouse pro-amniotic cavity (between the trophectoderm and the centre of future egg-cylinder) which is formed through the widening of rosette-like structures appearing between the emerging epiblast cells (Bedzhov and ZernickaGoetz. 2014).

The pig embryo is also an interesting model to investigate the dynamic morphological changes at early developmental stages because it represents the characteristics of the eutherian and especially the domestic ungulates, and because of the success of cloning by somatic stem cell nuclear transfer (Onishi et al., 2000; Hall 2008) and the continuous attempts to derive stable pluripotent stem cells from the pig embryo (Hou et al., 2016; Park et al., 2013; Gandolfi et al., 2012; Oestrup et al., 2009). Also, it was noticed that the majority of the embryonic mortality in the pig and cattle takes place during the post-hatching development stages (Wilmut et al., 1986; Stroband and Van der Lende 1990). All the features require a better understanding of structures of pregastrulation stages and create the need for further morphological research of the pig blastocyst at the period of epiblast epithelialization.

Because cellular flattening, epithelization and disintegration are primarily morphologically defined processes (similar to EMT and its reversion called mesenchymal-to-epithelial transition; Pei et al., 2019) this study uses light and electron microscopy techniques and 3D reconstruction to reveal the sequence of morphological events and the ultrastructural characteristics related to the disappearance of the polar trophoblast and the rise and fate of two topographically defined cell types enclosing the initial extracellular cavity in the epiblast. Either of the two following epithelialization scenarios may be found in the epiblast at the tissue level: (a) opening of the epiblast ball at the (dorsal) 12- o'clock-position to form a deep concave cup which establishes contact at its rim with the remaining polar trophoblast cells, or (b) cutting the epiblast ball at a circumferential 3- (and 9-) o'clock position to form a shallow cup which establishes contact with mural trophoblast cells and discards the dorsal half of the epiblast ball in process similar to polar trophoblast loss. Due to the concomitant initial differentiation of the anterior-posterior axis this study will also address the correlation of epiblast and trophoblast changes with the early formation of the anterior hypoblast.

\subsection{The early anterior-posterior axis differentiation and homeobox gene goosecoid}


The anterior-posterior axis in mammalian blastocyst emerges prior to the onset of gastrulation and is defined by anterior structural features described as anterior visceral endoderm (AVE) in the mouse (Thomas and Bedding. 1996; Rivera-Peréz et al., 2003; Takaoka. 2011; Takaoka and Hamada 2012), the anterior marginal crescent (AMC) in the rabbit (Viebahn et al., 1995) and the anterior hypoblast (AHB) in the pig (Hassoun et al., 2009). In contrast, in the chick the first signs of the anterior-posterior polarity are marked by the presence of Koller's sickle at the posterior pole of the embryonic disc (Callebaut and Van Neuten, 1994). The primitive streak formation is preceded by accommodation of a pseudostratified thickness by posterior epithelialized epiblast, which is suggested to be caused by signals secreted by the hypoblast or visceral endoderm, which antagonize the mesoderm induction in the anterior epiblast and therefore the development of the primitive streak is restricted to the posterior pole (Idkowiak et al., 2004a, b; Hyttel et al., 2011; Ding et al., 1998; Escalante-Alcalde et al., 2003). These posterior epiblast cells express Brachyury (Maretto et al., 2003; Mohamed et al., 2004) which is involved in the formation of the primitive streak.

The main player in this process is the activity of the primary embryonic organizer or what is known by Spemann organizer (Spemann and Mangold, 1924). An organizer is a specialized group of cells, which was first shown in amphibian to be located in the dorsal lip of the blastopore. Homologous structure were defined in other vertebrates and include the dorsal marginal shield in the fish (Shih and Fraser 1996), Hensen's node in the chick (Waddington and Schmidt, 1933; Hara, 1978; Izpisúa-Belmonte et al., 1993) and the node in the mouse at the anterior margin of the primitive streak (Blum et al., 1992; Beddington, 1994). The importance of the organizers progenies is characterized by (1) formation of the embryonic axial structures by recruiting cells from other embryonic tissues (2) induction of neural tissues and (3) establishing the vertebrate body plan (Blum et al., 2007). In vertebrates as in some invertebrates, the Spemann's organizer is among others marked by the expression of goosecoid ( $g s c$ ), a highly conserved gene which encodes a transcription factor and belongs to the homeobox gene family (Blumberg et al., 1991; Blum et al., 1992; De Robetris 1994; Broun et al., 1999). Gsc is known for its ability to induce the formation of a secondary embryonic axis recruiting the cells of the ventral side (the opposite side of the gsc normal activity) in Xenopus (Cho et al., 1991) and to repress target gene pathway components i.e. BMP4 (bone morphogenetic protein 4) in mouse and Xenopus (Fainsod et al., 1994; Artinger et al., 1997). The activity of the BMP4 is also antagonized by dorsal mesoderm molecules such as Chordin that can induce twinned axis and its expression in the organizer can be 
induced by gsc (Sasai et al., 1995).

During late post-gastrulation embryonic stages, the function of the $g s c$ have been well studied, whereas the early mechanism regulating the role of $g s c$ either before the formation of the organizer (pregastrulation stages) or in the organizer (during gastrulation) are yet to be defined. In mammals, establishing the significance of $g s c$ expression requires the use of an additional model other than the mouse (Yoshida et al., 2016; Van de Pavert, 2001; Meijer et al., 2000). The pig embryo is a candidate for this purpose as it shares the early morphological features of the flat embryonic disc, the molecular pathways and the anterior hypoblast as an early sign for the anterior-posterior polarity (Hassoun et al., 2009). The pig embryo was therefore chosen to test the possibility of conserved gsc expression at the early developmental stages in the mammals. Therefore, in addition to the high resolution morphological analysis described above, whole mount in situ hybridization for the expression of $g s c$ is applied here to determine (1) whether $g s c$ is indeed one of the earliest axis determinant factors and (2) whether the spatial gsc expression pattern is evolutionary conserved at pre- and early gastrulation stages of the pig. The molecular results of this study may refer to $g s c$ as one of the earliest axis determinant factors at the embryonic and extraembryonic anterior hypoblast as well as the posterior epithelialized epiblast. 


\section{Materials and Methods}

\subsection{Embryo collecting}

The embryos used in this study are provided from the same species of gilts but they are obtained from two different sources. The embryos of the first source are used for light and electron microscopy as well as the in situ hybridization whereas the embryos of the second source are used only for in situ hybridization. The first source: Embryos between 8 to 10 and 12-13 days post coitum ( $\mathrm{dpc}$ ) of age were selected from litters obtained from 8 late prepubertal gilts (Landrace x Large white, Institute of Animal Science and Behavior, 31535 Mariensee, Germany) after mating with Piétrain boars as described by Hassoun et al., (2009). The females were first stimulated by $5 \mathrm{ml}$ equine Regumate ${ }^{\circledR}(2.2 \mathrm{mg} / \mathrm{ml}$, Intervet, Unterschleißheim, Germany) per os once every morning for 13-15 days prior to mating, and 1500 IU pregnant mare gonadotropin serum PMGS (Integonan ${ }^{\circledR}$, Intervet) i.m. 3 days prior to mating and then superovulated using 500 IU human chorionic gonadotropin hCG (Ovogest ${ }^{\circ}$, Intervet) i.v. one day prior to mating. The gilts were mated or artificially inseminated twice over $24 \mathrm{~h}$, and the age of the embryos was calculated - differently to the method applied by Hassoun., et al (2009) - from the last day of mating; for example, embryos designated here "8 d.p.c" are 8 or 9 days old and therefore, the conceptuses of one litter may vary in age by $24 \mathrm{~h}$, and consequently, in stages as well (Table 1). After removing the uteri from the slaughtered gilts and transporting them to the laboratory, the embryos were collected after they were flushed from uteri 2-3 times with $20 \mathrm{ml}$ warm $\left(37^{\circ} \mathrm{C}\right)$ Phosphate buffer saline (PBS; Roche, Manheim, Germany) containing 2\% polyvinyl alcohol (Sigma Aldrich, Taufkirchen, Germany). A total number of 179 conceptuses were obtained from 8 litters ( 97 embryos from 4 litters at 8-9 dpc; 61 embryos from 2 litters at 9-10 dpc and 21 embryos from 12-13 dpc). A total number of 95 of the 179 embryos were fixed for light and electron microscopy and we analyzed 26 embryos for this study whereas the rest (84 of 179 embryos) were fixed for in situ hybridization and 12 conceptuses are used for this study. The selected embryos for light and electron microscopy and in situ hybridization are defined as stages 1-, 1+, 2-, 2+ and 4+ (Table 1). The second source: 9 Prepubertal gilts (landrace x Large White; institute of animal Husbandry and Genetics, Göttingen University) were simulated using synthetic progestogen (Regumate ®; Intervet, Unterschleißheim, Germany) per os once daily for 10-18 days for the purpose of inhibiting the secretion of gonadotropins. On the day before the mating, gilts were superovulated using pregnant mare serum gonadotropin (PMSG) and human chorionic gonadotropin (hCG). Each gilt was mated twice by a boar of Piètrain breed (Institute of 
Animal Husbandry and Genetics, Göttingen University); the first time of mating is scheduled $24 \mathrm{~h}$ after the gonadotropin treatment and the second is with a time intervals of $24 \mathrm{~h}$ from the first mating. The gestational age of the obtained conceptuses was calculated by the same method described above from the first source of embryos with a time difference of $24 \mathrm{~h}$. Uteri were removed after the gilts were slaughtered (at the Institute of Animal Husbandry and Genetics, Göttingen University) between 8-9 and 9-10 days post coitum (9 litters with a total of 96 blastocysts: 3 litters at 8-9 dpc with number of 37 embryos; 6 litters at 9-10 dpc with number of 59). After the removal of the uteri, the uterine horns were flushed with room temperature PBS instead of warm $\left(37^{\circ} \mathrm{C}\right) \mathrm{PBS}$ as in the previous embryos treatment, and thus, these embryos were labelled cold treatment embryos. All of the embryos were fixed for in situ hybridization and we used 10 embryos for my research defined as stages $0,1-, 1+, 2-$ and $2+($ Table 1$)$.

\subsection{Fixation and embedding for light and electron microscopy}

Blastocysts, which were already hatched from the zona pellucida but not implanted yet, were microdissected using iridectomy scissors and tungsten needles to remove most of the extraembryonic tissues. The microdissected embryos were first prefixed in a mixture of $1.5 \%$ paraformaldehyde (PFA; Sigma Aldrich, Taufkrichen, Germany) and 1.5\% glutaraldehyde (GA; Serva, Heidelberg, Germany)) for 2-3 h in room temperature, and they are photographed under a stereomicroscope (leica, Wetzlar, Germany) under light and dark field illumination. Thereafter, they are postfixed in 1\% Osmiumtetroxid (OsO4; Wachemie, Pacsel, Germany) and then whole mount photographed in dorsal and ventral views using dark field optics before being embedded in Araldit ${ }^{\circledR}$ (Plano, Wetzlar, Germany) as described in (Schwartz et al., 1984). They were also photographed inside the polymerized Araldit ${ }^{\circ}$ blocks in a stereomicroscope using bright field optics to help define the angle of sectioning.

\subsection{High-resolution light and transmission electron microscopy}

The 26 embryo analyzed in this study were serially sectioned at $1 \mu \mathrm{m}$ (semithin sections) using a manual microtome and diamond knives (Diatome Ultra $45^{\circ}$, Weinheim, Germany) with the aim of obtaining either a sagittal or a transverse plane of sectioning, and then stained with mixture of 2\% methylene blue (Merck, Darmstadt, Germany) and 1\% borax (Merck, Darmstadt, Germany), and 1\% Azur II (Merck, Darmstadt, Germany) according to (Schwartz et al., 1984). The orientation of each series of sections was ascertained as follows: peripheral morphological characteristics produced by the dissection with the extraembryonic trophoblast 
were identified in the sections and the whole mount photographs as defining landmarks for the orientation of the plane of sections. Every five sections were mounted on a glass slide numbered serially according to the sectioning direction. The analysis of the series of embryos for high resolution light microscopy were carried out with Zeiss Axioplan 2 program and saved in (TIFF) format files. After that, few sections were selected for further analysis by electron microscopy, on the basis of the presence, absence or discontinuity of the polar trophoblast (Rauber's layer) or the cavity formation in the epithelialized epiblast for further observation. Each of the selected sections is re-embedded in Araldit® (Viebahn et al., 1995) and $70 \mathrm{~nm}$ thin sections were taken up onto five grids filled with dissolved solution of Formvar (Sigma F-6146) and chloroform, covered with thin films and stored in specimen grid boxes (LKB, Stockholm, Sweden) before analysis with transmission electron microscope (Leo 906 E, Zeiss, Jena, Germany) using varied magnifications. The numbers of embryos staged for this study were as follow: seven embryos $(n=7)$ round or oval epiblast at stage 1-, $(n=7)$ cavitied epiblast at stage $1+,(n=7)$ concave-convex epiblast at stage 2 - and $(n=5)$ dome-shaped epiblast at stage $2+$.

\subsection{Three-Dimensional reconstruction (3DR)}

The previously taken (TIFF) figures of serial light microscopic sections of selected conceptuses of stages $1+(n=6)$ and 2- $(n=3)$ were aligned and manually segmented using the TrackEM2 (Schindelin et al., 2012) a plugin of the "Fiji-ImageJ-win64" open-source program (http://imagej.net/Fiji) to provide a 3D reconstruction of the gradually disintegrated polar trophoblast and the epiblast during the latter epithelialization prior to gastrulation of the pig embryonic disc. One of the five mounted sections of every slide of the sectioned embryo was used to reconstruct the whole three layers of the embryonic disc: the polar trophoblast, the epiblast and the hypoblast. The two axes of $\mathrm{x}$ - and $\mathrm{y}$ - were adjusted according to an estimate of the $\mu \mathrm{m} /$ pixel ratio described in the measurements of the Fiji web site tutorial (for more information see online https://imagej.net/TrakEM2_tutorials). The areas to be reconstructed were color coded as follows: dark green for polar trophoblast, blue for epiblast and white for the cavity of the epiblast (Fig 3). The colored segmented areas were then reconstructed by Fiji to be visualized either individually or combined using the 3D java plugin.

\subsection{In situ hybridization}

For in situ hybridization a digoxigenin-labelled goosecoid $(g s c)$ mRNA probe was generated from a pig $g s c$ cDNA. Total RNA was first isolated and purified from pig embryonic tissues 
using Total Isolation Kit (peqGOLD, Erlangen, Germany). Reverse transcriptase polymerase chain reaction (RT-PCR) was then used to form the required cDNA which spans the reading frame and 5 to $3{ }^{`}$ UTR sequence of pig goosecoid (NCBI reference sequence NC_010449). However, to generate the $g s c$ cDNA few primers were used in the RT-PCR (Primers: A1: 5 CCA GCA TGT TCA GCA TCG AC-3`; B1: 5 -TTC GTT CCT CCT TCT CGA CC-3` C1: 5`-CGG ACT ATG GCG CCT TCT AC -3`; D1: 5`-CGT CAG CTG TCC GAG TCC AA3` Nested PCR primers: p3: 5`AGA TGC TGC CCT ACA TGA ACG -3`; r1: 5`-TCA GCT GTC CGA GTC CAA ATC -3`). Primers A1, and C1 are located in exon 2 between base pair position 147-166 respectively 294-313 in the DNA of 1964 bp length (NCBI reference sequence NC_010449). The reverse primers D1, B1 are located in exon 3 between position 912-893 and 1026-1007. The other two primers p3 and r1 were designed based on the mouse gsc sequence (EMBL accession number M85271). The forward primer gsc-p3 is identical to the mouse cDNA sequence at positions 401-421 and is located in exon 2. The reversed primer gsc-r1 is complementary to the mouse cDNA sequence at positions 751-771 and is located at the end of exon 3. The obtained pig cDNA was used to generate gsc mRNA probes by PCR using plasmids (NucleoSpin®) and are flanked by SP6- and T7-promoter sequences. This resulting in 330 bp pig gsc mRNA fragment spanning part of pig gsc mRNA (1324 bp, Nucleotides XM_003482313) as it matches partial pig mRNA (330 bp, NCBI gene bank Y17718.1). A total number of 22 conceptuses were used to analyze the developmental stages as follow: two conceptuses $(n=2)$ at early ICM stage 0 ; six conceptuses $(n=6)$ at stage 1 -; five conceptuses $(n=5)$ at stage $1+$; five conceptuses $(n=6)$ at stage 2 and three conceptuses $(n=3)$ at late stage 4+. These specimens were collected and dissected as previously described for light and electron microscopy but with two exceptions: (1) the cold treatment before fixation using the room temperature PBS for flushing the embryos from the uterus, (2) the stage 0 was defined by the absence of the identification of the embryonic disc under the stereomicroscope, and because of these difficulties in determining the exact location of the disc and to avoid tearing it accidentally, one small cut was made randomly in the opposite side of the presumed embryonic disc to allow the fixation solution to get inside the whole blastocyst which is later reserved for further analysis using in situ hybridization. The cold treated blastocysts are the ones of the early stages for in situ hybridization (stages 0 and 1-). The chosen blastocysts for in situ hybridization were then fixed in $4 \%$ paraformaldehyde (PFA) in phosphate buffer for $2-3 \mathrm{~h}$ at room temperature; after being photographed as whole mounts under light and dark field illumination with stereomicroscope (Zeiss, Göttingen, Germany), specimens were dehydrated in a graded series of ethanol and frozen in $-20^{\circ} \mathrm{C}$ in $100 \%$ ethanol until used later 
for in situ hybridization. In situ hybridization was performed at $70^{\circ} \mathrm{C}$ using standard protocol edited from the early embryonic stages of the rabbit embryonic discs (Weisheit et al., 2002; Püschel et al., 2010). The period of specimens incubation in room temperature with proteinase K (Sigma-Aldrich, Taufkirchen, Germany) was $10 \mathrm{~m}$ for stages 1-, 1+ and 2 but it was increased to $15 \mathrm{~m}$ for the late stage $3+$ as the size enlarged and tissue density increased. After staining in BM-purple (Roche, Manheim, Germany) at room temperature in the dark, the reaction was stopped depending on the intensity and strength of the staining pattern and in my case the reaction was stopped between 36 to 48 hours. The embryos were photographed in Mowiol4-88 (Hoechst, Frankfurt, Germany) before they were embedded under cover photo glasses in Technovit ${ }^{\circledR}$ (Heraeus Kulzer, Werheim, Germany) in plastic tablets molds at $4{ }^{\circ} \mathrm{C}$ as described (Idkowiak et al., 2004a). Eventually, embryos were serially sectioned at $5 \mu \mathrm{m}$ thickness using glass knives microtome in sagittal plane (s. Püschel et al., 2010). Sections of goosecoid expression were examined and analyzed using bright field illumination with or without interference contrast (DIC, Axioskop, Zeiss, Göttingen, Germany) at low and high magnifications. After being analyzed and photographed the embryos of every stage of the best and clearest pattern of gene expression was used to be represented in this study. 


\section{Results}

\subsection{Refined staging for the morphogenesis of the embryonic disc in the pig.}

In view of the complex morphological features of the embryonic disc of the post-hatching blastocyst, which undergoes columnar epithelialization while transforming from a ball-shape (at stage 1) to the mammotypical flat embryonic disc (at stage 2) between 8 to $10 \mathrm{dpc}$, I refined the staging provided by Hassoun et al. (2009) by adding two substages on the basis of light and electron microscopical features of the epiblast and the polar trophoblast:

At stage 1- the embryonic disc consists of (a) two continuous extraembryonic epithelia, namely the polar trophoblast (dorsally) and the hypoblast (ventrally), the latter of which already displays anterior-posterior polarity [Fig, 1B, C: the anterior hypoblast (AHB) consisting of cuboidal cells compared to the squamous posterior hypoblast cells (Hassoun et al., 2009)], and (b) between these layers a multilayered ball-shaped mass of epiblast cells principally responsible for the overall round shape of the embryonic disc as it appears in dorsal views (Fig. 1A). At stage 1+ the epiblast is covered to a variable degree by the polar trophoblast which gradually degenerates and causes discontinuities either between polar trophoblast cells or between polar and mural trophoblast cells (Fig. 1E). Now, the epiblast surrounds a small extracellular cavity, principally a proamniotic cavity, which is either sealed by dorsal epiblast or polar trophoblast cells or open, thereby exposing the dorsal surface of the ventral epiblast to the uterine cavity if there is a discontinuity between polar and mural trophoblast (cf. Fig. 1F and E); the remnants of dorsal epiblast overlaying the cavity consist of a mass of unorganized cells while the remaining ventral population of epiblast cells forms a concave shape with the future outline of the embryonic disc, which is either round or slightly elliptical at this stage when seen in dorsal views (Fig. 1D).

At stage 2- the embryonic disc is flat, shows irregular oval outlines in dorsal views and appears translucent under bright-field illumination in places where the polar trophoblast is lost (Fig. 1G). The ventral epiblast, which is now fully epithelialized, has a principally convex shape but is concave in those parts where it is overlain by remnants of both polar trophoblast and dorsal epiblast (Fig. $1 \mathrm{H}$ and I). At stage $2+$ the embryonic disc is a bilaminar flat disc consisting of epiblast and hypoblast, only, and this is due to the complete loss of polar trophoblast and the complete opening of the ('proamniotic') epiblast cavity. As a 
consequence, the epiblast is a columnar epithelium apically in contact with the uterine lumen and peripherally connected to the proximal part of the mural trophoblast whose cells are narrower, denser and darker than the rest of the mural trophoblast. This "proximal mural trophoblast" forms a translucent ring of varying width around the periphery of the embryonic disc when seen in dorsal views (cf. Fig. 1J-L).
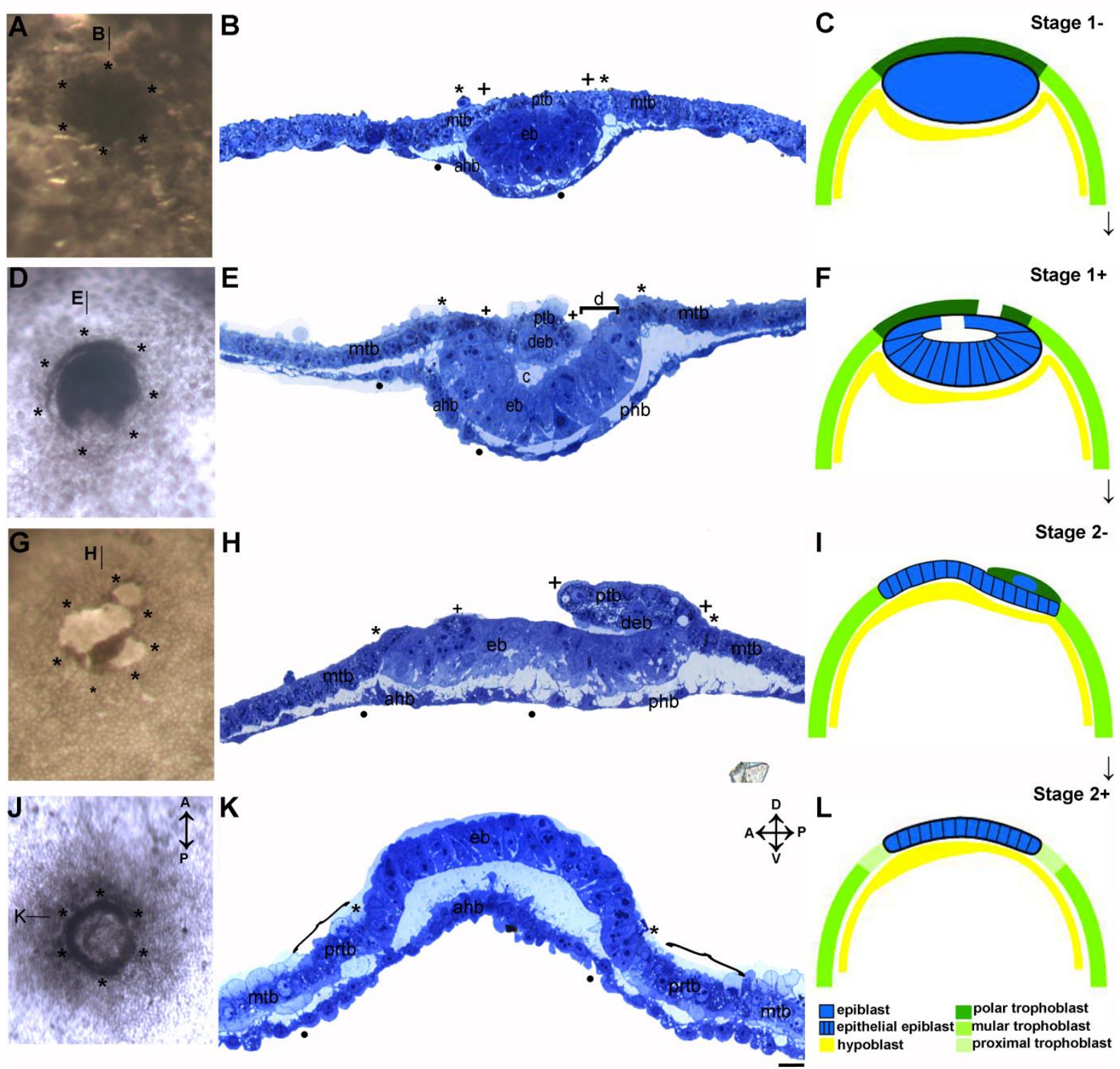

Fig.1 Morphogenesis of pregastrulation stages of pig embryo. Dorsal views (A, D, G and J) of OsO4 -fixed embryos, using brightfield $(A, G)$ or darkfield $(D, J)$ illumination, and sagittal $1 \mu \mathrm{m}$ semithin histological sections $(\mathrm{B}, \mathrm{E}, \mathrm{H}$, and $\mathrm{K}$ ) from the embryos shown in (A, D, G and J) respectively. (C, F, I and L) schematic drawings show the morphology of the four pre-gastrulation stages. Bars in overviews $A, D, G$ and $J$ indicate the positions and orientations of the sections $\mathrm{B}, \mathrm{E}, \mathrm{H}$ and $\mathrm{K}$ respectively. Asterisks label the periphery of the embryonic disc and mark the embryonic/extraembryonic borders determined in epiblast and mural trophoblast. (+) Signs define either the border or the remnant cells of the polar trophoblast. Black dots delineate the area of the anterior hypoblast. Stage 1- (A, B and C) and Stage 1+ (D, E and F) of an 8 d.p.c embryo and a 9 d.p.c embryo respectively with ball-shaped embryonic disc. Horizontal brackets in E labels the discontinuity of polar trophoblast and c refers to the cavity formation in epiblast. Stage 2- $(\mathrm{G}, \mathrm{H}$ and I) and stage 2+ (J, K and L) of a 9 d.p.c embryo and 10 d.p.c. embryo respectively with flat embryonic disc and remnants of polar trophoblast and dorsal epiblast. Embryonic and extraembryonic Layers of the blastocysts in the schematic drawings (C, F, I and L) are color-coded as in (L). Dorsal-ventral axis and anterior posterior-axis are marked with up-down and left- 
right arrows respectively. mtb, mural trophoblast; ptb, polar trophoblast; eb, epiblast; deb, dorsal epiblast; d, discontinuity; c, cavity; ahb, anterior hypoblast; phb, posterior hypoblast; ptb, proximal trophoblast. Scale bar: (A, D, G, J) $180 \mu \mathrm{m},(\mathrm{B}, \mathrm{E}, \mathrm{H}, \mathrm{K}) 60 \mu \mathrm{m}$.

\subsection{Characteristics of the ball-shaped embryonic disc (stage 1- )}

The seven spherical blastocyst of the stage 1- were collected between day 8 and $9 \mathrm{dpc}$ and had all already hatched from the zona pellucida. In whole-mount views, the embryonic disc appears as a small round or slightly oval dark region with a border of variable distinctness towards the surrounding extraembryonic tissues (cf. Fig. 2A, C and E). Sections reveal mostly multilayered partially polarized epiblast cells completely covered by a continuous polar trophoblast epithelium (Fig. 2B, D and F). The position of the margin between epiblast and polar trophoblast is different from the maximal diameter of the embryonic disc due to the spherical shape along the dorsoventral axis (cf. positions of + and $*$ marking the maximal disc diameter and the epiblast-trophoblast border, respectively, in fig. 2B, D and F). Axial differentiation at this stage is defined by the cuboidal and dense epithelium of the AHB cells which mark the anterior pole (located under the epiblast and extending into the extraembryonic region outside the embryonic disc) in contrast to the squamous hypoblast cells at the posterior pole. At this early stage, the morphological differences in cellular height between anterior and posterior hypoblast are not marked but anterior hypoblast cells are more closely connected to each other than the posterior hypoblast cells which display finger- or sheet-like cellular processes of various lengths. The hypoblast layer is loosely attached to the overlaying epiblast and in many specimens extends thin short branched cellular processes towards the basement membrane between these two cell layers (Fig. 2D and F); a basement membrane between the polar trophoblast and the epiblast is generally absent (s. electronmicroscopical results below).

The trophoblast is composed mostly of cuboidal cells with distinct borders and single round nuclei. However, some of the polar trophoblast cells appear to be squamous in regions where dorsal epiblast cells show a disorganized positioning within the embryonic disc. In these areas, ventral epiblast shows numerous metaphase plates as a sign of proliferation, a feature not observed in the polar trophoblast cells. Rather, a high number of dark round intracytoplasmic vesicles are located in the perinuclear region of polar trophoblast cells and variable sizes of yellowish or grey vesicles are found slightly smaller and less frequent in number than the dark vesicles (Fig. 2B and 2F). The basolateral surfaces of some of polar trophoblast cells form a few protrusions of different lengths into the underlying layer of the 
epiblast thereby separating small group of dorsal epiblast cells from the neighboring epiblast in many specimens (Fig. 2B). These dorsal epiblast cells form a closely associated row of epithelioid cells, which have an undulating contact area with the overlaying polar trophoblast as a result of the protrusions of the latter and as no basement membrane are found between the two layers (Fig. 2B and F, s. electron-microscopical results below). The nuclei of all epiblast are large, round, rich in chromatin, contain one or two nucleoli, and are the cause of a high nucleocytoplasmic ratio as they occupy almost half of the cytoplasmic volume. The nuclei tend to converge towards the center of the epiblast as can be seen in sections through the center of the spherical embryonic disc. The epiblast cells, the nuclei of which are arranged in a manner in the center of the embryonic disc described later, are localized in more ventral position in addition to some of the cells of the dorsal epiblast which are recognized by having a wedge shape with the narrow end towards the inner regions of the epiblast. Together, ventral and dorsal wedge-shaped epiblast cells form an asymmetrical rosette-like arrangement with comparatively thin apical compartments contacting each other and located in the center of the anterior-posterior axis but they are shifted dorsally along the dorsoventral axis (Fig. 2B, D and F); as part of this rosette-like shape and the central positioning of its nuclei, the basal regions of these ventral epiblast cells are almost free of organelles (Fig. 2B and F).

At the late phase of this stage, the epiblast has increased in size and numerous narrow extracellular spaces are seen between the ventral epiblast cells (Fig. 2D and F). This distribution of epiblast cells together with the structure of the polar trophoblast cells thus define the two topographical classes of epiblast cells as described in the staging system above: (1) the dorsal epiblast lying 'above' the center of the epiblast cells and closely associated with the polar trophoblast and (2) the ventral epiblast as the remaining epiblast cells and referred to, at later stages, as the definitive epiblast.

\subsection{The formation of epithelial ventral epiblast (stage 1+)}

The embryonic disc at stage $1+$ roughly maintains the globe-like shape throughout $9 \mathrm{dpc}$ when seen in dorsal views (Fig. 2G), but the polar trophoblast, which covered the whole embryonic disc at stage 1-, is discontinuous at this stage. The gradual disintegration of the polar trophoblast appears in the dorsal view as translucent areas under dark field illumination (Fig. 2I) and is characterized by discontinuities of variable numbers and sizes which are connected to the center of rosette-like arrangements observed at stage 1- and expose the apical epiblast surface to the uterine cavity to variable degrees (cf. Fig. 1E and 5G). The 
discontinuities are either single, short (Fig. 8A), numerous and scattered across the embryonic disc area (Fig. 1E), or they are arranged in a row as if caused by a combination of several small discontinuities (Fig. 2J). Discontinuities may be placed either between polar trophoblast cells or at the margin of the embryonic disc between the polar and mural trophoblast. Sections also show that the apical surface of the polar trophoblast cells is almost completely covered by long microvilli and that they may be partially capped with bleb-like cytoplasmic protrusions which appear to be free of organelles (Fig. 1E, 2J and 8A). These bleb-like structures are also frequently found laterally at the margin of the discontinuities between polar and mural trophoblast. Sections also show the epiblast to have an overall lens shape as it has increased in size (compared to stage 1-) in width and height and now shows an extracellular cavity in a location similar to that of the center of the rosette-like configuration at stage 1around the central area of the globe-like embryonic disc. This cavity separates the dorsal epiblast population from the ventral epiblast cells by an almost horizontal line. In addition, vertical protrusions of the polar trophoblast also separate these epiblast layers into dorsal epiblast, which frequently takes on a central position, and ventral epiblast, which frequently takes on a peripheral position. In sections where the dorsal epiblast and a cavity are present, the ventral epiblast is already epithelialized and its cells are being arranged in a concaveshaped pseudostratified epithelial sheet (Fig. 2H). Its cells are now elongated into a columnar shape, have a clear apical-basal polarity and are closely attached to each other mainly dorsally since narrow extracellular spaces are mainly found basally between cells. These extracellular spaces are also found at the lateral part of the embryonic disc in the transitional zone between dorsal and ventral epiblast (cf. Fig. 8D) but the ventral epiblast in the center of the embryonic disc displays more of these epithelial features than the epiblast near the border of the embryonic disc (s.a. Fig. 3H).

The discontinuities between polar and mural trophoblast have expanded as compared to the early phase of stage $1+$ and thus lead to a fusion between the ventral epithelial epiblast and the mural trophoblast either anteriorly, posteriorly or on both lateral extremities; thus the final concave shape of the epithelial epiblast is formed (Fig. 2J and 3J). In contrast to the ventral epiblast, dorsal epiblast cells covering a small epiblast cavity appear as a mass of cells which keep their irregular shape as at stage 1-. These dorsal epiblast cells maintain their attachment to the polar trophoblast cells and with the expansion of the number and size of discontinuities the separation between dorsal and ventral epiblast cells has increased in size in late stage 1+ specimens to form a conglomeration of the remaining dorsal epiblast and polar trophoblast 
cells (Fig. 2H, 3D and H). The cavity development of the epiblast shows faster progress than the widening of the discontinuities in the polar trophoblast in that a mostly intact polar trophoblast can be present along with a broad epiblast cavity in the same specimen (Fig. $2 \mathrm{G}$ and $2 \mathrm{H}$ ). Depending on the location of the trophoblast discontinuity two forms of cavities are found: (1) a closed cavity surrounded by epiblast cells and covered by polar trophoblast (Fig. $2 \mathrm{H}$ and $8 \mathrm{G}$ ), and (2) an open cavity exposing the dorsal surface of the ventral epiblast and connecting with a discontinuity in the polar trophoblast. This eventually lets the separation between dorsal and ventral epithelial epiblast expand laterally (Fig. 2J) in preparation of the complete loss of dorsal epiblast and polar trophoblast at stage 2- (s. below).

The anterior hypoblast exhibits cuboidal cells which form a dense chain with round large nuclei and numerous long branched finger-like cytoplasmic processes towards the continuous basement membrane covering the ventral epiblast surface (Fig. $2 \mathrm{H}$ ). The region of the anterior hypoblast also extends further beyond of the anterior embryonic disc border defined by the epiblast than at stage 1- and shows its maximal extension which can be seen outside of the borders of the still ball-shaped embryonic disc (cf. Fig. 1b and 1E). Overall, the pattern of both cavity and discontinuity formation varies between the studied specimens due to numerous discontinuities with multiple foci. 

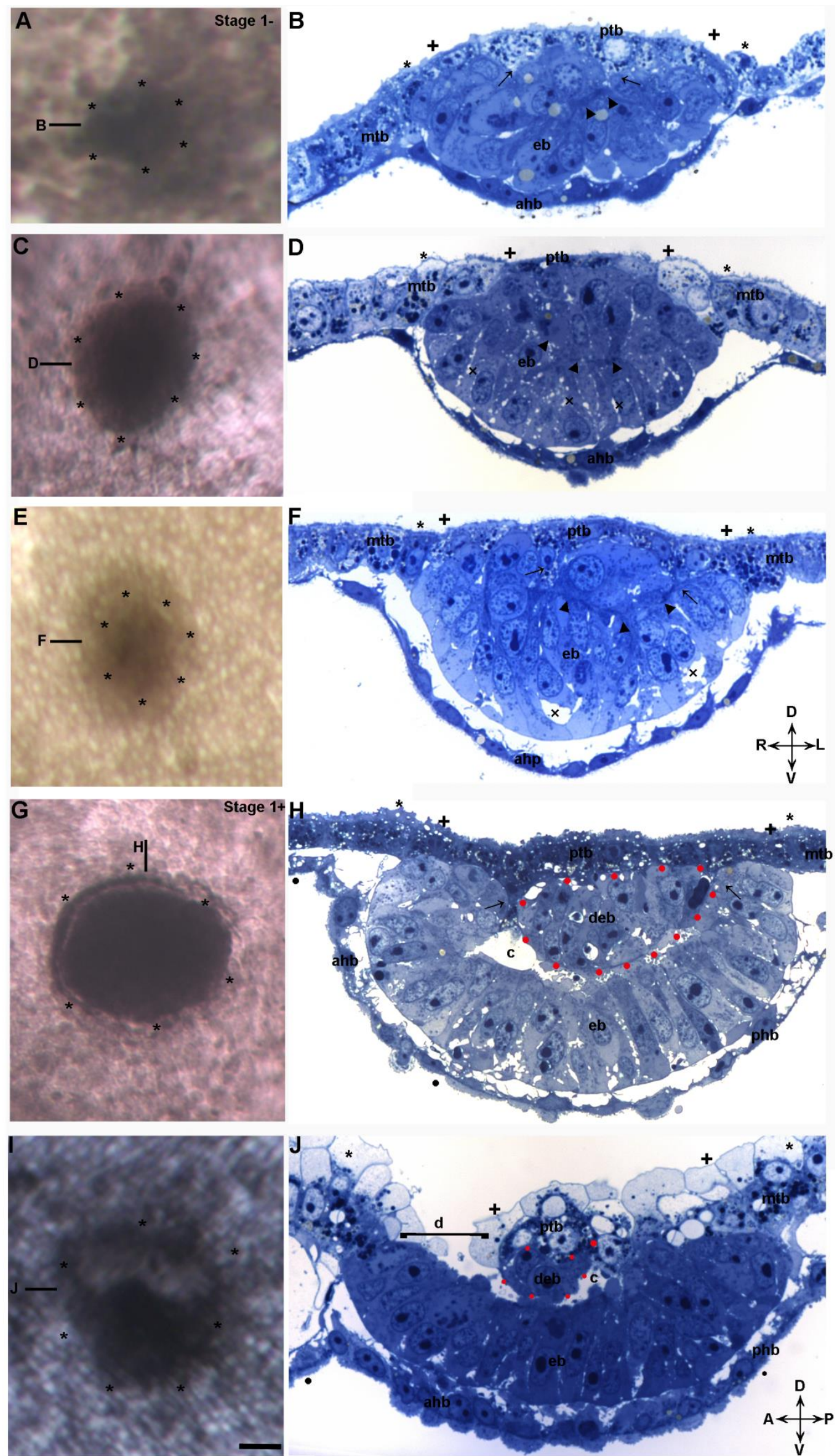
Fig. 2 Morphology of pregastrulation stages 1- and 1+ of pig embryo. Dorsal views of stage 1- (A, C and E) of two 8 d.p.c embryos and a 9 d.p.c embryo respectively and stage $1+(\mathrm{G}$ and $\mathrm{I}$ ) of a 9 d.p.c embryo. (B, D, F and J) transverse and sagittal $(\mathrm{H}) 1 \mu \mathrm{m}$ sections from embryos shown in A, C, E, I and G respectively. Bars in overviews indicate the positions and orientations of sections. Asterisks, (+) signs, black dots, left-right arrow, up-down arrow and the bracket label as in Fig.1. Arrowheads in (B, D and F) refer to the dense area of the center of the rosette-like structure. Arrows in (B, D, F and H) mark the protrusions of the polar trophoblast towards the underlying epiblast. X labels the extraembryonic spaces basally between ventral epiblast cells. Red dots define the dorsal epiblast mass of cells. $\mathrm{C}$ indicate the cavity between dorsal epiblast and ventral epiblast. mtb, mural trophoblast; ptb, polar trophoblast; eb, epiblast, deb, dorsal epiblast; d, discontinuity; c, cavity; ahb, anteriorhypoblast; phb, posterior hypoblast. Scale bar: (A, C, E, G, I) $100 \mu \mathrm{m},(\mathrm{B}, \mathrm{D}, \mathrm{F}, \mathrm{H}, \mathrm{J}) 30 \mu \mathrm{m}$.

\subsection{D reconstruction and topographical correlations during epiblast epithelialization (stage 1+)}

The 3D reconstruction of 6 embryonic discs at stage $1+$ compares the whole embryonic disc area with the relative size of the dorsal epiblast during the degeneration of the polar trophoblast. The dorsal epiblast cell mass occupies most of the central region of the embryonic disc but not the whole circumference (Fig. 3F, I and K); wherever the discontinuities of the polar trophoblast is increased in size, the dorsal epiblast size is decreased in size and forms an irregular shape corresponding to the degree of disintegration of the polar trophoblast (Fig. 3F). As the disintegration proceeds the remains of the dorsal epiblast are restricted to the posterior periphery of the embryonic disc (Fig. 3K). The embryonic disc displays a clear concavity in the areas below the cavity and both upper layers (dorsal epiblast and polar trophoblast), whereas the ventral epiblast exposed to the uterine cavity is already convex.

Schematic drawings of six of embryonic discs at stage 1+ (Fig. 4) show the topographical correlation of the forming cavity, the progressively extending discontinuities of the polar trophoblast, and the differentiation of the anterior-posterior axis at stage $1+$. The cavity in 4 of 6 the presented specimens are mainly located in the center of the embryonic disc (Fig. 4E, J, $\mathrm{K}$, and $\mathrm{L}$ ) whereas in the other two specimens it is shifted slightly anteriorly and to the right side of the embryonic disc (Fig. 4D and F). Seen in dorsal views the cavity forms a wedgelike shape (Fig. 4F, J and K). The discontinuities are distributed in various areas on the polar trophoblast, and can be seen anteriorly or posteriorly or in both poles; the location of the start of the polar trophoblast disintegration is thus variable, but it is found anteriorly in most specimens (Fig. 4). In comparison with the discontinuities at the posterior pole, the anterior discontinuities tend to be larger. 

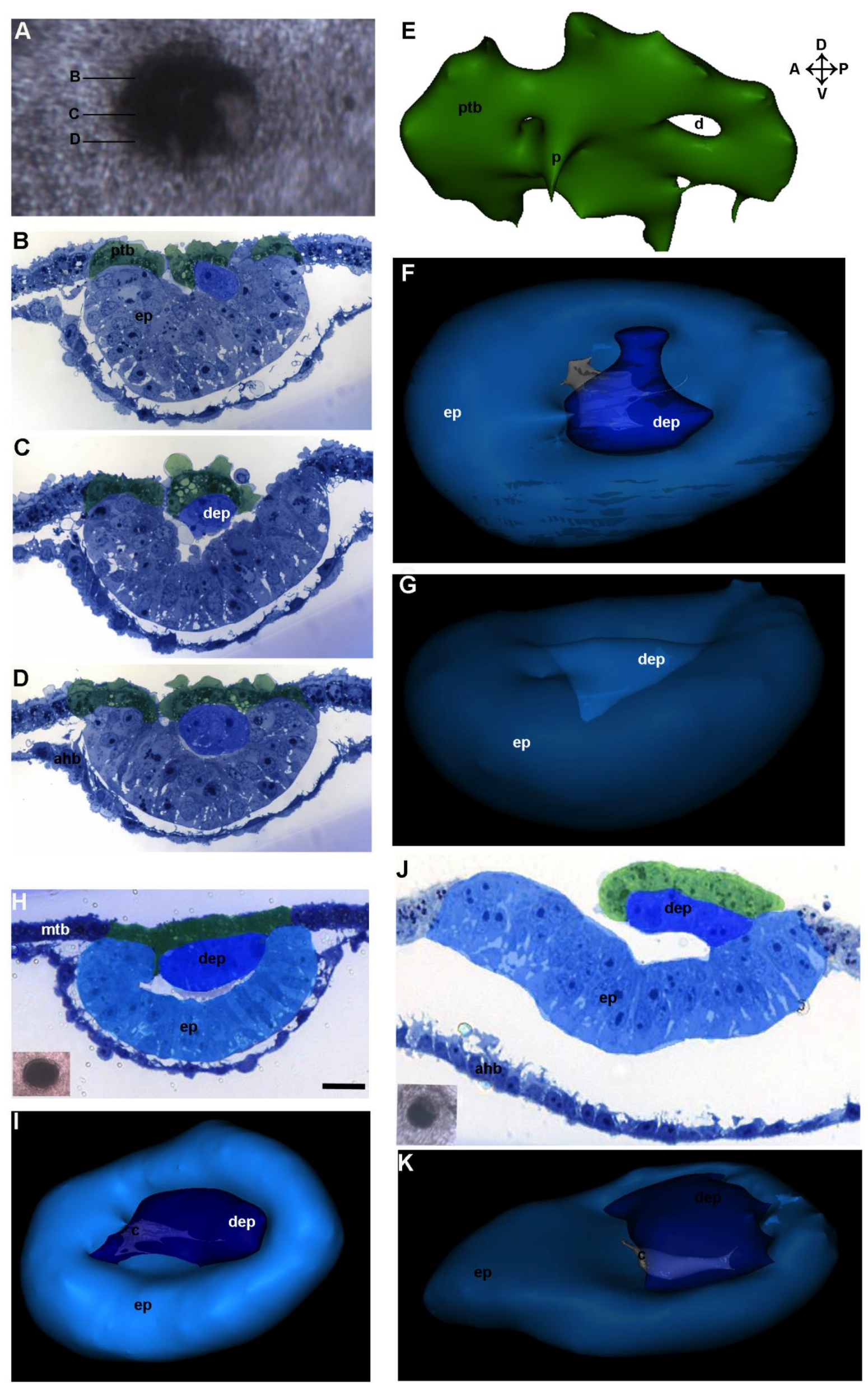
Fig. 3 3D reconstruction of pig embryonic disc at pregastrulation stage 1+ of pig embryo. (A) Dorsal view of a 9 d.p.c embryo. (B, C and D) $1 \mu \mathrm{m}$ sagittal sections from the embryo shown in A and are oriented and positioned by bars in A. (H and J) $1 \mu \mathrm{m}$ sagittal sections from two 9 d.p.c embryos (insert) in $\mathrm{H}$ and $\mathrm{J}$ respectively. E shows a $3 \mathrm{D}$ reconstruction of polar trophoblast of the embryonic disc in $\mathrm{A}$. ( $\mathrm{F}$ and $\mathrm{G}$ ) display a dorsal and lateral 3D reconstruction respectively of the epiblast, dorsal epiblast and cavity of the embryonic disc in A. (I and K) dorsal 3D reconstructions of $\mathrm{H}$ and $\mathrm{J}$ respectively. Dorsal-ventral axis and anterior posterior-axis are marked with leftright and up-down arrows respectively. Polar trophoblast (green), epiblast (blue), dorsal epiblast (dark blue), cavity (white). ptb, Polar trophoblast; mtb, mural trophoblast; eb, epiblast; deb, dorsal epiblast; p, protrusion of polar trophoblast; d, discontinuity of polar trophoblast. Scale bar: (A) $100 \mu \mathrm{m},(\mathrm{B}, \mathrm{C}, \mathrm{D}, \mathrm{H}, \mathrm{J}) 40 \mu \mathrm{m}$.
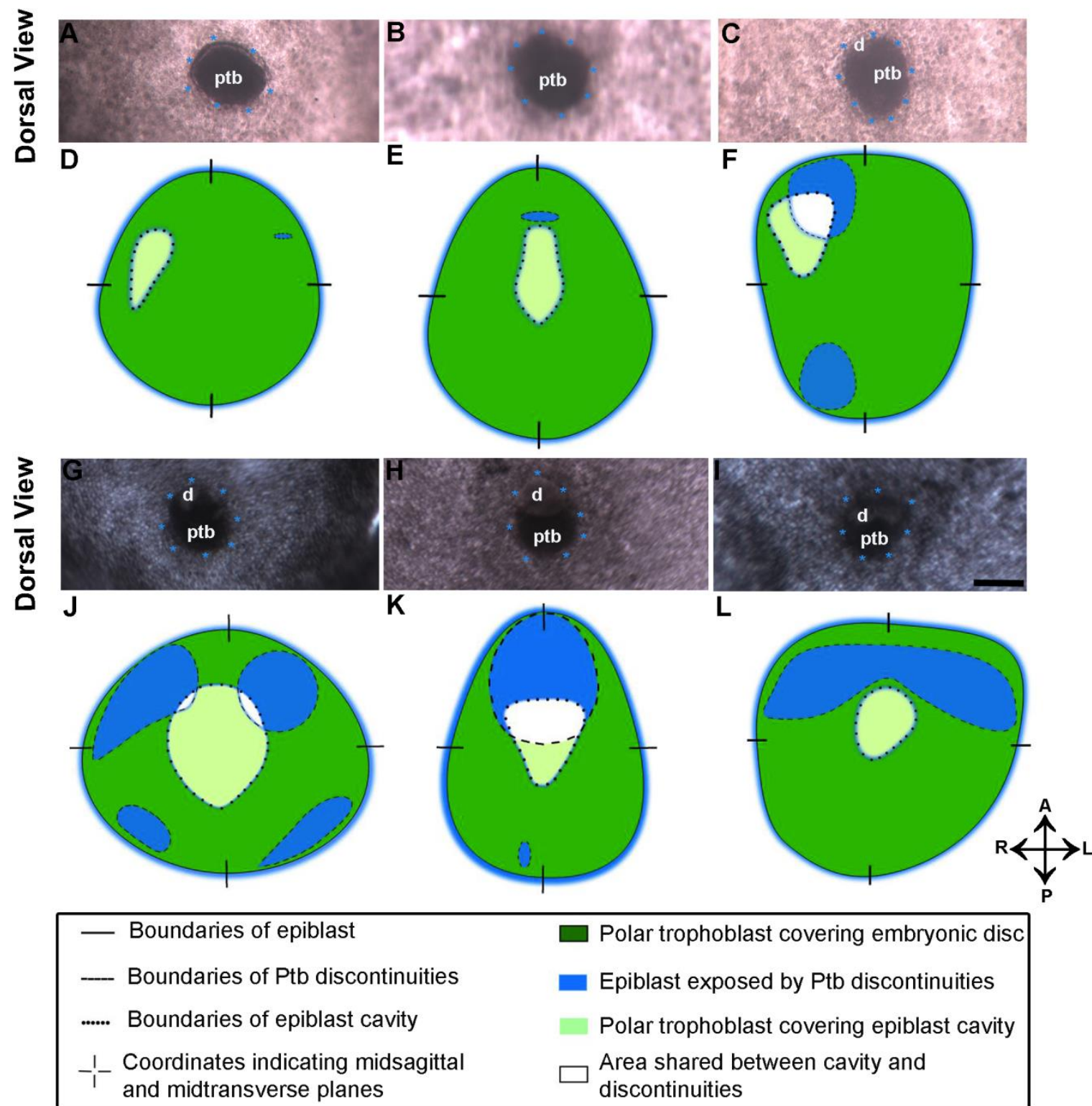

Polar trophoblast covering embryonic disc

Epiblast exposed by Ptb discontinuities

Polar trophoblast covering epiblast cavity

Area shared between cavity and discontinuities

Fig.04 Schematic correlation of anterior-posterior axis with the morphological characteristics of stage 1+ of pig embryo. Dorsal views (A, B, C, G, H and I) of 9 d.p.c embryos using brightfield (A-C) or darkfield (G-I) illumination. (D, E, F, J, K and L) schematic drawings of the embryonic discs (A, B, C, J, K and L) respectively. Blue asterisks are placed peripheral to the epiblast borders. Light black areas in (G-I) mark the discontinuities of polar trophoblast. The characteristics of embryonic disc of stage 1+ in (D, E, F, J, K and L) are color-coded and labelled as in the label box. Dorsal-ventral axis and anterior posterior-axis are marked with left-right and updown arrows respectively. ptb, polar trophoblast; d, discontinuities of polar trophoblast. Scale bar: (A-C, G-I) $160 \mu \mathrm{m})$. 


\subsection{The concave-convex shape of the 'definitive epiblast' (stage 2- )}

The embryonic discs at stage 2- (at $10-11 \mathrm{dpc}$ ) have a mostly flat configuration, while the polar trophoblast and dorsal epiblast are found as remnants partially located over the embryonic disc and these can be distinguished already in whole mount light microscopy due to the contrast between the embryonic disc and the polar trophoblast. The embryonic disc is elongated in the anterior-posterior axis and has gained an oval or irregular pear shape which may have a slight ventral bending in the center of the disc causing an overall irregular outline of the embryonic disc (Fig. 5A and 5B). The epiblast part previously (at stage 1+) addressed as ventral epiblast is now the flat 'definitive epiblast' and consists of a more or less uniform pseudostratified columnar epithelium attached to the mural trophoblast at the peripheral boundary (Fig. 5C and 5C'). The ventral surface of the epiblast is irregular and few extracellular spaces are still found between the basal parts of the cells whereas the dorsal surface is smoother than the ventral one and has few short cellular apical microvilli besides the fact that the cell nuclei are mostly located half-way of the height of the epithelial sheet. Due to the considerable transformation in shape from a spherical to a flat configuration and depending on the location of the polar trophoblast remnants the epithelial epiblast sheet has either an undulating, concave-convex shape (Fig. 5C and 5G) or a dome shape (Fig. 5F) in sections. The concave part coincides with the remnants of polar trophoblast and dorsal epiblast conglomeration and is located at the posterior side in most specimens whereas the 'free' part of epiblast shows a straight (at the extreme peripheral areas of the anterior half, not shown) or a convex shape after losing the connecting between polar trophoblast and mural trophoblast and after the complete disappearance of polar trophoblast cells in that area. This configuration is found anteriorly in 4 of the 6 specimens (Fig. 5F). The cellular remnants differ from the regular single cell sheet appearance and take on the appearance of cells gathering in two stratified layers; their outer surfaces of the dorsal, lateral and ventral cells are covered with bleb-like structures (cf. Fig. 2J of stage 1+ and 5C' of stage 2-) and the cells of the remnant polar trophoblast contain abundant small vacuoles providing an almost hollowedout appearance to the polar trophoblast (Fig. 5C'). With reference to the presence or loss of polar trophoblast cells and their contacts to the definitive epiblast or mural trophoblast, the polar trophoblast cells may take on the following configuration: (a) segments of polar trophoblast cells are closely attached to each other and contain remnants of dorsal epiblast cells which are completely separated and isolated from the definitive epithelial epiblast and surrounded only by polar trophoblast; this part of polar trophoblast connects to the superficial parts of the mural trophoblast (Fig. 5C') instead of the basolateral connection that was 
previously seen at stages 1 - and $1+$, (b) a few polar trophoblast cells touch the underlying epiblast through their bleb-like outer surfaces without defined intercellular connections to it or to the mural trophoblast (Fig. 5G, s. electron microscopy below), or (c) scattered cells are found penetrating superficially into the apical regions of the epiblast (Fig. 5C).

The anterior hypoblast stretches further towards the center of the embryonic disc than at previous stages and its cytoplasmic processes are elongated and frequently fork-shaped in the widened space between the hypoblast and the overlying epiblast; these processes are mostly oriented towards the basement membrane between the hypoblast and the epiblast and mural trophoblast, respectively. Four schematic superimpositions of the embryonic disc components show that in four of the six studied specimens the position of the polar trophoblast remnant is located at the posterior side, while the anterior pole is developing in the area free of polar trophoblast (Fig. 5B, 5E, 5I, and 5K). 

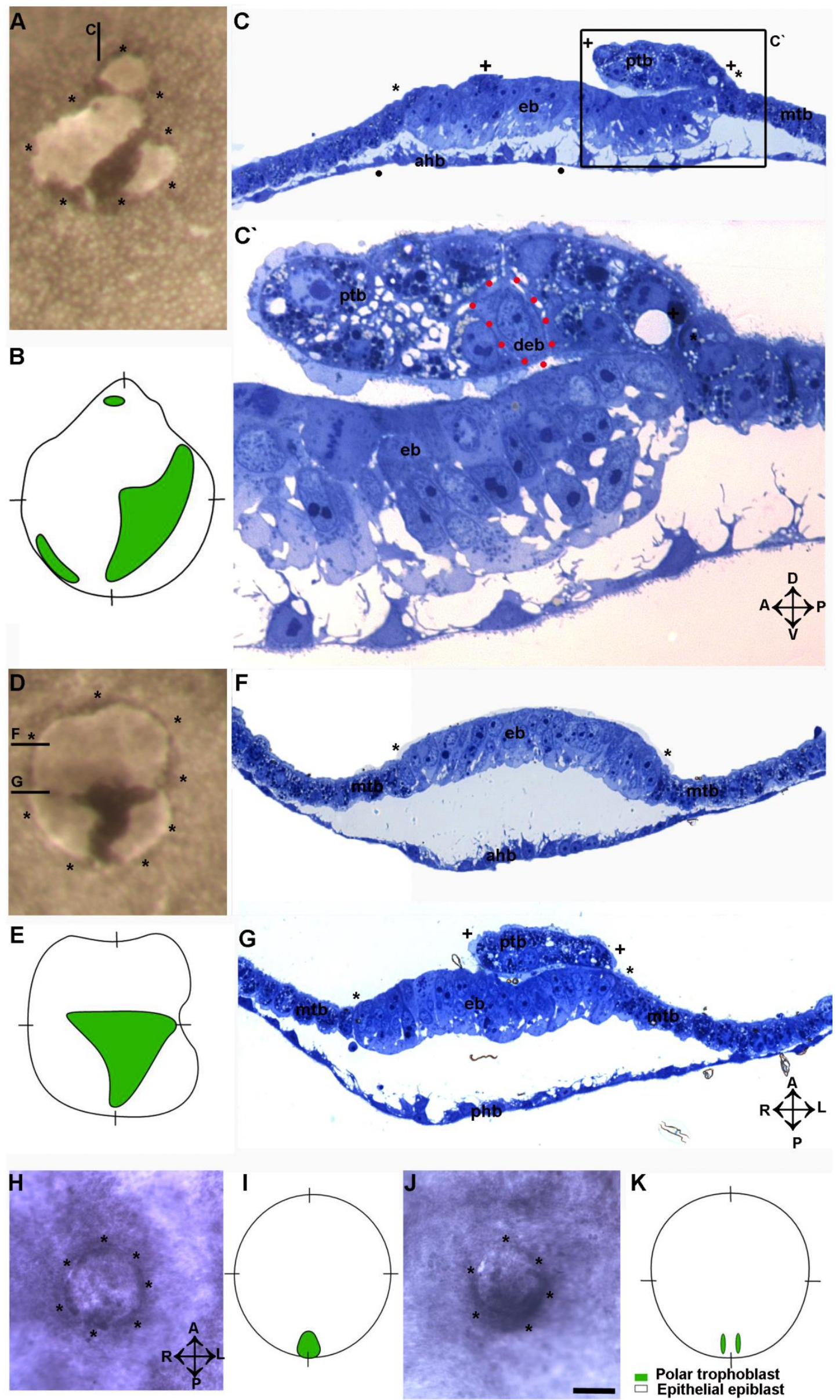
Fig. 5 Morphology of pregastrulation stage 2- of pig embryo. Dorsal view of (A) a 9 d.p.c embryo and (D, H and J) 10 d.p.c embryos. (C) Sagittal and (E and G) transverse $1 \mu \mathrm{m}$ histological sections from the embryos shown in A and D respectively. (B, E, I and K) Schematic drawings of the embryonic discs shown in (A, D, H and J) respectively. Labelling of bars, asterisks, (+) signs, and black dots is as in Fig.1. Dark areas in the overviews and the green colour in schematic drawings refer to the remnant of polar trophoblast. Box in $\mathrm{C}$ marks higher magnification of remnants of polar trophoblast and dorsal epiblast at the posterior pole of the embryonic disc. Red dots in C' define the remnants of the dorsal epiblast between the remnants of the polar trophoblast. Dorsalventral axis and anterior posterior-axis in $\left(\mathrm{C}\right.$ and $\left.\mathrm{C}^{\prime}\right)$ are marked with left-right and up-down arrows respectively but they are inverted in the rest of the figure. ptb, polar trophoblast; mtb, mural trophoblast; eb, epiblast; deb,

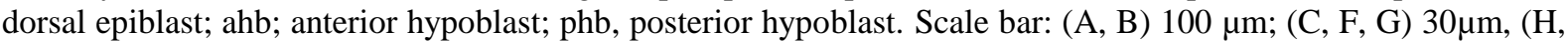
J) $180 \mu \mathrm{m},\left(C^{\prime}\right) 10 \mu \mathrm{m}$.

\subsection{Ultrastructure prior to epiblast cavity formation (stage 1-)}

The close apposition of neighboring polar trophoblast cells seen at stage 1 - in the light microscope is characterized at the electron microscopical level by the close contact between neighboring cell membranes and by presence of few small desmosomes associated with long bundles of intermediate filaments which appear to be interwoven and splay out of the junctions into the cytoplasm (cf. Fig. 6G and I). Near the basal border of polar trophoblast with epiblast cells, bands of microfilaments run parallel to the cell membrane (Fig. 6A and C) which is similar to the description of microfilament bundles by Green et al. (1987) and Ghadially (1989). The cytoplasm of these polar trophoblast cells is rich in free ribosomes loosely scattered throughout the cell and occasional stretches of rough endoplasmic reticulum (RER). The mitochondria of the polar trophoblast are abundant, highly variable in size and have either a round or an oval shape; morphologically they can be categorized into three types reminiscent of mitochondria at different stages of apoptosis (Sun et al., 2007): (a) normal mitochondria with either tubular or laminar cristae (Fig. 6I); they tend to be rare, (b) vesicular mitochondria in which the inner membrane encloses vesicular matrix and the cristae appears to be enlarged in size (Fig. 6C; this type appears to be most prominent at this stage), and (c) swollen mitochondria which have expanded matrix space at least on one side in addition to the vesicular compartments giving the mitochondria a swollen and almost translucent appearance (s. black arrows in Fig. 6D and supplementary material Fig. 3C). Polar trophoblast cells also contain variations of intracellular inclusions: (a) white or grey round lipid droplets of homogeneous appearance, similar in size, and scattered throughout the cytoplasm (Fig. 6D and I), (b) black round vesicles of primary lysosomes which have electron-density with relatively homogenous morphology and different sizes (s. Fig. 6D and supplementary material Fig. 3C, D and G), (c) vesicles of heterogeneous heterolysosomes and autolysosomes containing organellar debris (s. Fig. 6D and supplementary materials Fig. 3C, D, F, H and I), (d) residual bodies which contain 'empty spaces' and remnants of lipid droplets and organelles in many cases are another type of heterogeneous vesicles of lighter electron density 
than the autolysosomes and loaded with residues of different kinds (s. Fig. 6D and supplementary materials Fig. 3E), and (e) autophagosomes with double membrane (Supplementary materials Fig. 3B and C).

Similar to the tightly connected polar trophoblast cells, epiblast cells have closely apposed cell membranes, too, but they are joined to each other by a special type of desmosomes which are mainly found on the lateral surface of the ventral and central epiblast cells near the center of the embryonic disc where the epiblast cells may have a rosette-type arrangement (s. Fig. 2B, D). At the early phase of stage 1 - (specimens at $8 \mathrm{dpc}$ ) these special desmosomes are arranged singly measuring in the longitudinal axis between $335 \mathrm{~nm}$ for a short desmosome and 890 for a long one (Fig. 6E) and displaying a $86 \mathrm{~nm}$ wide felt of parallel microfilament bundles on the cytoplasmic side. The adjacent intercellular space is proximately $20 \mathrm{~nm}$ wide and filled by electron-dense material (Table 2 and supplementary materials Fig. 1A). In some specimens at age $9 \mathrm{dpc}$ these special desmosomes are also found dorsally between the dorsal and ventral epiblast cells composed of several shorter segments (frequently three) together measuring up to $738 \mathrm{~nm}$. Individual segments are about $190 \mathrm{~nm}$ long and $99 \mathrm{~nm}$ wide, the intercellular space measuring $16 \mathrm{~nm}$ (s. Table 2, Fig. 6H and supplementary materials (Fig. 1B). With this arrangement they are reminiscent of series of desmosomes described as 'zipper-like desmosomes` by Rusu et al. (2013). Apart from these special desmosomes the contact areas of the multicellular rosette epiblast are equipped with interdigitating cell membranes which are also accompanied by few tight junctions (Fig. 6B). The cytoplasm of these tightly attached cells is rich in Golgi vesicles and rough endoplasmic reticulum (Fig. 6B and $\mathrm{C}$ ) and one or two cells of the ventral epiblast may contain a phagosome and apoptotic bodies. Microtubules are found in the organelle free areas near the basal surface of the ventral epiblast or near the apical surface of some of the dorsal epiblast cells (Fig. 6C); some of the latter also show similar areas of cytoplasm almost free of organelles. The number of mitochondria in the epiblast cytoplasm is larger than the number of the mitochondria in the polar trophoblast but they are smaller in size (Fig. 6C). The attendance of high concentration of the mitochondria is clearly observed only in the cytoplasm of some of the epiblast cells (Fig. 6J). They are combined in the cells of the rosette-like structure, especially around the area of the pre-cavity opening (s. below) with many Golgi vesicles which give the cytoplasm of these epiblast cells a granular appearance. This granular cytoplasm is also found in the adjacent cells with 'zipper-like' desmosomes and elongated tight junctions are located either directly under the protrusions of the polar trophoblast or at the basal surface of the dorsal 
epiblast beneath these protrusions; at their lateral walls few filopodia are seen which enclose an extracellular space between the dorsal and ventral epiblast (Fig. 6J). Large yolk globules of diameter of $6 \mu \mathrm{m}$ are found in the cells of the epiblast of some 8 and $9 \mathrm{dpc}$ embryos (Supplementary materials Fig. 2A), there is resemblance between them and the yolk granules mentioned in (Barends et al., 1989) of 5 day blastocysts.

The extracellular space surrounded by cellular protrusions (filopodia) containing tight junctions is taken to be the first sign of a pro-amniotic cavity in the epiblast and is therefore called 'pre-cavity' space (Fig. 6J'). The presence of the filopodia at the walls of the cells beside the tight junctions and the coated special desmosomes distinguishes this pre-cavity space from extracellular spaces between the ventral epiblast cells which are positioned literally only and separate the lateral membranes of the ventral epiblast cells (cf. $6 \mathrm{~J}^{\prime}$ ). Near the hypoblast the ventral epiblast and the mural trophoblast are covered ventrally by a continuous basement membrane which is, however, in some specimens disrupted locally (especially in the anterior part of the embryonic disc) by one or more protrusions of the ventral epiblast towards the hypoblast layer which some of its cells contain few lipid droplets and elongated mitochondria (s. Fig. 6F and supplementary materials Fig. 2B). 

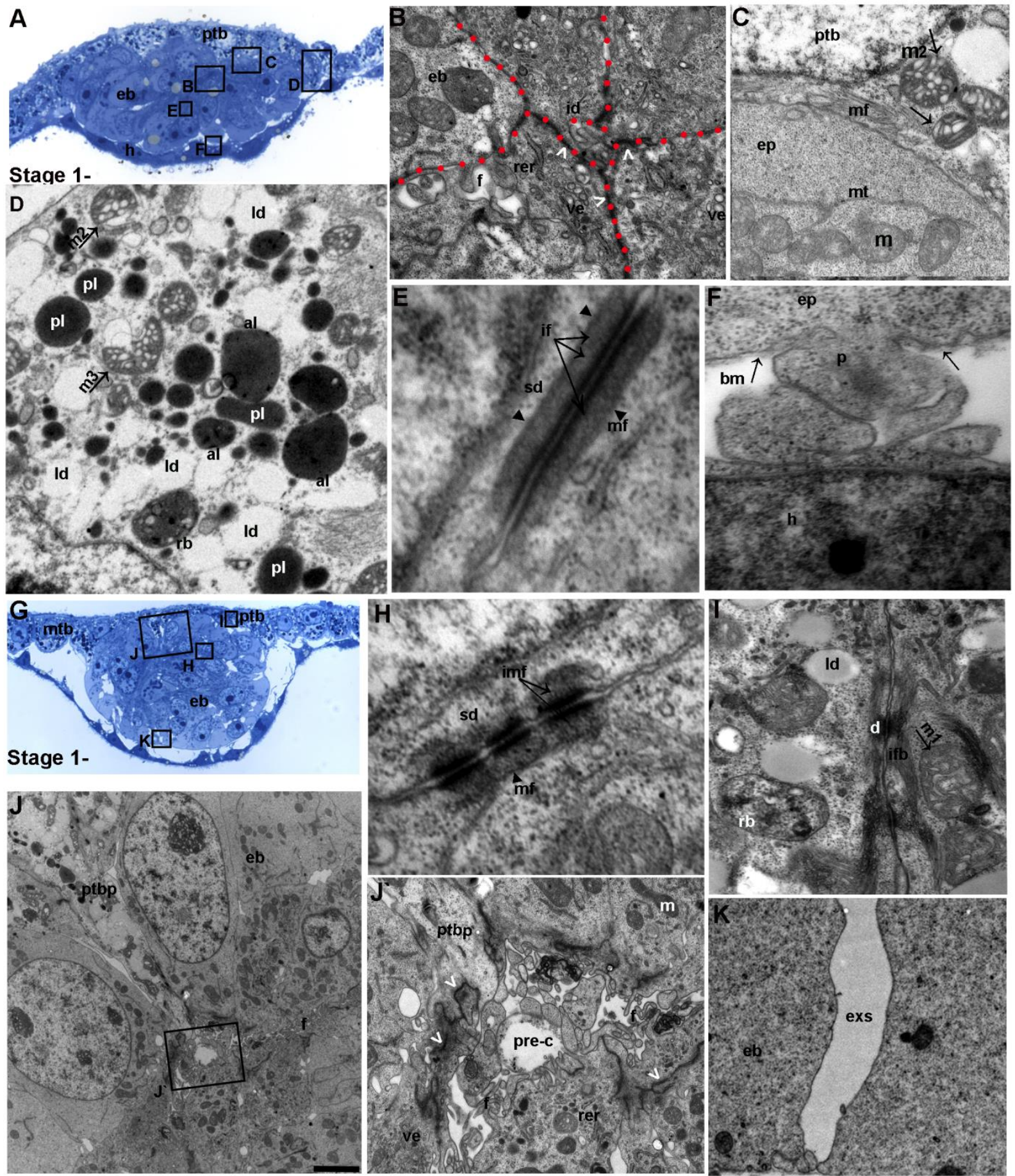

Fig. 6 Ultrastructure of pregastrulation stage 1- of pig embryo. (A and G) light micrographs of $1 \mu \mathrm{m}$ section of embryos obtained at 8 d.p.c. (B-F) and (H-K) electron microscopy micrographs from the section shown in A and $\mathrm{G}$, respectively. (B) wedged-shape cells of the rosette-like structure in the centre of the epiblast. Interdigitations are formed apically between plasma membranes. The white arrowhead mark apical tight junctions at the centre of the rosette-like structure. Red dots define the plasma membranes of the cells of the rosette-like structure. The cytoplasm is rich with Golgi vesicles and mitochondria. (C) Comparison between the mitochondria in the epiblast and the overlaying polar trophoblast with microfilaments parallel to the basal membrane. (D) Cytoplasm organelles of a polar trophoblast. High attendance of lipid droplets, primary lysosomes, autolysosomes and residual bodies. Arrows point to variant types of mitochondria. ( $\mathrm{E}$ and $\mathrm{H}$ ) Special immature desmosomes between ventral epiblast cells. (F) Discontinuity in the basement membrane between epiblast and hypoblast. (I) desmosomes and intermediate filaments between epiblast cells. Many lipid droplets and normal mitochondria. (J) Pre-cavity structure between epiblast cells underlying polar trophoblast protrusions. $\left(\mathrm{J}^{\prime}\right)$ Box in $\mathbf{J}$ marks the higher magnification of the pre-cavity, filopodia and tight junctions. (K) Extracellular space is located basally between the ventral epiblast cells. ptb, polar trophoblast; eb, epiblast; m1, normal mitochondria in polar trophoblast; $\mathrm{m} 2$, vesicular-swollen mitochondria in polar trophoblast; $\mathrm{m} 3$, swollen mitochondria in polar 
trophoblast; P, protrusion; bm, basement membrane; ld, lipid droplets; pl, primary lysosomes; al, autolysosomes; rb, residual bodies; sd, special desmosomes; if, intermediate filaments; mf, microfilament; ifb, intermediate filament bundles; ptbp, protrusion of polar trophoblast; $\mathrm{d}$, desmosome; rer, rough endoplasmic reticulum; $\mathrm{mt}$, microtubules; f, filopodia; ve, Golgi vesicles. Scale bar: (A, G) $120 \mu \mathrm{m}$, (D, J) $750 \mathrm{~nm},(\mathrm{~B}, \mathrm{C}, \mathrm{F}, \mathrm{I}, \mathrm{J}$, K) 500 $\mathrm{nm},(\mathrm{H}) 250 \mathrm{~nm},(\mathrm{E}) 100 \mathrm{~nm}$.

\subsection{Ultrastructure during the disintegration of polar trophoblast and dorsal epiblast (stage 1+)}

The polar trophoblast cells at an early phase of stage $1+$ show small areas of degeneration at the light microscopy level as the cells stay closely adherent and form a row of contiguous cuboidal forms (cf. Fig. 2H and 7A). Examination by electron microscopy shows that the dorsal surface of the polar trophoblast is villous and has excessively long filamentous-like microvilli and a prominent irregularly swollen apical shape due to bleb-like dorsal cytoplasmic protrusions almost free of organelles; they are connected apicolaterally with protrusions of neighboring cells by tight junctions (Fig. 7B and C). The cytoplasm of these cells contains larger number of primary lysosomes, autolysosomes and residual bodies, Phagosomes and endosomes than to the situation found at the previous stage (s. Fig. 7D and supplementary materials Fig. 4A, B, C and D) and an excessive number of small vacuoles (Fig. 7B) which are distributed all over the cytoplasm and are taken as early signs of polar trophoblast loss. The vesicular type of mitochondria and a large number of vesicular-swollen mitochondria are found in older stage 1+ embryos, i.e. during the further receding of polar trophoblast cells. In addition, some nuclei show condensation and an irregular nuclear envelope (Fig. 7C). Many interdigitating, thick finger-like structures are found at the lateral parts of some of the cells; close to this there are many long intermediate filaments bundles distributed irregularly either in parallel to the ventral membrane or with a random distribution inside the cells and without connection to the many desmosomes which attach polar trophoblast cells to their neighbors.

Some of the polar trophoblast cells have protrusions that project basally towards the epiblast and extend along the full height of the dorsal epiblast cells to reach almost their basal surface near the epiblast cavity. These processes contain many mitochondria, white-to-grey lipid droplets, vacuoles and few intermediate filaments bundles located vertically parallel to the protrusion (Fig. 7B and $\mathrm{B}^{\prime}$ ). There is an undefined membrane covering the end of these protrusions which may give these protrusions the shape of an opening funnel. The initial sign of distribution between two polar trophoblast cells is shown as bleb-like extension from one cell to the other covering the small distance between the two cells, but despite the space 
between these two cells, they are still connected by a tight junction along the whole apicolateral surface of the bleb (Fig. 7C). Some cells have a lateral border covered by long microvilli towards the other epiblast cells and these microvilli also partially cover the lateral and dorsal surface between the polar trophoblast cell and the epiblast cell beneath it (Fig. 7C). The discontinuity between the polar trophoblast cells is locally widened conspicuously and the cell at the edge of the gap take a claw-like shape as a small protrusion at the margin of the discontinuity; in addition, the surface of this claw-like cell process is also covered with long microvilli (Fig. 7J). The polar trophoblast cells at the two margins of the discontinuity are connected with the now uncovered epiblast cells in two ways: (a) by the attachment between the microvilli of the polar trophoblast cells and the epiblast only (Fig. 7J), or (b) by a tight junction between the lateral ventral surface of the polar trophoblast and the lateral border of the ventral epithelial epiblast (Fig. 8E); these polar trophoblast cells are still connected with the dorsal epiblast cell lying underneath by a few desmosomes (Fig. 7j). Many lipid droplets undergo disintegration and their inclusions are gradually emptied leaving a vacuole-like structure (s. white arrow Fig. 7B and supplementary materials Fig. 2C).

As the blastocyst develops further during this stage the cytoplasmic vacuoles enlarge in size and number and occupy a large space of some of the polar trophoblast cytoplasm which appears 'fenestrated' and has lost most of its inclusions (Fig. 8B). The large bleb-like structures near the apical surface of the polar trophoblast have a smooth surface and fine granulation inside and increase in size when the epiblast cells undergo the late phase of the degeneration process. The apical bleb-like cytoplasmic protrusion of the polar trophoblast cells are evenly arranged in a line at the level of the base of the bleb-like protrusions (Fig. $8 \mathrm{H})$. 

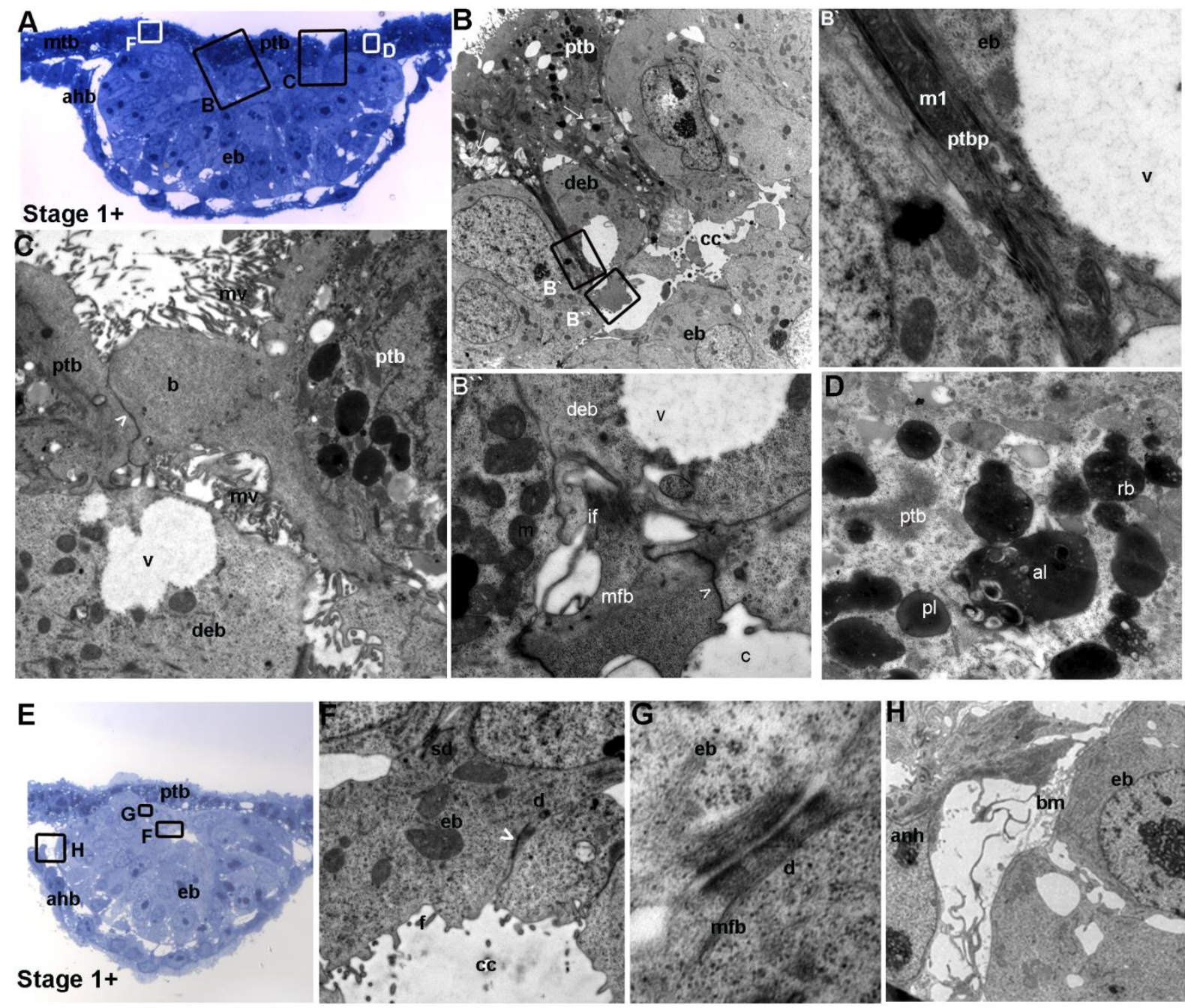

I

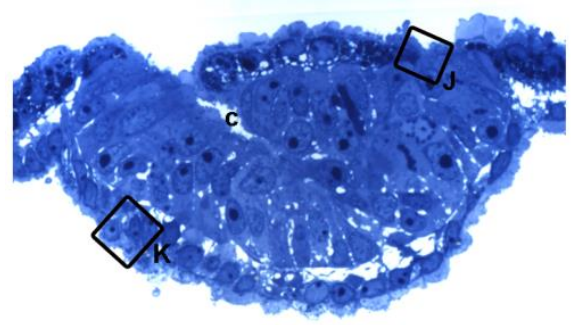

Stage 1+
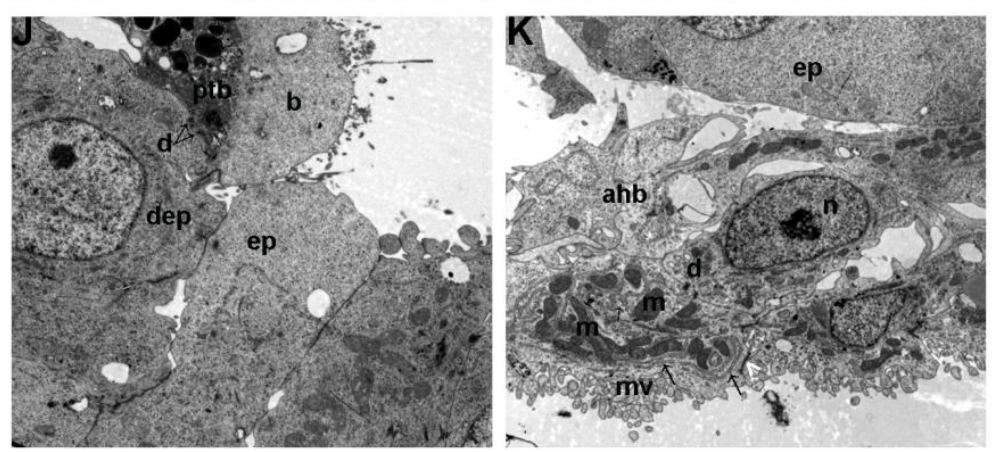

Fig. 7 Ultrastructure of pregastrulation stage 1+ of pig embryo. (A, E and I) Light micrographs of $1 \mu \mathrm{m}$ section of embryos obtained at 9 d.p.c. (B-D), (F-H) and ( $\mathrm{J}$ and $\mathrm{K}$ ) Electron microscopy micrographs from the section shown in A, E and I respectively. (B) Polar trophoblast protrusions enclose dorsal epiblast cells overlying the cavity between dorsal epiblast and ventral epiblast. (B') Box in B marks higher magnification of polar trophoblast protrusion adjacent to dorsal epiblast vacuole. (C) Pre-discontinuity between polar trophoblast cells. Lateral bleb is extended from one cell to the other. Long and shorter microvilli are located on the upper surface and lateral membrane respectively. (B“) Box in B marks the cytoplasm of the dorsal epiblast. Microfilaments bundles are found parallel to the cavity. The white arrowhead marks tight junctions between the cells. (D) Polar trophoblast cytoplasm. (F) Cells of the epiblast closed cavity. Filopodia fill the inner surface of the cavity. (G) Special mature trilogy desmosomes between ventral epiblast cells. (H) Extracellular matrix of basement membrane is located peripherally of the embryonic disc border. (J) Short protrusions between polar trophoblast and ventral epiblast in the area of polar trophoblast discontinuity. (K) The cytoplasm of anterior hypoblast. mtb, mural trophoblast; ptb; polar trophoblast; eb, epiblast; deb, dorsal epiblast; c, cavity; cc, closed cavity; bm, basement membrane; m, mitochondria; v, vacuole; b, bleb; mv, microvilli; sd; special desmosome; d, desmosome; ahb; anterior hypoblast; pl; primary lysosome; al; autolysosome; ptbp; polar trophoblast protrusion; rb; residual body; mfb; microfilament bundles; if, intermediate filaments; rer, rough endoplasmic reticulum; f, 
filopodia. Scale bar: (A, I) $120 \mu \mathrm{m}$, (E) $140 \mu \mathrm{m},(C, F, H, K) 400 \mathrm{~nm},(B, J) 600 \mathrm{~nm}$, (D) $250 \mathrm{~nm}$, (G) $100 \mathrm{~nm}$.

\subsection{Ultrastructure during epiblast cavity formation (Stage 1+)}

The parts of the dorsal epiblast cells which cover the dorsal side of the closed epiblast cavity and are located either near the polar trophoblast protrusions or under the initial discontinuity within the polar trophoblast contain large intracellular vacuoles (Fig. 7B and C respectively). The cells which enclose the cavity either dorsally or ventrally are connected by junctional complexes of tight junctions and desmosomes and the surface of the cells which face the inner space of the cavity have few short and small microvilli (Fig. 7F and 8F). Some microfilaments bundles are found ventrally in the dorsal epiblast and parallel to the dorsal cavity border (Fig. 7B`). The zipper-like desmosomes are mature as compared to the previous stage and are arranged as triple plaques and have distinct longer intermediate filament besides thicker and longer microfilament bundles stretching out in the cytoplasm parallel to desmosomes plaques (Fig. 7G). Many of these desmosomes are found dorsally or ventrally next to the cavity (Fig. $7 \mathrm{G}$ and $\mathrm{F}$ ). The total length of the triple desmosomes at this stage is about $597 \mathrm{~nm}$ whereas each segment in them measures - as before - approximately $190 \mathrm{~nm}$ and the peripheral microfilaments extend to a total width of $990 \mathrm{~nm}$. The filament layer between the plaque and the cytoplasmic which is parallel microfilament measures $140 \mathrm{~nm}$ and the intercellular space measures $24 \mathrm{~nm}$ (s. Table 2 and supplementary materials Fig. 1C).

As the discontinuities in the polar trophoblast widen and the polar trophoblast cells show more signs of degradation (large vacuoles and swollen blebs) dorsal epiblast cells now keep strong attachment with these polar trophoblast cells by desmosomes and become dorsally and laterally covered by the latter cells (Fig. 8B and G). This polar trophoblast-dorsal epiblast complex (as the rest of the polar trophoblast cells are covering the remainder of the dorsal epiblast) which were completely or partially separated from the rest of the ventral epiblast is kept attached to the underlying concave ventral epiblast either by polar trophoblast cell's bleb-like structures or by lateral tight junction complex between polar trophoblast and ventral epiblast (Fig. 8A and B). The trophoblast-epiblast complex takes on a ball shape (Fig. 8A) or an arm shape (Fig. 8D). Some of the covered dorsal epiblast nuclei show an irregular nuclear membrane (Fig. 8G'). In the ventral epiblast cells (but not in the dorsal epiblast) few mitosis are found at this stage and are also seen in the light microscope (Fig. 8A). A limited number phagosomes are also emerged in the ventral epiblast, only, at this stage either apically near the boundary of the embryonic disc or ventrally at the basal side of the disc. Clumps of 
extracellular matrix material associated with basal epiblast regions accompany the extension in the basement membrane during the gradual flattening of the ventral epiblast epithelium is (Fig. 7H).

The anterior hypoblast cells are closely attached to each other by tight junctions and desmosomes and the cytoplasm is rich in both linear and circular rough endoplasmic reticulum in contrast to the posterior hypoblast. The anterior hypoblast cytoplasm displays an abundant number of tubular mitochondria; cell nuclei are large and there is little rough endoplasmic reticulum, small lipid droplets (supplementary materials Fig. 2D) and with fewer ribosomes than in the epiblast. The basal surface displays short but thick microvilli (Fig. 7M). In the posterior hypoblast, the nucleo-cytoplasmic ratio is high, the nuclei are squamous (occupying most of the cell volume) and the cytoplasm has only few mitochondria and inclusions (Fig. 8C). The cells of the posterior hypoblast lie further apart from each other and connected by long cytoplasmic processes (Fig. 8C). 

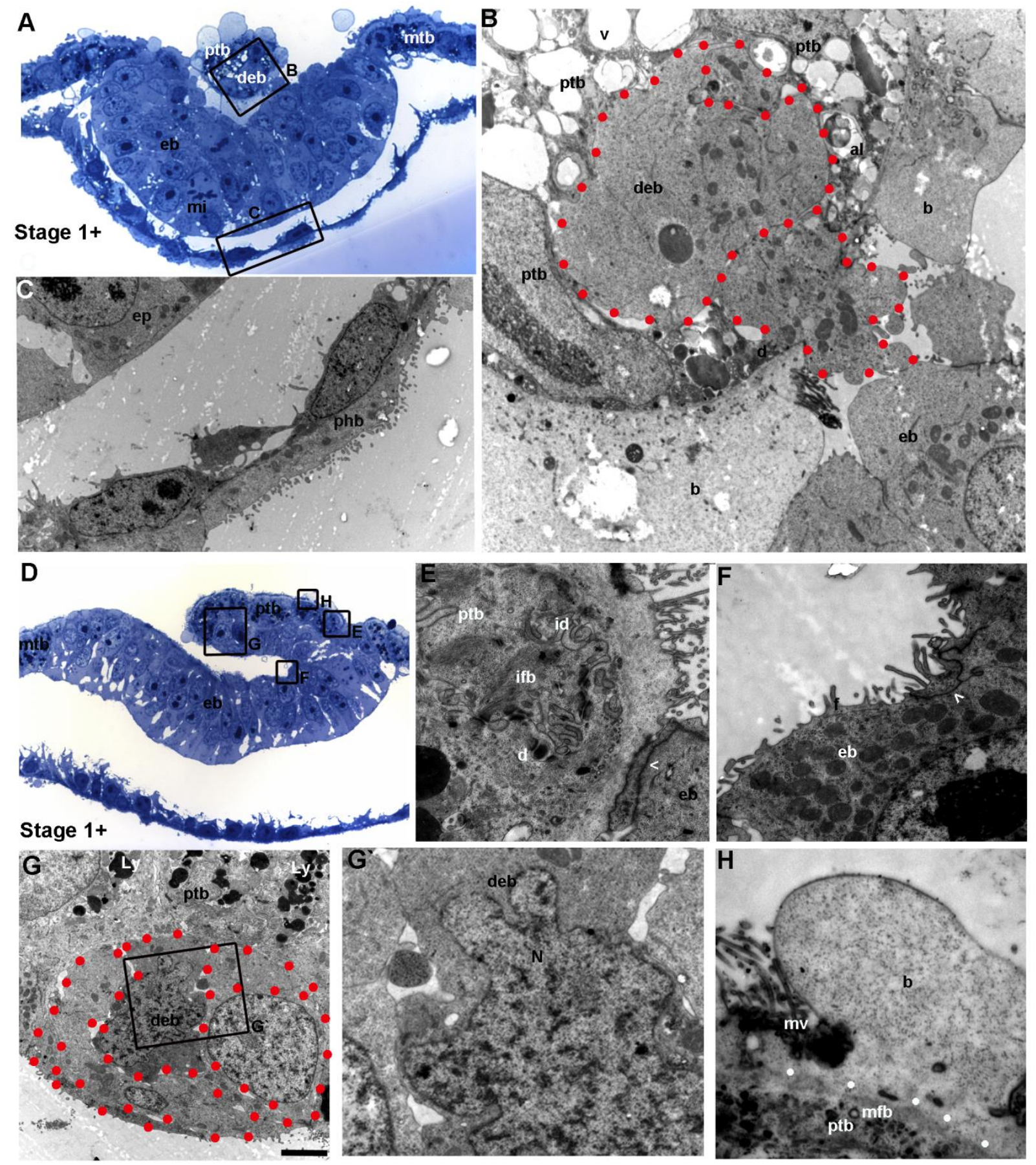

Fig. 8 Ultrastructure of remnants of polar trophoblast and dorsal epiblast at pre-gastrulation stage 1+ of pig embryo. (A and D) Light micrographs of $1 \mu \mathrm{m}$ section of embryos obtained at 9 d.p.c. (B and C) and (E-H) Electron microscopy micrographs from the section shown in A and D respectively. (B) Remnants of dorsal epiblast with autophagosomes polar trophoblast cells overlying open cavity. Red dots define the borders of the dorsal epiblast. (C) The cytoplasm of posterior hypoblast. (E) Interdigitations, desmosomes and long intermediate filaments bundles in the remnant of polar trophoblast. Long microvilli are on the upper and lateral surface of the cell. The white open arrowhead marks the tight junction between the polar trophoblast remnant and the ventral epiblast. (F) Filopodia are on the upper surface of the ventral epiblast facing the open cavity. (G) Remnants of dorsal epiblast cells. Red dots mark the dorsal epiblast/polar trophoblast borders. (G') Box in $G$ marks the irregularity in the nucleus of the dorsal epiblast. (H) Bleb of polar trophoblast has a smooth surface and lateral microvilli. Microfilaments located parallel to the upper surface mark the border of the polar trophoblast cell cytoplasm and the bleb. mtb, mural trophoblast; ptb, polar trophoblast; eb, epiblast; deb, dorsal epiblast; mi, mitosis; v, vacuole; b, bleb; ifb; intermediate filament bundles; id, interdigitation; d, desmosome; al, autolysosomes; $\mathrm{N}$, nucleus; mv, microcilli; $\mathrm{mfb}$; microfilament bundles; phb, posterior hypoblast; f, filopodia. Scale bar: (A, D) $140 \mu \mathrm{m},(\mathrm{B}, \mathrm{C}, \mathrm{E}, \mathrm{F}, \mathrm{G}) 600 \mathrm{~nm},\left(\mathrm{G}^{\prime}, \mathrm{H}\right) 450 \mathrm{~nm}$. 


\subsection{Ultrastructure during the formation of the concave-convex epiblast shape (stage 2-)}

The outline of the polar trophoblast remnants is swollen and contains large blebs along the dorsal and ventral surfaces and these are completely covered by long, interwoven microvilli (Fig. 9I). The structure of these cytoplasmic inclusions is very much like at the late phase of the polar trophoblast development at stage 1+: there are residual bodies, lysosomes and large vacuoles; desmosomes lie between and inside the few remaining cells which display interdigitations and within the cytoplasm of these interdigitating protrusions long and short intermediate filament bundles (Fig. 9E and I). The trophoblast/dorsal epiblast complex remnants display microvilli which touch the free apical surface of the ventral epiblast (Fig. 9I) but laterally, at the anterior margin of the complex remnant, polar trophoblast cells are connected to the epiblast by few desmosomes and near some filopodia in the epiblast (Fig. 9E). The surface of the mural trophoblast cells which are close to the embryonic disc border is covered with numerous short microvilli and they are strongly and laterally linked to the epithelial epiblast with apical tight junctions and few desmosomes (Fig. 9C). The epiblast cells which are in contact with the mural trophoblast contain more rough endoplasmic reticulum and many vesicles comparing with the other epiblast cells (Fig. 9C and B`) which are apicolaterally attached by tight junctions and immediately further below by some zipperlike desmosomes (Fig. 9B); the plaques in these desmosomes are more electron-dense and measure $30 \mathrm{~nm}$ in width; the intercellular space between the plaques is $35 \mathrm{~nm}$ wide and the felt of microfilament bundles are $85 \mathrm{~nm}$ wide and are slightly longer than at the previous stage. The total length of the zipper-like desmosome, which may contain up to four segments at this stage, is approximately $1127 \mathrm{~nm}$, the length of each segment being variable between 186 and $269 \mathrm{~nm}$ (cf Fig. 9B` and 7I, Table 2 and supplementary materials Fig. 1D). The apical surface of the epiblast sheet displays few short microvilli as compared to the trophoblast (Fig. 9C), and a few large phagosomes and apoptotic bodies are found dorsally in the epiblast near the apical surface; various types cell debris are found inside these residual bodies (Fig. 9F and supplementary materials Fig. 4E). The basement membrane displays many as zigzag-like curves along the ventral pole of the epiblast and in addition to the extra layers of the membrane that is found at the margins of the embryonic disc as in stage $1+($ fig. $7 \mathrm{~J}$ ). In the space between the epiblast and the hypoblast the basement membrane is accompanied by a loose agglomeration of electron dense material (Fig. 9H). Additional basement membranelike material is found in the ventral extracellular spaces between the epiblast cells (Fig. 9G). Some of the anterior hypoblast cells have a triangular shape due to the elongated and dense 
cytoplasmic processes towards the epiblast. Many mitoses are found amongst these hypoblast cells and they frequently contain basal connections to the neighboring hypoblast cells by regular desmosomes (s. black arrow in Fig. 9J).
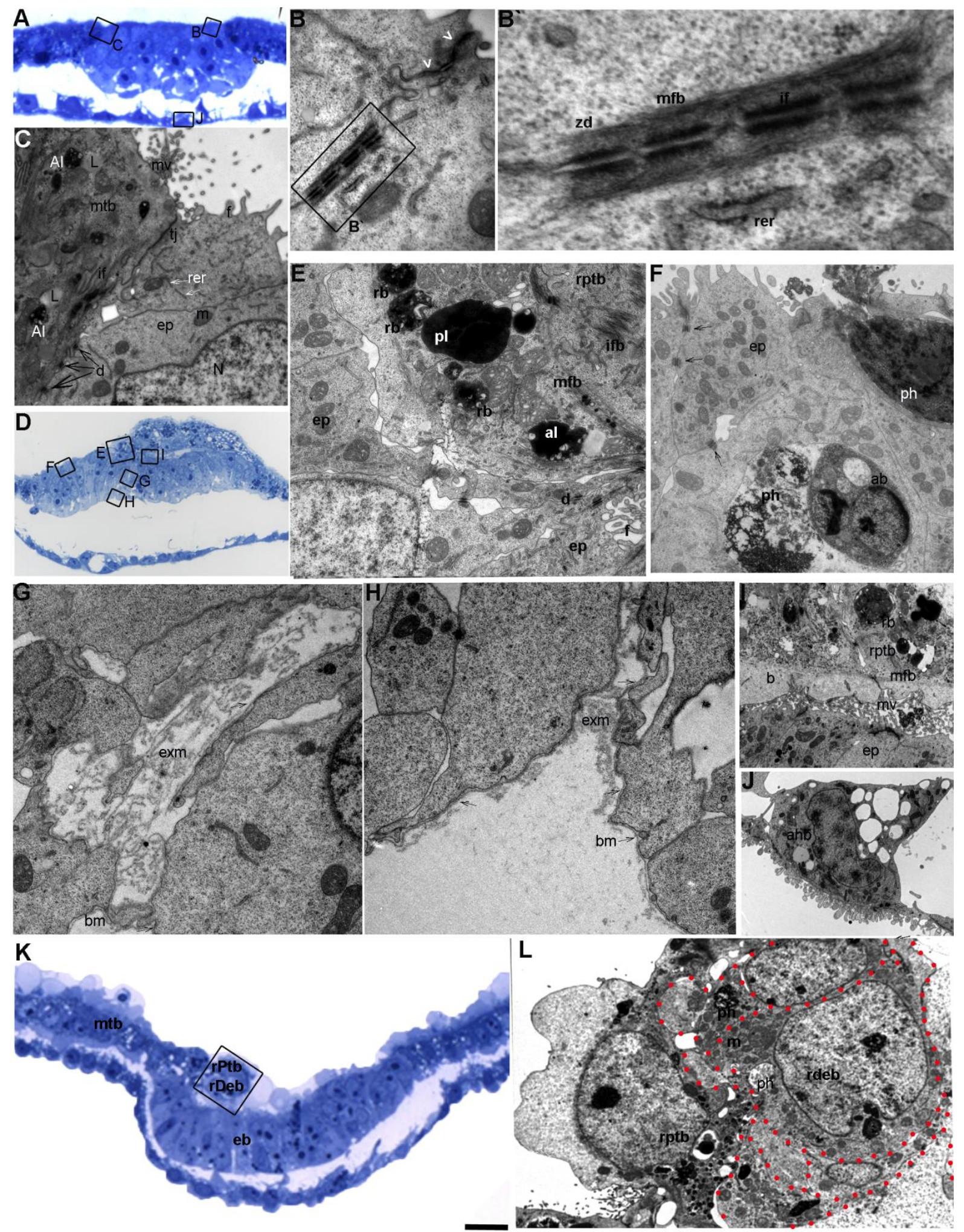

Fig. 9 Ultrastructure of pregastrulation stage 2- of pig embryo. (A, D and K) Light micrographs of $1 \mu \mathrm{m}$ section of embryos obtained at 9 d.p.c. (B, C and J), (E-I) and (L) Electron microscopy micrographs from the section shown in A, D and K respectively. (B) Apical junction complex between epithelialized epiblast cells. White open 
arrowheads refer to tight junctions. (B`) Box in B mark high magnification of special desmosomes (zipper-like desmosomes). (C) The fusing of mural trophoblast with epithelialized epiblast anteriorly. (E) Remnants of polar trophoblast and underlying epithelialized concave epiblast. (F) Phagosomes and apoptotic bodies in the epiblast cytoplasm. Arrows refer to desmosomes. ( $\mathrm{G}$ and $\mathrm{H}$ ) Basement membrane and extracellular matrix of basement membrane are inside and outside extracellular basal spaces of epiblast, respectively. (I) Blebs and microvilli of polar trophoblast remnants above epiblast. (J) Wedge-like hypoblast cell with prominent cytoplasmic processes. (L) Disintegrated dorsal epiblast cells with phagosomed polar trophoblast remnants. Red dots mark the borders of the dorsal epiblast cells. mtb, mural trophoblast; rptb, remnants of polar trophoblast; eb, epiblast; rdeb, remnants of dorsal epiblast; ld, lipid droplets; pl, primary lysosome; al, autolysosomes; ifb, intermediate filaments bundles; d, desmosomes; $\mathrm{zd}$, zipper-like desmosomes; mfb, microfilament bundles; rer, rough endoplasmic reticulum, ph, phagosome; ab, apoptotic body; rb, residual body; bm, basement membrane; exm; extracellular matrix of basement membrane; f, filopodia; mv, microvilli. Scale bar: (A, D) $140 \mu \mathrm{m},(\mathrm{K}) 100 \mu \mathrm{m}$, (B`) $500 \mathrm{~nm},(\mathrm{~B}, \mathrm{C}, \mathrm{E}, \mathrm{F}, \mathrm{I}, \mathrm{J}, \mathrm{L}) 750 \mathrm{~nm},(\mathrm{G}, \mathrm{H}) 900 \mathrm{~nm}$.

\subsection{Goosecoid expression at pregastrulation stages 0, 1-, 1+, 2 and stage 4+}

Goosecoid $(g s c)$ is already expressed in the embryonic disc throughout pre-gastrulation stages 0, 1- and 1+ before they compete for loss of polar trophoblast to various degrees and particularly strong expression is maintained during gastrulation. The pig blastocyst at stage 0 ( $n=2$ embryos) shows a contrast level of strength of $g s c$ expression between embryonic disc and the surrounding extraembryonic tissues. Gsc expression is distributed in a salt-and-pepper appearance inside the embryonic disc as it is shown in the whole mount view (Fig.10 A) whereas it is stronger and darker in the surrounding extraembryonic trophoblast. The sagittal sections show a strong but unspecific distribution of $g s c$ expression at the upper surface of the polar trophoblast as well as the extraembryonic mural trophoblast, whereas $g s c$ is expressed basally at a modest level in few flat cells of embryonic hypoblast at one side of the embryonic disc and close to the center of the inner cell mass (ICM) but distal to the margins of the embryonic disc (Fig.10 B).

At stage 1- $(\mathrm{n}=6)$ the ICM is already segregated into differentiated epiblast cells and underlying hypoblast. Few weak stained single cells are located at the anterior pole of the ball-shaped embryonic disc but keep their distance from the embryonic circumference, share no contact with the surrounding extraembryonic tissues and are particularly organized in a narrow almost central sickle-shape. In contrast to the weak embryonic staining, the extraembryonic trophoblast is strongly stained in which appears as dark dots and distributed almost thoroughly in the trophoblast cells (Fig. 10C). The sagittal sections confirm the previous observations in the whole mount view. The $g s c$ expression domain reveals anteriorposterior differentiation: strong expression is found in the cuboidal embryonic hypoblast single cells at one side of embryonic disc close to the center and apart from the embryonic margins whereas the expression of the gsc in the squamous posterior cells is weak. In 
addition, strong particularly apical staining is found in the mural (extraembryonic) and polar trophoblast and in coarse huge granules in the apical surface and the cytoplasm around the nuclei in the mural trophoblast evenly. In contrast, the same pattern of expression in the polar trophoblast is gradually reduced from the anterior and posterior to the midline polar trophoblast cells. In the same time the epiblast lacks the positivity of the $g s c$ expression (Fig. 10D).

At stage $1+(\mathrm{n}=5$ embryos $)$, in contrast to the early two stages, the embryonicextraembryonic expression at this stage is almost reversed. The positivity of the gsc expression is particularly strong and almost confined to the embryonic anterior pole to middle region whereby the extraembryonic tissue lacks the previous thorough staining (cf. Fig. 10C and $10 \mathrm{E}$ ). The expression appears in the whole mount overview as an anterior wide crescent with weak expression towards the middle of the disc as well as extends anteriorly in a small region outside the embryonic border (cf. Fig. 10E and 10G). In the midline sagittal section the distribution of the expression corresponds to the developed differentiation of the anterior hypoblast cells. The anterior hypoblast cells of the anterior pole and the central region are positive except for the cells located at the margins of both sides of the anterior embryonic hypoblast (Fig. 10F). At the same stage in concomitant with the advanced development in epiblast epithelialization, the $g s c$ expression is shifted more anteriorly and extended to the extraembryonic anterior region as it occupies the whole anterior embryonic hypoblast and small area of the extraembryonic hypoblast. The hypoblast cells are higher in the central area of the layer than in the first specimen (cf, Fig. 10B, 10D). Interestingly, remnants of the gsc expression found in the earlier stages in the mural trophoblast is limited at this stage to few anterior and posterior (extraembryonic) mural trophoblast cells next to the embryonic disc. The distribution of the gsc mRNA is found at the anterior side apically in broader patches and surrounds the nuclei, whereby the basal fine granules are distributed in the mural trophoblast at the anterior as the posterior side (Fig. $10 \mathrm{H}$ ).

The $g s c$ expression at stage $2(n=6)$ applies to the rapid elongation to the anterior hypoblast domain which occupies two-third of the anterior-posterior axis of the embryonic disc. The latter shown in Fig. 11A is difficult to define the absolute circumference of the embryonicextraembryonic borders due to the folding of the tissues in this region but it was virtually drowned by asterisks using the successive sections and the size and location of the gsc expression. The extraembryonic domain of the $g s c$ expression in the mural trophoblast is 
strongly reduced or lost. The distribution of the gsc expression is found in the whole region of the elongated embryonic anterior hypoblast and in the majority of the cuboidal central parts of it. In addition, the expression domain of the anterior extraembryonic hypoblast has markedly increased in size compared to the previous stage (cf. Fig. 10H and 11B). Surprisingly, to the first time in the pregastrulation stages, I found that some of the epithelialized epiblasts at the posterior pole are strongly positive in the area of the precursors of the primitive streak. These positive epiblast cells are extended from the posterior border of the embryonic disc to the end of margin of the last positive cuboidal anterior hypoblast cells. The two domains of the $g s c$ in the hypoblast and the posterior epiblast appear as if they complete the extension of each other (Fig. 11B).

During further development at stage 4+ $(\mathrm{n}=3)$, the $g s c$ expression is still strong and shows differentiated distribution in the layers of the node at the most anterior third of the primitive streak and forms a huge round spot at the midline of the embryonic disc and closer to the anterior pole (Fig. 11C). At the node, both the hypoblast and the epiblast cells are strongly stained. Anteriorly to the node, the gsc is expressed in the prechordal mesoderm cells which migrate gradually towards the anterior region above the hypoblast whereas the primitive streak cells lack the expression of the gsc (Fig. 11D and 11D'). 

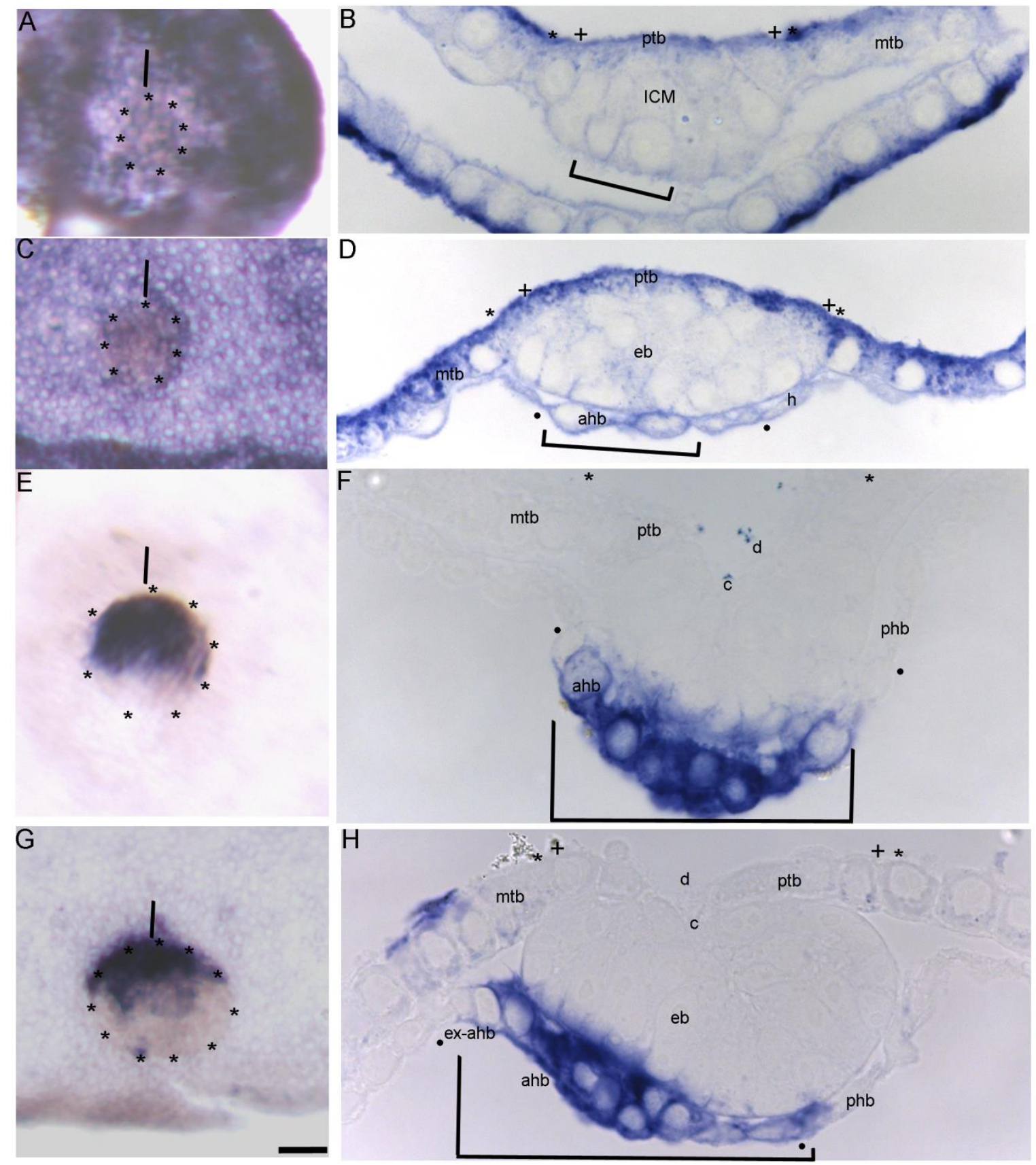

Fig. 10 Goosecoid expression at stage 0 (A, B), stage 1- (C, D) and stage 1+ (E-H) pig embryos as seen in over views (A, C, E and G) after whole mount in situ hybridization using bright field illumination, and 5- $\mu \mathrm{m}$ Technovit ${ }^{\circledR}$ sagittal sections $(\mathrm{B}, \mathrm{D}, \mathrm{F}, \mathrm{H})$ of the same specimens, respectively. The border of the embryonic disc (in A-H) is identified by asterisks placed peripheral to the borders, whereas the position and orientation of the sections are defined by bars (in A, C, E and G). The embryonic and extraembryonic anterior hypoblast (ahb) is labelled by dots and the extension of the goosecoid expression is marked by square brackets at every stage. The (+) at stage0, 1- and 1+(in B, D, F and H) marks the margin of the polar trophoblast; mtb, mural trophoblast; ptb, polar trophoblast; ahb, anterior hypoblast; ex-ahb, extraembryonic anterior hypoblast; h, hypoblast; eb, epiblast; peb, posterior epiblast; c, cavity in the epiblast; $d$, discontinuity in the polar trophoblast. Scale bar: (A, G) 140 $\mu \mathrm{m},(\mathrm{B}, \mathrm{H}) 20 \mu \mathrm{m}$. 
A

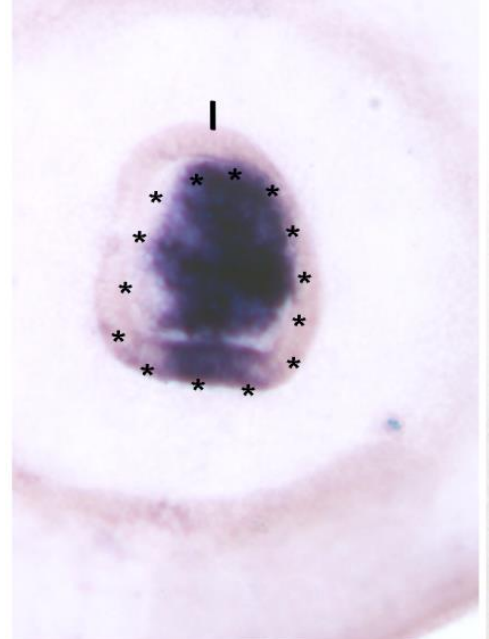

B

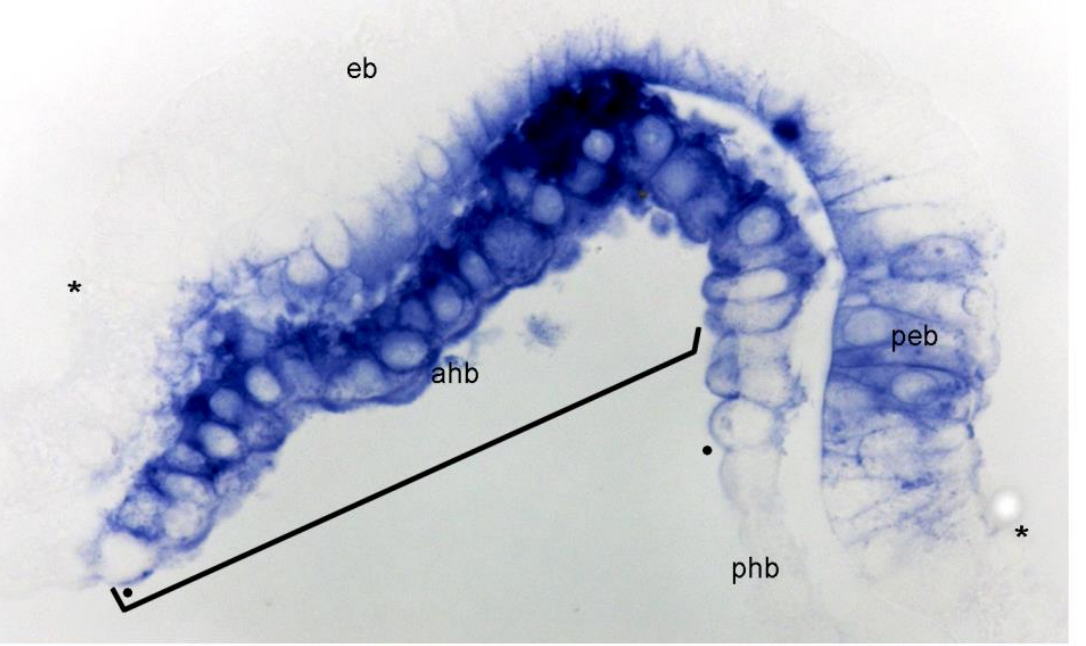

C

D
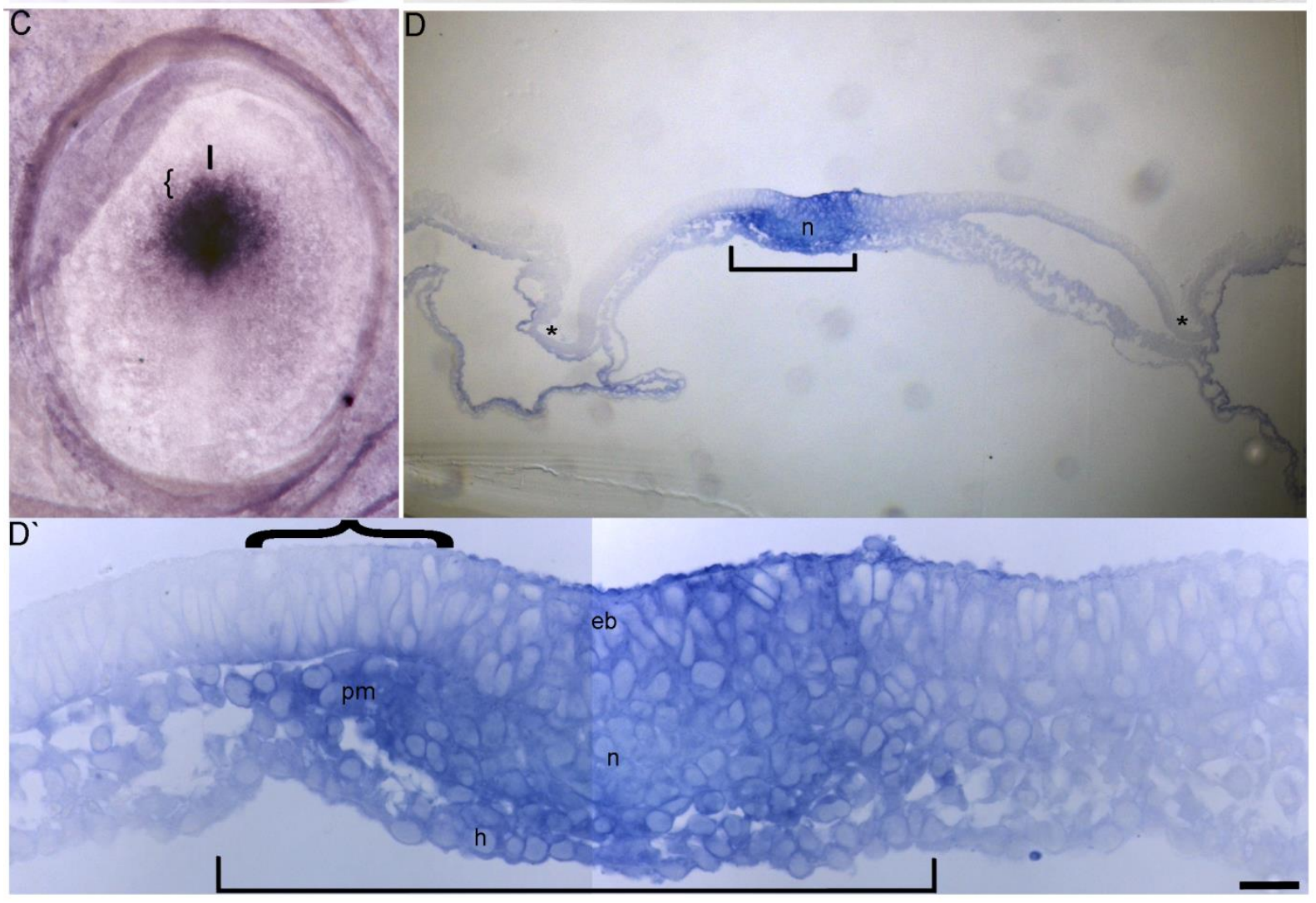

Fig. 11 Goosecoid expression at stage 2 (A, B) and stage 4+ (C-D') pig embryos as seen in over views (A and C) after whole mount in situ hybridization using bright field (A) and dark-field (C) illumination, and 5- $\mu \mathrm{m}$ Technovit ${ }^{\circ}$ sagittal sections (B and D) of the same specimens, respectively. The border of the embryonic disc (in A) is identified highlighted by asterisks placed peripheral to the borders, whereas the position and orientation of the sections are defined by bars (in A and C). Brackets mark length and extentsion of the prechordal mesoderm in (C and D) at stage 4+. The embryonic and extraembryonic anterior hypoblast (ahb) is labelled by dots and the extension of the goosecoid expression is marked by square brackets at every stage; mtb, mural trophoblast; ahb, anterior hypoblast; ex-ahb, extraembryonic anterior hypoblast; h, hypoblast; eb, epiblast; pm, prechordal mesoderm; n, node. Scale bar: (A, C) $50 \mu \mathrm{m}$, (D) $35 \mu \mathrm{m}$, (B) $15 \mu \mathrm{m}$, (D') $10 \mu \mathrm{m}$. 


\section{Discussion}

Light and electron microscopy combined with 3D reconstruction of the pig pre-gastrulation embryonic disc helped to define several small steps of epithelialization (and some refinement of the early pre-gastrulation stages 1 and 2) and to elucidate the morphological and cytological characteristics of the embryonic disc layers during the transition of the epiblast from an overall ball shape into the pseudostratified epithelium of the flat embryonic disc. At stage 1- dorsal and ventral epiblast cells contract apically and form a rosette-like structure between them when subsequently a cavity is formed. At stage 1+ the cavity separates the two sub-populations of epiblast cells horizontally whereas basal protrusions from the polar trophoblast separate the dorsal epiblast vertically. An immature special type of desmosomes is located exclusively between the ventral epiblast cells during the subsequent full epithelial polarization and cellular rearrangement to form a slightly concave layer of ventral epiblast cells. Ventral epiblast cells form lateral connections with the mural trophoblast by desmosomes at the anterior and posterior borders after apical blebbing, a lysosomes rich cytoplasm and lateral microvilli mark the first signs of disappearance of the polar trophoblast. Dorsal epiblast cells, meanwhile, maintain their undifferentiated characteristics and disintegrate during stages 2 - and $2+$ together with the remnants of the trophoblast in an anterior to posterior gradient.

\subsection{The morphogenesis and epithelialization process of the epiblast before the onset of gastrulation}

In this study, I elucidate the presence of two cell types in the epiblast after segregating of the inner cell mass and after hatching from the zona pellucida of the 8 and $9 \mathrm{dpc}$. The identification of the two subpopulations of cells was first set in accordance with their location and in which their names were originally derived. The dorsal cells refer to a cluster of cells in the dorsal center of the embryonic disc apposed to the polar trophoblast whereas the ventral epiblast constitutes the rest of the cells and it is opposed to the basement membrane and the hypoblast. The clarification of the dorsal and ventral epiblast can be detected at stage 1 - in the sections where a cytoplasmic thickness is identified under light microscopy illumination, but the most difference has been specified at stage $1+$ by the gradual change in the form of the ventral epiblast cells from spherical to cuboidal, and strong adhered rearranges layer of cells. These findings have close resemblance to the two subpopulation of cells found in the bovine epiblast of the pre-gastrulation blastocyst, where spherical cells are opposing the polar 
trophoblast and without signs of polarization were located inside or above basal layer of pyramidal to cuboidal cells connected with desmosomes and tight junctions after the exposure of epiblast (Vejlsted et al., 2005).

It was also reported by (Fléchon, 1978) that the presence of two epiblast cell morphologies appear in the early rabbit blastocyst before the shedding of the polar trophoblast cells. These findings obtained by the analysis of the in vivo embryos are supported during the cell culture of the pre-gastrulation pig epiblast as two distinct morphological types of cells are obtained: (1) ESC-like cells, which are unstable and fail to proliferate and (2) epithelial-like cells which could form aggregate clusters. Accordingly, I can suggest that these morphological differences can bear with it a different fate and role of the dorsal and ventral epiblast. The latter differentiates to form an epithelial-like sheet as a necessary preparation before the onset of the gastrulation; a process begins in the epithelial epiblast. In the pig, the process of ventral epiblast epithelialization coincides with the formation of a central cavity separating the dorsal epiblast from the ventral epiblast horizontally. I have been able to analyze the aspects of characteristics of the cavity formation, which could be conserved from the mechanism to form the amniotic cavity in the murine pre-gastrulation blastocyst but in contrast to the description of vertical orient slit (Hall et al., 2010). Moreover, the cavity in the pig epiblast was firstly described as spaces of specific type between the superficial layers of cells united into one large cavity with marked microvilli projecting inside the cavity (Barends et al., 1989). This description of small cystic cavities with microvilli encircling by epiblast cells were also found in the bovine epiblast but without fusing into one cavity. In contrast to the previous findings, my study indicates that one cavity is horizontally formed between the dorsal epiblast cells and some of the ventral epiblast cells by forming a rosette-like structure at the center of the embryonic disc. The interdigitating of apical membranes of the narrow ends of the rosette-like structure cells, found at stage 1-, is untied and numerous filopodia processes are formed in a reverse process to the known role of filopodia in cell-cell adhesion between epithelial cells (Millard and Martin, 2008; Gallo and Letourneau, 2004).

Remarkably, the pre-amniotic cavity in the mouse and human pre-gastrulation blastocyst is formed as the epiblast cells are rearranged in a rosette-like structure but the apical membranes of the these cells are separated by charge repulsion mediated through actomyosin contraction which is transmitted through adherens junctions (Bedzhov and Zernicka-Goete, 2014) and fluid-containing vesicles trafficked between the apical interfaces of the rosette-like structure 
cells when they are differentiated from naïve to primed pluripotent cells (Shahbazi et al., 2017; Taniguchi, 2018). Thus, the mechanism of the amniotic cavity formation in the mouse and human can be correlated in its first step to that in the pig. The presence of the filopodia at the apical ends of the rosette-like structure can be explained by the role of filopodia in cell mobility and migration through the stress fibers of actin and myosin which provide contractile forces for cell morphogenesis (Mattila and Lappalainen, 2008; Pelligrin and Mellor, 2007; Hotulainen and Lappalainen, 2006) and as a result contribute in opening the cavity and separating the dorsal and ventral epiblast cells. This morphogenesis of the ventral cell layer during the cavity formation, and subsequently the gradual epithelialization and the rearrangement in one sheet of cells require flexibility in cell-cell contact as well as cell movements, which are provided according to my findings by an immature special type of desmosomes between the ventral epiblast cells. These immature desmosomes are lacking the inner cell plaques and boarded by felts of actin microfilaments will eventually develop into what is known by zipper-like desmosomes as they are called by (Rusu et al., 2013). The immature development into mature status between the eventual epithelial ventral epiblast cells can be related to degree of mobility at the immature stages while the mature ZLDs desmosomes are involved in the cellular stability (Gorfinkiel and Blanchard, 2011; Rusu et al., 2013).

These dynamic morphological changes can explain the high concentration of mitochondria and rough endoplasmic reticulum as well as numerous Golgi apparatus vesicles that we found in the cytoplasm of the rosette-like structure and specifically in its ventral cells compared to the cytoplasm of the rest of the epiblast cells prior to the opening of the cavity, a process in need for energy and a sign of protein synthesis which can be provided by the mitochondria's role in blastocyst differentiation, expansion and hatching (Sathananthan and Trouson, 2000). During the formation of the rosette-like structure the cytoplasm of some of the ventral epiblast cells still bear large lipid droplets but they disappear as long as the cavity is opened and the ventral epiblast differentiation and epithelialization precede and discontinuity in the polar trophoblast appears. This loss of epiblast lipid droplets can be considered as a specific sign of this developmental stage (Talbot and Garrett 2001).

\subsection{The polar trophoblasts phagocytosis, cell death and the fate of the dorsal epiblast}

In association with the formation of the cavity which is completely enclosed by epiblast cells, 
our results indicate that a lateral bleb between two polar trophoblast cells caused the first sign of departure but not separation as the two cells maintain adhesion by tight junctions at the anterior side of the embryonic disc. Many microvilli are formed laterally and dorsally between these two cells and the underlined epiblast. Eventually, holes in the wall of the polar trophoblast appear as single or multiple ruptures (Fléchon, 1978) lead to the disappearing of the polar trophoblast in contentment with the full epithelialization of the ventral epiblast. The mechanisms of the pig polar trophoblast discontinuities and disappearance are still not clear. The polar trophoblast cells are easily distinguished from the underlying epiblast cells under light microscopy illumination not only by the different electron density due to the variation of ribosomal concentration (Hesseldahl, 1971; Williams and Biggers 1990), but also by the black dotted appearance of the polar trophoblast cytoplasm due to numerous lysosomes of different kind and (auto)phagosomes at both stages 1- and 1+. In many species including human and mouse, trophoblast cells exhibit intense phagocytic activity tend to be increased in polar trophoblast (Li et al., 2016; Bevilacqua and Abrahamsohn, 1988). It is generally considered to be a mark for mouse trophoblast giant cells differentiation and it showed to be early programmed in preimplantation steps (Bevilacqua et al., 2010). In contrast to other vertebrates which have no cell death prior to gastrulation, in mammalian embryogenesis cell death begins early in blastocyst differentiation (Spanos et al., 2002).

In accordance with the changing characteristics and morphology of the polar trophoblast in my study from early stage 1- to stage 2- several possible mechanisms for its progressive disintegration in the pig embryonic disc are possible : (1) phagocytosis/autophagocytosis, (2) apoptosis, and as described by (Penaloza et al., 2006) there are overlapping features and much crosstalk among different types of cell death allows e.g. autophagy to convert to apoptosis and vice versa and hence (3) initial autophagocytosis followed by apoptosis. Autophagocytosis is a stress adaptation process that promotes originally cell survival by undergoing partial autodigestion to prolong survival for short time (Levin and Kroemer, 2008; Tsujimoto and Shimizu, 2005), and it is associated with autophagosomes which fuse with primary lysosomes to form autolysosomes (D'Herde et al., 2009). Remarkably, this corresponds with the trophoblast at the pregastrulation stages which are in the phase prior to the rapid elongation period after the formation of the epithelialized epiblast and the rich cytoplasm with the lysosomes and autolysosomes. In addition to that, the polar trophoblast cells in the pregastrulation pig embryonic disc are cuboidal to high columnar and in contrast to the flattened polar trophoblast cells in the rabbit and horse (William and Biggers, 1990; Enders et 
al, 1988), the squamous cells in the pig polar trophoblast are limited to only few cells at the center of the embryonic disc. Hence, as the bulky cytoplasm cannot be easily shed to be phagocytosed and in this case it is consumed by autophagosomes for partially self-digesting (Penaloza et al., 2006; Clarke et al., 1990).

Other morphological characteristics of the autophagocytosis cell death are presented in the polar trophoblast cells at stage 1- and the early stage 1+ with large autophagic vacuoles and the condensation of cytoplasm and chromatin. The pig polar trophoblast is reported to undergo endocytosis with numerous caveolae and coated pits (Barends et al., 1989; Geisert et al., 1982) which is frequently seen in autophagic cell death (Clarke et al., 1990) and correspond to phagocytotic activity (Baumach et al., 1990). The lipid droplets and lipid metabolism are suggested to play an important role in non-apoptotic cell death which is triggered by specific fatty acids (Magtanong et al., 2016). These lipid droplets show signs of degradation forming empty vacuoles at stage 1+ when a new type of program cell death may be involved. At stage 1+ our results describe that the polar trophoblast cells show signs of apoptosis: the cell shrinkage, cytoskeletal reorganization, cell surface alternations and membrane blebbing (Elmore, 2017; Linkermann and Green 2014). Apical membrane blebbing is found at stage 1+ and according to (Paluch and Raz 2013; Wickman et al., 2013) apoptotic blebbing is driven by hydrostatic pressure generated by cortical cytoskeletal actomyosin cortex; these bundle of actin filaments in my study are found apically and cortically parallel to the plasma membrane, in similarity to the blebbing of ewe polar trophoblast cells before their loss (Fléchon et al., 1978).

Even though many apoptosis characteristics are observed but during the disappearing of the polar trophoblast cells and the formation of the discontinuities, the cells remaining maintain their strong adherence to neighboring cells by many desmosomes and numerous interdigitations in contrast to the polar trophoblast in the rabbit and horse where these cells become isolated and scattered rather than withdrawn as a unit. But with a similar morphology to the late pig polar trophoblast at stage 1+ the polar trophoblast in both these species becomes highly vacuolated and its apical outlines become irregular (Williams and Biggers, 1990; Enders et al., 1988). My electron microscopy analysis identified three forms of mitochondria in the cytoplasm of polar trophoblast cells at stages 1- and 1+ according to the differences of their inner mitochondrial membrane which is varied between normal or separated into separate vesicular matrix or vesicular swollen in similarity to what has been 
described by (Sun et al., 2007) who identified different types mitochondria during three developed phases of apoptosis.. In light of the above, neither autophagy nor apoptosis can apply alone for all the morphological and developmental characteristics of the polar trophoblast cells from healthy to dying cells. According to that I have been able demonstrate that what starts as a mechanism for survival under stress condition for the bulky giant polar trophoblast cells by autophagy cell death is continued by the first type of program cell death apoptosis. Eventually, the polar trophoblast cells undergo both programs of cell death and are phagocytosed by the neighboring cells (Bursch, 2001; Dai and Gilbert, 1997).

The contribution of phagocytosis in polar trophoblast cell loss is supported by the suggestion that in healthy cells the intracellular presence of large phagocytic vacuoles refers that cell remnants are cleared by phagocytosis (Lopata 1982; Enders and Schlafke, 1981). This suggestion is used in the horse and the rabbit to prove that the polar trophoblast is phagocytosed by the epiblast, which contains very large phagosomes only after the disintegration of the polar trophoblast (Enders et al., 1988; Williams and biggers, 1990). In temporal contrast and spatial similarities to these findings, my results identified variant sizes of phagocytic cavities exclusively in the ventral epiblast at stage 1- when the polar trophoblast is still intact epithelium and also found at stages $1+$ and $2+$ whereas remnants of polar trophoblast are still presented. At stage 1- the phagosomes cavities are found in the ventral epiblast cells close or involved in the formation of the epiblast cavity and already contain filopodia at their apical membrane. Besides the importance of the filopodia in cell mobility and opening cavity as I already mentioned in the previous paragraph, the filopodia support the phagocytic uptake of cellular particles (Horthemke et al., 2017). The filopodia are found in the pig not only protruded inside the cavity but they are presented in the cells underlying the remnants of polar trophoblast at stages $1+$ and 2- in the pig embryonic disc, and also in the cystic cavities in the bovine (vejlsted et al., 2005), and intruded in small pockets of intercellular spaces between horse epiblast cells (enders et al., 1988).

In a comparative study of cattle embryos of similar pre-gastrulation stages it was concluded that the rupture of the polar trophoblast is unlikely to be involved in the epiblast transition from ball into flat epithelium (van Leeuwen et al., 2015). In contrast I suggest that in the pig these processes are intimately related. I found that during the disintegration of the polar trophoblast cells at stage 1+ many desmosomes are formed between the dying polar trophoblast cells and the dorsal epiblast cells I identified before. Similarly, this strong 
adhesion is also reported between one polar trophoblast cell and two epiblast cells in the rabbit embryonic disc (Williams and Biggers, 1990). The pig dorsal epiblast cells at stage 1+ are a mass of round cells less differentiated than the progressively epithelialized ventral epiblast. At the time of o the gradual disappearing within the polar trophoblast, the two subpopulation cells of epiblast are separated horizontally by the cavity and laterally by the polar trophoblast protrusions which projected vertically towards the upper layer of the epiblast at the center of the embryonic disc. Similar protrusions were involved in separating the epiblast cells of the horse pre-gastrulation embryonic disc during the loss of the polar trophoblast by basally projecting between the epiblast cells giving the epiblast an interrupted appearance (Enders et al., 1988). In comparison to horse whose epiblast is 1 to 2 cells thick, the pig epiblast is 3 to 4 cell thick and the polar trophoblast protrusions separate the upper layer of the epiblast till the cavity level. Thus, the only remained cell-cell contacts of the dorsal epiblast cells are contacts with the overlying dying polar trophoblast and with each other.

Furthermore, my results indicate few deterioration characteristics of the dorsal epiblast, e.g. blebbing, cytoplasm shrinkage and irregular nuclei cytoplasmic membrane and condensed chromatin. I therefore suggest that the dorsal epiblast is going to be lost with the polar trophoblast and will have no role in the gastrulation or the formation of the primitive streak in contrast to the study of (Xia et al., 2011) in which they identified an unusual group of cells in the central area of the pig pre-gastrulation embryonic disc (close to my dorsal epiblast location) as the precursors of the primitive streak. These isolated cells need to be polarized and epithelialized, prerequisite conditions for the formation of primitive streak. The contact to the basement membrane is suggested to be required for emerging polarity of epiblast cells (Bedzhov and Zernicka-Goetz, 2014) and the dorsal cells in the pig do not form contact with it. The basement membrane is extended between the hypoblast and the overlying ventral epiblast and between the hypoblast and the mural trophoblast, but no basement membrane is found between the epiblast and the polar trophoblast (Barends et al., 1989). In transmission electron microscopy, the basement membrane at stage 1- appears as a strained thin rope close to the epiblast than to the hypoblast, except cites near the margins of the embryonic disc where it is continuous with areas of the extracellular matrix.

At stage $1+$ this extracellular matrix is protruded basally through the extracellular spaces between the ventral epiblast cells providing a contact even with a basally second row of cells 
of ventral epiblast, the only cells to be polarized. This change may reflect morphogenetic processes since it was proposed that extracellular matrix of basement membrane move during morphogenesis (Loganathan et al., 2016,) and the composition structure of it evolve (Fléchon 2017). Besides the importance of the basement membrane as a substrate for eventual migration of epithelialized epiblast cells, the basement membrane is not completely continuous. I found by electron microscopy some discontinuities in the basement membrane through which some epiblast cells are protruded towards the hypoblast. This finding may explain reported ferritin diffusion in the pig embryo (Barends et al., 1989). At stage 2remnants of polar trophoblast and one or two epiblast cells appear floating over the epithelium epiblast and has one side contact with mural trophoblast. The polar trophoblast here lost its epithelial characteristics, they have no basolateral polarity as they appear as irregular mass of strongly attached almost round cells and all their surfaces are completely covered with blebs and microvilli similar to big apoptotic bodies which lead me again to the suggestion of the late apoptosis and the phagocytosis by the epiblast.

\subsection{Early anterior-posterior axis differentiation and the precursors of the primitive streak}

The staging system defined in the results of this study enables a comparison of the expression of the goosecoid ( $g s c$ ) with the morphological characteristics of every stage. With regard to $g s c$ in the pregastrulation pig blastocyst, the initial sign of positive cells was seen at stage 0 in mosaic pattern in the embryonic disc area and strong extraembryonic staining surrounding the embryonic disc. In the subsequent stages (1-, 1+ and 2), the gsc expression was very clearly presented in the cuboidal anterior hypoblast cells. It forms a crescent shape and then shifted centrally and towards the extraembryonic hypoblast. This continued strong expression in the anterior hypoblast cells in the pregastrulation stages may refer to the possible role of the $g s c$ in the initial axis formation process (Idkowiak et al., 2004a). Interestingly, at stage 2 the gsc is expressed in two domains: whereas strong staining is confined to the anterior embryonic and extraembryonic hypoblast weaker staining emerges in some of the posterior epithelial epiblast cells (Fig. 12). These cells are thought to be the precursors of the primitive streak which suggests an involvement in the establishment of the body plan and the organizer (Fig. 12). This is confirmed by the gsc positive cells in the node (the mammal's organizer).

In contrast to my results, the onset of the expression of the $g s c$ in the pregastrulation pig embryo was reported (Van de Pavert, 2001) to be found at 9 dpc conceptuses when the polar 
trophoblast starts to disintegrate and an extracellular space (cavity) is formed between the epiblast cells (at stage 1+ according to my staging system). This late weak expression is reported to be found asymmetrically in the hypoblast but without defining which actual side of the axis is positive with gsc expression. Eventually, with the unfolding of the epiblast at 10 dpc embryos the gsc expression area (Van de Pavert, 2001). Another study of the same embryonic age assumed that the beginning $g s c$ expression in the hypoblast marks the posterior end of the anterior-posterior axis (Meijer et al., 2000). In the mouse, it was found that the $g s c$ is already expressed in the prestreak embryo and it was apparent in the anterior visceral endoderm which is responsible for the induction and formation of the anterior neural structure in the ectoderm (Belo et al., 1997; Shawlot et al., 1998; Tam and Steiner, 1999). In the early gastrulation in the mouse, the $g s c$ mRNA is accumulated in a small patch on the side of the posterior epiblast where the primitive streak is going to be formed (Blum et al., 1992) similar to my pattern of $g s c$ expression at stage 2. In contrast to the situation in mammals, the first hallmark of anterior-posterior polarity in the chick is the formation of the Koller's sickle (Callebaut and Van Nueten, 1994) at the posterior end of the embryonic disc and the gsc is expressed in this structure (Niehrs et al., 1993; Van de Pavert, et al., 2001). It remains to be clarified whether Koller's sickle can be considered as a functional equivalent to the anterior hypoblast in the pig and rabbit and AVE in the mouse.

In the organizer of Xenopus, both signaling molecules (e.g., chordin) and transcription factors (e.g., gsc) on the dorsal side of the embryo are involved in inhibition of the ventral signal formed by BMP4 activity (Zhu et al., 1998). This ability of gsc to repress target gene pathways including BMP4 is also found in the mouse (Zhu et al., 1998; Boucher et al., 2000). In the pig, the expression of BMP4 was not detected at early pregastrulation stages and emerges in the posterior primitive streak at stage 3 (Yoshida et al., 2016) and at the borders between the epiblast and mural trophoblast at stage 2 (Valdez Magna et al., 2014). I can then speculate that the $g s c$ domain in the hypoblast may be involved in suppression of BMP4 signaling which is in line with the controversial suggestion of the role of the prestreak hypoblast as a head organizer in the chick embryo by inducing the preneural plate (Callebaut et al., 1998). In addition a further function of $g s c$ is related to cell behavior and should be taken into account: $g s c$ has been shown to be involved in mesoderm cell migration (Niehrs et al. 1993, Luu et al. 2008). Especially it has been suggested that gsc works as a switch by repressing convergent extension in prechordal mesoderm cells (Ulmer et al. 2018). This function may be related to the role of the second expression domain of $g s c$ in the posterior 
epiblast at the location of the future primitive streak.

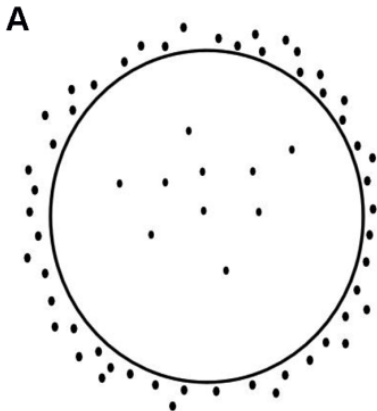

Stage 0

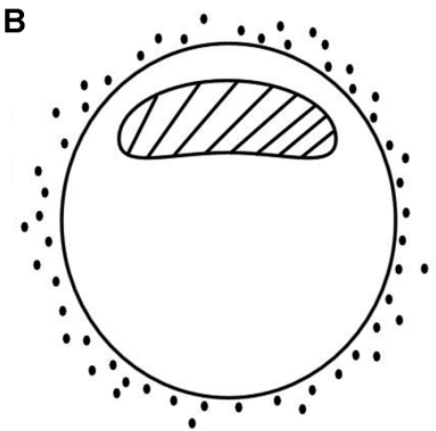

Stage 1-

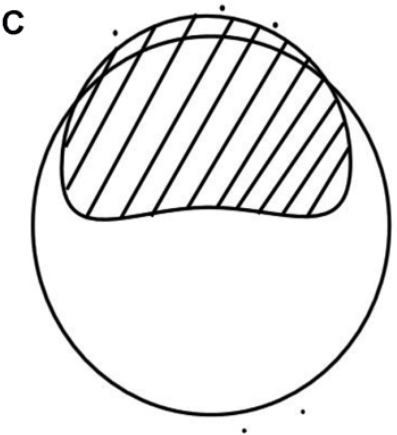

Stage 1+
D

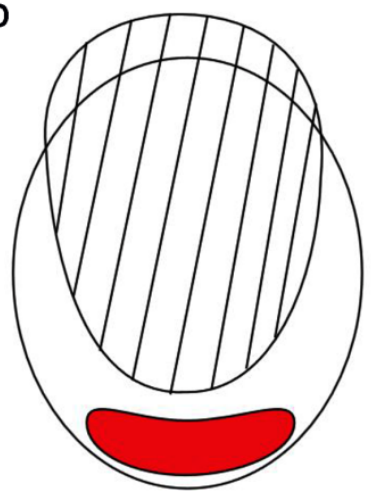

Stage 2

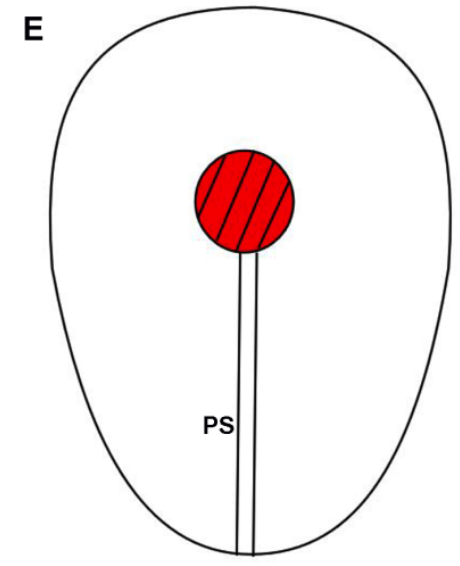

Stage 4+

\section{Gsc in AHB $\square$ Gsc in posterior epiblast}

Gsc in the node

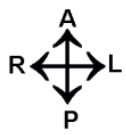

Fig.12 Schematic correlation of the two gsc expression domains in the pig embryonic disc during epiblast development (A-D) and gastrulation (E). Dots outside the embryonic disc refer to the positive staining of $g s c$ in the extraembryonic mural trophoblast (A, B and C). The gsc expression at stage 0 in the embryonic tissue is located in some of flat hypoblast cells in the ICM besides the polar trophoblast (A). At stages 1- and 1+ the gsc expression is extended from crescent shape (B) to indented ring (C) due to the elongation and differentiation of the anterior hypoblast (AHB). Gsc expression at stage 2 (D) is confined to the embryonic and extraembryonic anterior hypoblast and to some posterior epiblast cells precursors of the primitive streak, the node, and the prechordal mesoderm. The later fate may be reflected by $g s c$ expression in the node area at stage $4+(\mathrm{E})$. 


\section{Abstract}

The epiblast of the amniote embryo is of paramount importance during early development as it gives rise to all tissues of the embryonic proper. In most mammals, the epiblast emerges by segregation of the inner cell mass into (a) flat one-layered hypoblast also known as visceral endoderm and (b) epiblast precursors which subsequently undergo epithelialization and create the embryonic disc. In a next step the anterior-posterior axis emerges by directed migration of hypoblast cells towards the future anterior pole. These cells display a cuboidal morphology and, molecularly, are involved in suppression of the posterior fate in the overlying epiblast cells. In the pig embryonic disc, the flat epithelial epiblast emerges after anterior-posterior axis formation and during the disintegration of the polar trophoblast. Both epiblast epithelialization and polar trophoblast loss are still ill-understood despite being crucial processes for ensuring tissue integrity during gastrulation and will, therefore, be subject of this thesis. High resolution light and transmission electron microscopy, three-dimension (3D) reconstruction and in situ hybridization of the organizer gene goosecoid (gsc) as an early marker for the formation and polarity of the anterior-posterior axis were applied to 8- to 10days-old pig embryos.

Because of the morphological complexity of the early embryonic disc during the epiblast shape transition I refined - as the first step of my thesis - the staging system of the two existing pregastrulation stages into four stages $(1-, 1+, 2-$ and 2+): At stage 1- the epiblast is partially polarized and soon segregates into (1) a dorsal part which forms a closely associated non-polarized mass of cells and (2) ventral epiblast cells which form special immature desmosomal contacts located near the center of the embryonic disc and bordered by a dense felt of microfilaments parallel to the desmosomal plaque. Ventral and dorsal epiblast cells form rosette-like arrangements at their apical narrow ends by interdigitation. The cytoplasm of the intact polar trophoblast is rich with grey lipid droplets, primary lysosomes and different types of heterolysosomes and (auto)phagosomes and three types of mitochondria. Trophoblast cells closely adhere to each other by many lateral desmosomes and long bundles of intermediate filaments interwoven into the cytoplasm and cortical bundles of microfilaments oriented parallel to the apical surface. At stage 1+ the epiblast forms an extracellular cavity which separates horizontally dorsal epiblast cells from ventral epiblast cells. In addition, long polar trophoblast protrusions towards the epiblast separate the two epiblast populations vertically. The polar trophoblast shows increase sign of disintegration with cytoplasmic 
condensations, apical blebs, large vacuoles, residual bodies, and numerous lysosomes. Dorsal epiblast cells are only closely attached to the remnants of the polar trophoblast by desmosomes while ventral epiblast cells show epithelial characteristics and are closely attached to each other by special triplet desmosomes. At stage 2- only remnants of polar trophoblast are found and lie mostly posteriorly and show apical blebs and long microvilli. The ventral epiblast forms a concave epithelium under the remnants of polar trophoblast and shares adhesion contacts with mural trophoblast and with each other by what is known as zipper-like desmosomes, the mature serial form of the special desmosome.

The expression of the homeobox transcription factor goosecoid $(\mathrm{gsc})$ is found early at stage 0 of $8 \mathrm{dpc}$ embryos in the flat hypoblast of the ICM and in the extraembryonic trophoblast. Later it is confined to the extraembryonic and embryonic parts of the anterior hypoblast. The expression pattern develops from an anterior crescent shape into half-ring shape. Intriguingly, two opposite domains of $g s c$ are found at pregastrulation stage 2: (1) in the anterior hypoblast, which shifts both more centrally and more anteriorly towards the extraembryonic tissue and (2) in posterior epiblast cells where the primitive streak will eventually form. At stage $4+$ the node (the mammalian equivalent to Spemann's organizer) is strongly gsc positive.

The results of the study are discussed in the context of epiblast development and early axis formation, cavity formation by the rosette-like cellular rearrangement as seen in pre-amniotic cavity formation in the mouse and human, and I speculate that the separation of the apical membrane of epiblast cells is not only caused by charge repulsion mediated through actomyosin contraction but also involves the role of filopodia in cell mobility and migration. The polar trophoblast disintegration shares overlapping characteristics of two modes of programmed cell death, autophagy and apoptosis. The dorsal, non- epithelialized mass of cells shares the fate of the attached polar trophoblast. Both cell types show signs of apoptosis and they may be eventually phagocytosed by the neighboring ventral epiblast cells as the latter contain up to stage 2 - few but large phagocytosis vacuoles.

In sum, I propose that the epiblast does not undergo an unfolding process but that its cells (1) rearrange their position with the help of highly flexible immature special desmosome during epithelialization, and (2) form a concave epithelium fusing with mural trophoblast anteriorly or posteriorly, while the central mass of dorsal epiblast is lost with the disappearing polar trophoblast. Furthermore, I propose that the pattern of the gsc expression in the 
pregastrulation stages reflects two different roles of the gene: (1) in the anterior hypoblast, gsc may repress the activity of the BMP4 at stages 0,1 - and 1+ in the epiblast; (2) in the epiblast gsc may be involved in activation of the fate and features of the prospective prechordal mesoderm. 


\section{References}

1. Artinger, M., Blitz, I., Inoue, K., Tran, U., and Cho, K.W.Y. (1997). Interaction of goosecoid and brachyury in Xenopus mesoderm patterning. Mech. Dev. 65, 187-196.

2. Barends, P.M.G., Stroband, H.W.J., Taverne, N., Kronnie, G. te, Leën, M.P.J.M., and Blommers, P.C.J. (1989). Integrity of the preimplantation pig blastocyst during expansion and loss of polar trophectoderm (Rauber cells) and the morphology of the embryoblast as an indicator for developmental stage. Reproduction 87, 715-726.

3. Baumbach, G.A., Bartley, N.G., Kattesh, H.G., and Godkin, J.D. (1990).

Immunolocalization and endocytosis of the uterine secretory protein, uteroferrin, in preimplantation pig trophectoderm on day 11 of pregnancy. Anat. Embryol. (Berl.) 182, 563568.

4. Beddington, R.S. (1994). Induction of a second neural axis by the mouse node.

Development 120, 613-620.

5. Bedzhov, I., and Zernicka-Goetz, M. (2014). Self-Organizing Properties of Mouse Pluripotent Cells Initiate Morphogenesis upon Implantation. Cell 156, 1032-1044. 6. Belo, J.A., Bouwmeester, T., Leyns, L., Kertesz, N., Gallo, M., Follettie, M., and De Robertis, E.M. (1997). Cerberus-like is a secreted factor with neutralizing activity expressed in the anterior primitive endoderm of the mouse gastrula. Mech. Dev. 68, 45-57.

7. Bertocchini, F., Alev, C., Nakaya, Y., and Sheng, G. (2013). A little winning streak: The reptilian-eye view of gastrulation in birds. Dev. Growth Differ. 55, 52-59.

8. Betteridge, K.J., and Fléchon, J.-E. (1988). The anatomy and physiology of pre-attachment bovine embryos. Theriogenology $29,155-187$.

9. Bevilacqua, E.M., and Abrahamsohn, P.A. (1988). Ultrastructure of trophoblast giant cell transformation during the invasive stage of implantation of the mouse embryo. J. Morphol. 198, 341-351.

10. Bevilacqua, E.M., and Abrahamsohn, P.A. (1989). Trophoblast invasion during 
implantation of the mouse embryo. Arch. Biol. Med. Exp. (Santiago) 22, 107-118.

11. Bevilacqua, E., Hoshida, M.-S., Amarante-Paffaro, A., Albieri-Borges, A., and Zago Gomes, S. (2010). Trophoblast phagocytic program: roles in different placental systems. Int. J. Dev. Biol. 54, 495-505.

12. Blomberg, L., Hashizume, K., and Viebahn, C. (2008). Blastocyst elongation, trophoblastic differentiation, and embryonic pattern formation. Reprod. Camb. Engl. 135, 181-195.

13. Blum, M., Gaunt, S.J., Cho, K.W.Y., Steinbeisser, H., Blumberg, B., Bittner, D., and Robertis, E.M.D. (1992). Gastrulation in the mouse: The role of the homeobox gene goosecoid. Cell 69, 1097-1106.

14. Blum, M., Andre, P., Muders, K., Schweickert, A., Fischer, A., Bitzer, E., Bogusch, S., Beyer, T., van Straaten, H.W.M., and Viebahn, C. (2007). Ciliation and gene expression distinguish between node and posterior notochord in the mammalian embryo. Differentiation $75,133-146$.

15. Blumberg, B., Wright, C.V., De Robertis, E.M., and Cho, K.W. (1991). Organizerspecific homeobox genes in Xenopus laevis embryos. Science 253, 194-196.

16. Bolton, H., Graham, S.J.L., Van der Aa, N., Kumar, P., Theunis, K., Fernandez Gallardo, E., Voet, T., and Zernicka-Goetz, M. (2016). Mouse model of chromosome mosaicism reveals lineage-specific depletion of aneuploid cells and normal developmental potential. Nat. Commun. 7, 11165.

17. Boucher, D.M., Schäffer, M., Deissler, K., Moore, C.A., Gold, J.D., Burdsal, C.A., Meneses, J.J., Pedersen, R.A., and Blum, M. (2000). goosecoid expression represses Brachyury in embryonic stem cells and affects craniofacial development in chimeric mice. Int. J. Dev. Biol. 44, 279-288.

18. Broun, M., Sokol, S., and Bode, H.R. (1999). Cngsc, a homologue of goosecoid, participates in the patterning of the head, and is expressed in the organizer region of Hydra. 
Development 126, 5245-5254.

19. Bursch, W. (2001). The autophagosomal-lysosomal compartment in programmed cell death. Cell Death Differ. 8, 569-581.

20. Callebaut, M., and Van Nueten, E. (1994). Rauber's (Koller's) sickle: the early gastrulation organizer of the avian blastoderm. Eur. J. Morphol. 32, 35-48.

21. Callebaut, M., Van Nueten, E., Harrisson, F., Van Nassauw, L., and Schrevens, A. (1998). Induction of (pre) gastrulation and/or (pre) neurulation by subgerminal ooplasm and Rauber's sickle in cultured anti-sickle regions of avian unincubated blastoderms. Eur. J. Morphol. 36, $1-10$.

22. Carlson, B.M. (2002). Embryology in the medical curriculum. Anat. Rec. 269, 89-98.

23. Cho, K.W.Y., Blumberg, B., Steinbeisser, H., and De Robertis, E.M. (1991). Molecular nature of Spemann's organizer: the role of the Xenopus homeobox gene goosecoid. Cell 67, $1111-1120$.

24. Chuai, M., Hughes, D., and Weijer, C.J. (2012). Collective epithelial and mesenchymal cell migration during gastrulation. Curr. Genomics 13, 267-277.

25. Clarke, P.G.H. (1990). Developmental cell death: morphological diversity and multiple mechanisms. Anat. Embryol. (Berl.) 181, 195-213.

26. Dai, J.-D., and Gilbert, L.I. (1997). Programmed cell death of the prothoracic glands of Manduca sexta during pupal-adult metamorphosis. Insect Biochem. Mol. Biol. 27, 69-78. 27. Degrelle, S.A., Campion, E., Cabau, C., Piumi, F., Reinaud, P., Richard, C., Renard, J.-P., and Hue, I. (2005). Molecular evidence for a critical period in mural trophoblast development in bovine blastocysts. Dev. Biol. 288, 448-460.

28. De Robertis, E.M.D., Fainsod, A., Gont, L.K., and Steinbeisser, H. (1994). The evolution of vertebrate gastrulation. Development 1994, 117-124. 
29. Dey, S.K., Lim, H., Das, S.K., Reese, J., Paria, B.C., Daikoku, T., and Wang, H. (2004). Molecular cues to implantation. Endocr. Rev. 25, 341-373.

30. D’Herde, K., Diez-Fraile, A., and Lammens, T. (2009). Apoptotic, Autophagic and Necrotic Cell Death Types in Pathophysiological Conditions: Morphological and Histological Aspects. In Phagocytosis of Dying Cells: From Molecular Mechanisms to Human Diseases, D.V. Krysko, and P. Vandenabeele, eds. (Dordrecht: Springer Netherlands), pp. 33-62.

31. Ding, X., Hausen, P., and Steinbeisser, H. (1998). Pre-MBT patterning of early gene regulation in Xenopus: the role of the cortical rotation and mesoderm induction. Mech. Dev. $70,15-24$.

32. Dumortier, J.G., Verge-Serandour, M.L., Tortorelli, A.F., Mielke, A., Plater, L. de, Turlier, H., and Maître, J.-L. (2019). Hydraulic fracturing and active coarsening position the lumen of the mouse blastocyst. Science 365, 465-468.

33. Elmore, S. (2007). Apoptosis: a review of programmed cell death. Toxicol. Pathol. 35, 495-516.

34. Enders, A.C., and Schlafke, S. (1981). Differentiation of the blastocyst of the rhesus monkey. Am. J. Anat. 162, 1-21.

35. Enders, A.C., Lantz, K.C., Liu, I.K., and Schlafke, S. (1988). Loss of polar trophoblast during differentiation of the blastocyst of the horse. J. Reprod. Fertil. 83, 447-460.

36. Fainsod, A., Steinbeisser, H., and De Robertis, E.M. (1994). On the function of BMP-4 in patterning the marginal zone of the Xenopus embryo. EMBO J. 13, 5015-5025. 37. Fléchon, J.E. (1978). Morphological aspects of embryonic disc at the time of its appearance in the blastocyst of farm mammals [Sow, ewe and rabbit, scanning electron microscopy]. Scanning Electron Microsc. USA.

38. Fléchon, J.-E. (2017). Planar polarity of the extraembryonic epithelia in the preimplantation porcine conceptus. Int. J. Dev. Biol. 61, 505-517.

39. Gallo, G., and Letourneau, P.C. (2004). Regulation of growth cone actin filaments by 
guidance cues. J. Neurobiol. 58, 92-102.

40. Gandolfi, F., Pennarossa, G., Maffei, S., and Brevini, T. a. L. (2012). Why is it so Difficult to Derive Pluripotent Stem Cells in Domestic Ungulates? Reprod. Domest. Anim. 47, 11-17.

41. Gardner, R.L., Papaioannou, V.E., and Barton, S.C. (1973). Origin of the ectoplacental cone and secondary giant cells in mouse blastocysts reconstituted from isolated trophoblast and inner cell mass. Development 30, 561-572.

42. Gelsert, R.D., Renegar, R.H., Thatcher, W.W., Michael Roberts, R., and Bazer, F.W. (1982). Establishment of Pregnancy in the Pig: I. Interrelationships Between Preimplantation Development of the Pig Blastocyst and Uterine Endometrial Secretions. Biol. Reprod. 27, 925-939.

43. Ghadially, F.N., and More, I. a. R. (1989). Ultrastructural Pathology of the Cell and Matrix 3rd edition. Histopathology 15, 102-102.

44. Gorfinkiel, N., Schamberg, S., and Blanchard, G.B. (2011). Integrative approaches to morphogenesis: Lessons from dorsal closure. Genesis 49, 522-533.

45. Green, K.J., Geiger, B., Jones, J.C., Talian, J.C., and Goldman, R.D. (1987). The relationship between intermediate filaments and microfilaments before and during the formation of desmosomes and adherens-type junctions in mouse epidermal keratinocytes. J. Cell Biol. 104, 1389-1402.

46. Halacheva, V., Fuchs, M., Dönitz, J., Reupke, T., Püschel, B., and Viebahn, C. (2011). Planar cell movements and oriented cell division during early primitive streak formation in the mammalian embryo. Dev. Dyn. Off. Publ. Am. Assoc. Anat. 240, 1905-1916. 47. Hall, V. (2008). Porcine embryonic stem cells: a possible source for cell replacement therapy. Stem Cell Rev. 4, 275-282.

48. Hall, V.J., Jacobsen, J.V., Rasmussen, M.A., and Hyttel, P. (2010). Ultrastructural and molecular distinctions between the porcine inner cell mass and epiblast reveal unique 
pluripotent cell states. Dev. Dyn. 239, 2911-2920.

49. Hara, K. (1978). Spemann's organizer in birds. Organ. Milest. Half-Century Spemann $221-265$.

50. Hassoun, R., Schwartz, P., Feistel, K., Blum, M., and Viebahn, C. (2009). Axial differentiation and early gastrulation stages of the pig embryo. Differ. Res. Biol. Divers. 78, $301-311$.

51. Hesseldahl, H. (1971). Ultrastructure of early cleavage stages and preimplantation in the rabbit. Z. Für Anat. Entwicklungsgeschichte 135, 139-155.

52. Horsthemke, M., Bachg, A.C., Groll, K., Moyzio, S., Müther, B., Hemkemeyer, S.A., Wedlich-Söldner, R., Sixt, M., Tacke, S., Bähler, M., et al. (2017). Multiple roles of filopodial dynamics in particle capture and phagocytosis and phenotypes of Cdc42 and Myo10 deletion. J. Biol. Chem. 292, 7258-7273.

53. Hotulainen, P., and Lappalainen, P. (2006). Stress fibers are generated by two distinct actin assembly mechanisms in motile cells. J. Cell Biol. 173, 383-394.

54. Hou, D.-R., Jin, Y., Nie, X.-W., Zhang, M.-L., Ta, N., Zhao, L.-H., Yang, N., Chen, Y., Wu, Z.-Q., Jiang, H.-B., et al. (2016). Derivation of Porcine Embryonic Stem-Like Cells from In Vitro-Produced Blastocyst-Stage Embryos. Sci. Rep. 6, 25838.

55. Hyttel, P., Sinowatz, F., Vejlsted, M., and Betteridge, K. (2009). Essentials of Domestic Animal Embryology E-Book (Elsevier Health Sciences).

56. Hyttel, P.M., Kamstrup, K.M., and Hyldig, S.M.W. (2011). From Hatching into Fetal Life in the Pig. p.

57. Idkowiak, J., Weisheit, G., Plitzner, J., and Viebahn, C. (2004a). Hypoblast controls mesoderm generation and axial patterning in the gastrulating rabbit embryo. Dev. Genes Evol. 214, 591-605.

58. Idkowiak, J., Weisheit, G., and Viebahn, C. (2004b). Polarity in the rabbit embryo. Semin. 
Cell Dev. Biol. 15, 607-617.

59. Izpisúa-Belmonte, J.C., De Robertis, E.M., Storey, K.G., and Stern, C.D. (1993). The homeobox gene goosecoid and the origin of organizer cells in the early chick blastoderm. Cell $74,645-659$.

60. Lawson, K.A., Meneses, J.J., and Pedersen, R.A. (1991). Clonal analysis of epiblast fate during germ layer formation in the mouse embryo. Dev. Camb. Engl. 113, 891-911. 61. Levine, B., and Kroemer, G. (2008). Autophagy in the pathogenesis of disease. Cell 132, $27-42$.

62. Li, Y., Xu, J., Zhou, C.-Q., Zhang, C.-L., and Zhuang, G.-L. (2016). Nonprofessional phagocytosis in trophectoderm cells of human preimplantation blastocysts. Syst. Biol. Reprod. Med. 62, 243-248.

63. Linkermann, A., and Green, D.R. (2014). Necroptosis. N. Engl. J. Med. 370, 455-465. 64. Loganathan, R., Rongish, B.J., Smith, C.M., Filla, M.B., Czirok, A., Bénazéraf, B., and Little, C.D. (2016). Extracellular matrix motion and early morphogenesis. Dev. Camb. Engl. 143, 2056-2065.

65. Lopata, A., Kohlman, D.J., and Kellow, G.N. (1982). The fine structure of human blastocysts developed in culture. Prog. Clin. Biol. Res. 85 Pt B, 69-85.

66. Luckett, W.P. (1975). Ontogeny of the Fetal Membranes and Placenta. In Phylogeny of the Primates: A Multidisciplinary Approach, W.P. Luckett, and F.S. Szalay, eds. (Boston, MA: Springer US), pp. 157-182.

67. Luu, O., Nagel, M., Wacker, S., Lemaire, P., and Winklbauer, R. (2008). Control of gastrula cell motility by the Goosecoid/Mix.1/ Siamois network: basic patterns and paradoxical effects. Dev. Dyn. Off. Publ. Am. Assoc. Anat. 237, 1307-1320.

68. Maddox-Hyttel, P., Alexopoulos, N.I., Vajta, G., Lewis, I., Rogers, P., Cann, L., Callesen, H., Tveden-Nyborg, P., and Trounson, A. (2003). Immunohistochemical and ultrastructural characterization of the initial post-hatching development of bovine embryos. Reprod. Camb. 
Engl. 125, 607-623.

69. Magtanong, L., Ko, P.J., and Dixon, S.J. (2016). Emerging roles for lipids in nonapoptotic cell death. Cell Death Differ. 23, 1099-1109.

70. Maretto, S., Cordenonsi, M., Dupont, S., Braghetta, P., Broccoli, V., Hassan, A.B., Volpin, D., Bressan, G.M., and Piccolo, S. (2003). Mapping Wnt/ $\beta$-catenin signaling during mouse development and in colorectal tumors. Proc. Natl. Acad. Sci. 100, 3299-3304.

71. Mattila, P.K., and Lappalainen, P. (2008). Filopodia: molecular architecture and cellular functions. Nat. Rev. Mol. Cell Biol. 9, 446-454.

72. Meijer, H.A., Pavert, S.A.V.D., Stroband, H.W.J., and Boerjan, M.L. (2000). Expression of the organizer specific homeobox gene Goosecoid (gsc) in porcine embryos. Mol. Reprod. Dev. 55, 1-7.

73. Millard, T.H., and Martin, P. (2008). Dynamic analysis of filopodial interactions during the zippering phase of Drosophila dorsal closure. Dev. Camb. Engl. 135, 621-626.

74. Mohamed, O.A., Clarke, H.J., and Dufort, D. (2004). Beta-catenin signaling marks the prospective site of primitive streak formation in the mouse embryo. Dev. Dyn. Off. Publ. Am. Assoc. Anat. 231, 416-424.

75. Nakamura, O., and Toivonen, S. (1978). Organizer-a milestone of a half-century from Spemann (Elsevier/North-Holland Biomedical Press).

76. Nakatsuji, N., Snow, M.H.L., and Wylie, C.C. (1986). Cinemicrographic study of the cell movement in the primitive-streak-stage mouse embryo. Development 96, 99-109.

77. Nakaya, Y., and Sheng, G. (2008). Epithelial to mesenchymal transition during gastrulation: an embryological view. Dev. Growth Differ. 50, 755-766.

78. Nakaya, Y., and Sheng, G. (2013). EMT in developmental morphogenesis. Cancer Lett. $341,9-15$. 
79. Niehrs, C., Keller, R., Cho, K.W., and De Robertis, E.M. (1993). The homeobox gene goosecoid controls cell migration in Xenopus embryos. Cell 72, 491-503.

80. Norberg, H.S. (1973). Ultrastructural aspects of the preattached pig embryo: Cleavage and early blastocyst stages. Z. Für Anat. Entwicklungsgeschichte 143, 95-114.

81. Oestrup, O., Hall, V., Petkov, S.G., Wolf, X.A., Hyldig, S., and Hyttel, P. (2009). From zygote to implantation: morphological and molecular dynamics during embryo development in the pig. Reprod. Domest. Anim. Zuchthyg. 44 Suppl 3, 39-49.

82. Onishi, A., Iwamoto, M., Akita, T., Mikawa, S., Takeda, K., Awata, T., Hanada, H., and Perry, A.C. (2000). Pig cloning by microinjection of fetal fibroblast nuclei. Science 289, 1188-1190.

83. Paluch, E.K., and Raz, E. (2013). The role and regulation of blebs in cell migration. Curr. Opin. Cell Biol. 25, 582-590.

84. Park, D., Yang, G., Bae, D.K., Lee, S.H., Yang, Y.-H., Kyung, J., Kim, D., Choi, E.-K., Choi, K.-C., Kim, S.U., et al. (2013). Human adipose tissue-derived mesenchymal stem cells improve cognitive function and physical activity in ageing mice. J. Neurosci. Res. 91, 660670.

85. Pei, D., Shu, X., Gassama-Diagne, A., and Thiery, J.P. (2019). Mesenchymal-epithelial transition in development and reprogramming. Nat. Cell Biol. 21, 44-53.

86. Pellegrin, S., and Mellor, H. (2007). Actin stress fibres. J. Cell Sci. 120, 3491-3499. 87. Penaloza, C., Lin, L., Lockshin, R.A., and Zakeri, Z. (2006). Cell death in development: shaping the embryo. Histochem. Cell Biol. 126, 149.

88. Posfai, E., Tam, O.H., and Rossant, J. (2014). Chapter One - Mechanisms of Pluripotency In Vivo and In Vitro. In Current Topics in Developmental Biology, M. Rendl, ed. (Academic Press), pp. 1-37.

89. Püschel, B., Bitzer, E., Blum, M., and Viebahn, C. (2010). Mounting, embedding, and 
sectioning of early rabbit embryos. Cold Spring Harb. Protoc. 2010, pdb.prot5356.

90. Rivera-Pérez, J.A., Mager, J., and Magnuson, T. (2003). Dynamic morphogenetic events characterize the mouse visceral endoderm. Dev. Biol. 261, 470-487.

91. Rossant, J., and Tam, P.P.L. (2009). Blastocyst lineage formation, early embryonic asymmetries and axis patterning in the mouse. Dev. Camb. Engl. 136, 701-713.

92. Rusu, M.C., Pop, F., Mănoiu, V.M., Lupuşoru, M.O., and Didilescu, A.C. (2013). Zipperlike series of desmosomes supported by subplasmalemmal actin belts in thymic epithelial reticular cells in the rat. Ann. Anat. Anat. Anz. Off. Organ Anat. Ges. 195, 359-364.

93. Sasai, Y., Lu, B., Steinbeisser, H., and De Robertis, E.M. (1995). Regulation of neural induction by the Chd and Bmp-4 antagonistic patterning signals in Xenopus. Nature 376, $333-336$.

94. Sathananthan, A.H., and Trounson, A.O. (2000). Mitochondrial morphology during preimplantational human embryogenesis. Hum. Reprod. Oxf. Engl. 15 Suppl 2, 148-159. 95. Schindelin, J., Arganda-Carreras, I., Frise, E., Kaynig, V., Longair, M., Pietzsch, T., Preibisch, S., Rueden, C., Saalfeld, S., Schmid, B., et al. (2012). Fiji: an open-source platform for biological-image analysis. Nat. Methods 9, 676-682.

96. Schwartz, P., Piper, H.M., Spahr, R., and Spieckermann, P.G. (1984). Ultrastructure of cultured adult myocardial cells during anoxia and reoxygenation. Am. J. Pathol. 115, 349361.

97. Shahbazi, M.N., Scialdone, A., Skorupska, N., Weberling, A., Recher, G., Zhu, M., Jedrusik, A., Devito, L.G., Noli, L., Macaulay, I.C., et al. (2017). Pluripotent state transitions coordinate morphogenesis in mouse and human embryos. Nature 552, 239-243.

98. Shawlot, W., Deng, J.M., and Behringer, R.R. (1998). Expression of the mouse cerberusrelated gene, Cerr1, suggests a role in anterior neural induction and somitogenesis. Proc. Natl. Acad. Sci. 95, 6198-6203.

99. Sheng, G. (2015). Epiblast morphogenesis before gastrulation. Dev. Biol. 401, 17-24. 
100. Shih, J., and Fraser, S.E. (1996). Characterizing the zebrafish organizer: microsurgical analysis at the early-shield stage. Dev. Camb. Engl. 122, 1313-1322.

101. Spanos, S., Rice, S., Karagiannis, P., Taylor, D., Becker, D.L., Winston, R.M.L., and Hardy, K. (2002). Caspase activity and expression of cell death genes during development of human preimplantation embryos. Reprod. Camb. Engl. 124, 353-363.

102. Spemann, H., and Mangold, H. (1924). über Induktion von Embryonalanlagen durch Implantation artfremder Organisatoren. Arch. Für Mikrosk. Anat. Entwicklungsmechanik 100, 599-638.

103. Stankova, V., Tsikolia, N., and Viebahn, C. (2015). Rho kinase activity controls directional cell movements during primitive streak formation in the rabbit embryo. Dev. Camb. Engl. 142, 92-98.

104. Stroband, H.W., and Van, T. der L. (1990). Embryonic and uterine development during early pregnancy in pigs. J. Reprod. Fertil. Suppl. 40, 261-277.

105. Sun, M.G., Williams, J., Munoz-Pinedo, C., Perkins, G.A., Brown, J.M., Ellisman, M.H., Green, D.R., and Frey, T.G. (2007). Correlated three-dimensional light and electron microscopy reveals transformation of mitochondria during apoptosis. Nat. Cell Biol. 9, 10571065.

106. Sun, R., Lei, L., Liu, S., Xue, B., Wang, J., Wang, J., Shen, J., Duan, L., Shen, X., Cong, Y., et al. (2013). Morphological changes and germ layer formation in the porcine embryos from days 7-13 of development. Zygote Camb. Engl. 23, 266-276.

107. Takaoka, K., and Hamada, H. (2012). Cell fate decisions and axis determination in the early mouse embryo. Development 139, 3-14.

108. Takaoka, K., Yamamoto, M., and Hamada, H. (2011). Origin and role of distal visceral endoderm, a group of cells that determines anterior-posterior polarity of the mouse embryo. Nat. Cell Biol. 13, 743-752. 
109. Talbot, N.C., and Garrett, W.M. (2001). Ultrastructure of the embryonic stem cells of the 8-day pig blastocyst before and after in vitro manipulation: development of junctional apparatus and the lethal effects of PBS mediated cell-cell dissociation. Anat. Rec. 264, 101113.

110. Tam, P.P., and Steiner, K.A. (1999). Anterior patterning by synergistic activity of the early gastrula organizer and the anterior germ layer tissues of the mouse embryo. Dev. Camb. Engl. 126, 5171-5179.

111. Taniguchi, K., Heemskerk, I., and Gumucio, D.L. (2019). Opening the black box: Stem cell-based modeling of human post-implantation development. J. Cell Biol. 218, 410-421.

112. Thomas, P., and Beddington, R. (1996). Anterior primitive endoderm may be responsible for patterning the anterior neural plate in the mouse embryo. Curr. Biol. CB 6, 1487-1496.

113. Tsujimoto, Y., and Shimizu, S. (2005). Another way to die: autophagic programmed cell death. Cell Death Differ. 12 Suppl 2, 1528-1534.

114. Ulmer, B., Tingler, M., Kurz, S., Maerker, M., Andre, P., Mönch, D., Campione, M., Deißler, K., Lewandoski, M., Thumberger, T., et al. (2017). A novel role of the organizer gene Goosecoid as an inhibitor of Wnt/PCP-mediated convergent extension in Xenopus and mouse. Sci. Rep. 7.

115. Valdez Magaña, G., Rodríguez, A., Zhang, H., Webb, R., and Alberio, R. (2014). Paracrine effects of embryo-derived FGF4 and BMP4 during pig trophoblast elongation. Dev. Biol. 387, 15-27.

116. Van de Pavert, S.A., Schipper, H., de Wit, A.A., Soede, N.M., van den Hurk, R., Taverne, M.A., Boerjan, M.L., and Stroband, H.W. (2001). Comparison of anterior-posterior development in the porcine versus chicken embryo, using goosecoid expression as a marker. Reprod. Fertil. Dev. 13, 177-185.

117. van Leeuwen, J., Berg, D.K., and Pfeffer, P.L. (2015). Morphological and Gene Expression Changes in Cattle Embryos from Hatched Blastocyst to Early Gastrulation Stages 
after Transfer of In Vitro Produced Embryos. PLoS ONE 10.

118. Vejlsted, M., Avery, B., Schmidt, M., Greve, T., Alexopoulos, N., and Maddox-Hyttel, P. (2005). Ultrastructural and immunohistochemical characterization of the bovine epiblast. Biol. Reprod. 72, 678-686.

119. Viebahn, C. (1999). The anterior margin of the mammalian gastrula: comparative and phylogenetic aspects of its role in axis formation and head induction. Curr. Top. Dev. Biol. 46, 63-103.

120. Viebahn, C., Mayer, B., and Miething, A. (1995). Morphology of Incipient Mesoderm Formation in the Rabbit Embryo: A Light- and Retrospective Electron-Microscopic Study. Cells Tissues Organs 154, 99-110.

121. Viebahn, C., Stortz, C., Mitchell, S.A., and Blum, M. (2002). Low proliferative and high migratory activity in the area of Brachyury expressing mesoderm progenitor cells in the gastrulating rabbit embryo. Development 129, 2355-2365.

122. Waddington, C.H., and Schmidt, G.A. (1933). Induction by heteroplastic grafts of the primitive streak in birds. Wilhelm Roux Arch. Für Entwicklungsmechanik Org. 128, 522563.

123. Weisheit, G., Mertz, K., Schilling, K., and Viebahn, C. (2002). An efficient in situ hybridization protocol for multiple tissue sections and probes on miniaturized slides. Dev. Genes Evol. 212, 403-406.

124. Wickman, G.R., Julian, L., Mardilovich, K., Schumacher, S., Munro, J., Rath, N., Zander, S.A., Mleczak, A., Sumpton, D., Morrice, N., et al. (2013). Blebs produced by actinmyosin contraction during apoptosis release damage-associated molecular pattern proteins before secondary necrosis occurs. Cell Death Differ. 20, 1293-1305.

125. Williams, B.S., and Biggers, J.D. (1990). Polar trophoblast (Rauber's layer) of the rabbit blastocyst. Anat. Rec. 227, 211-222. 
126. Wilmut, I., Sales, D.I., and Ashworth, C.J. (1986). Maternal and embryonic factors associated with prenatal loss in mammals. Reproduction 76, 851-864.

127. Xia, P., Liu, Z., and Qin, P. (2011). Fine structures of embryonic discs of in vivo posthatching porcine blastocysts at the pre-primitive streak stage. Reprod. Domest. Anim. Zuchthyg. 46, 366-372.

128. Yoshida, M., Kajikawa, E., Kurokawa, D., Tokunaga, T., Onishi, A., Yonemura, S., Kobayashi, K., Kiyonari, H., and Aizawa, S. (2016). Conserved and divergent expression patterns of markers of axial development in eutherian mammals. Dev. Dyn. 245, 67-86.

129. Zhu, C.C., Yamada, G., Nakamura, S., Terashi, T., Schweickert, A., and Blum, M. (1998). Malformation of trachea and pelvic region in goosecoid mutant mice. Dev. Dyn. 211, 374-381. 


\section{Supplementary Materials}

\section{Figures}
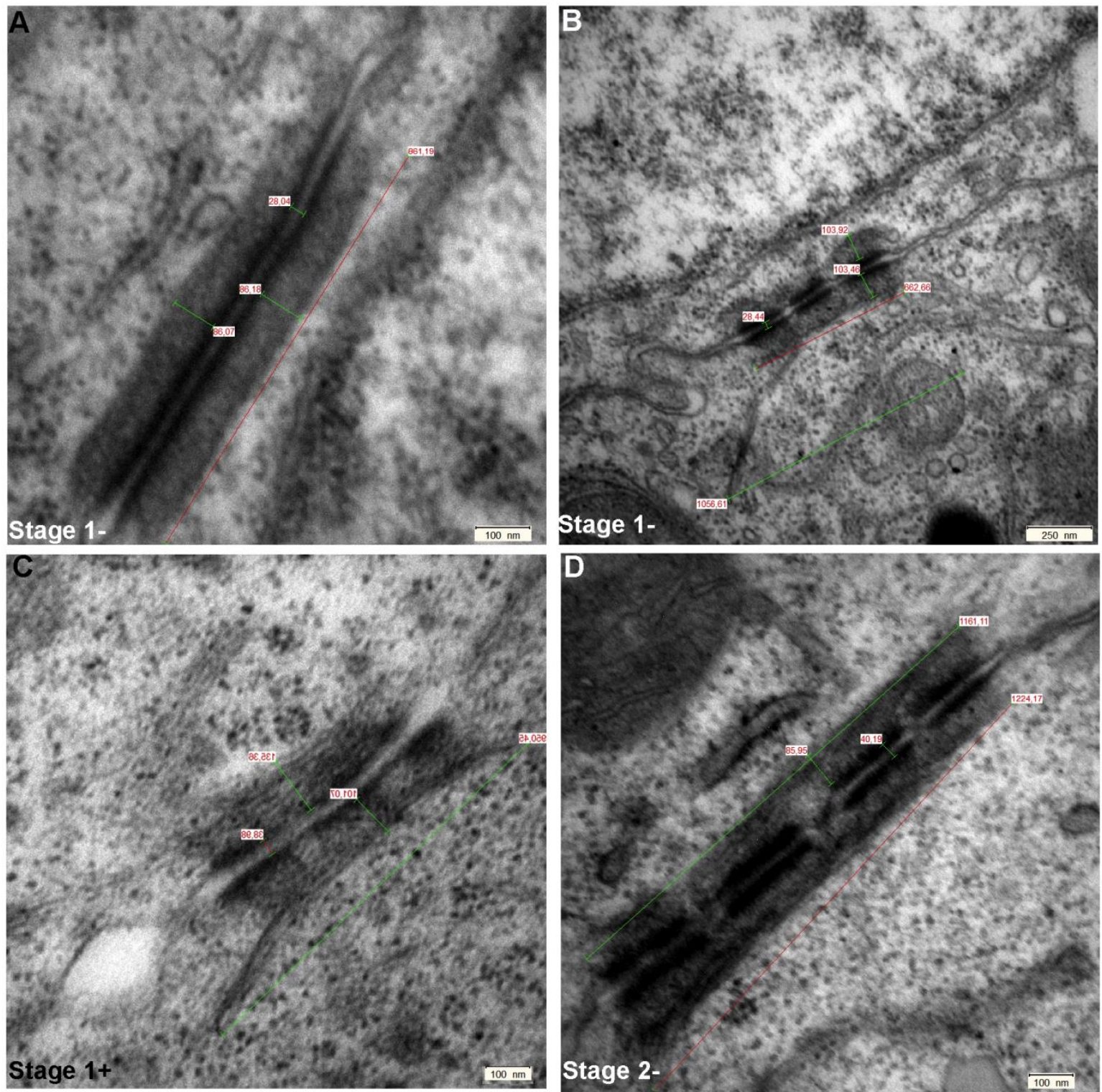

Fig. 1 Measurements of desmosomes during epiblast epithelialization (shown in Fig. 6, 7 and 9). Immature individual special desmosome (A) and triple special desmosome (B) bordered by intracellular felts of microfilaments at stage 1- . (C) Triple special desmosomes with long longitudinally microfilaments at stage 1+ and mature zipper-like desmosome at stage 2- between apical epithelial epiblast cells (D). The measurements define the length and width of the paralleled filaments and the space between the two plaques. Scale bar: (A, C, D) $100 \mathrm{~nm}$, (B) $250 \mathrm{~nm}$. 

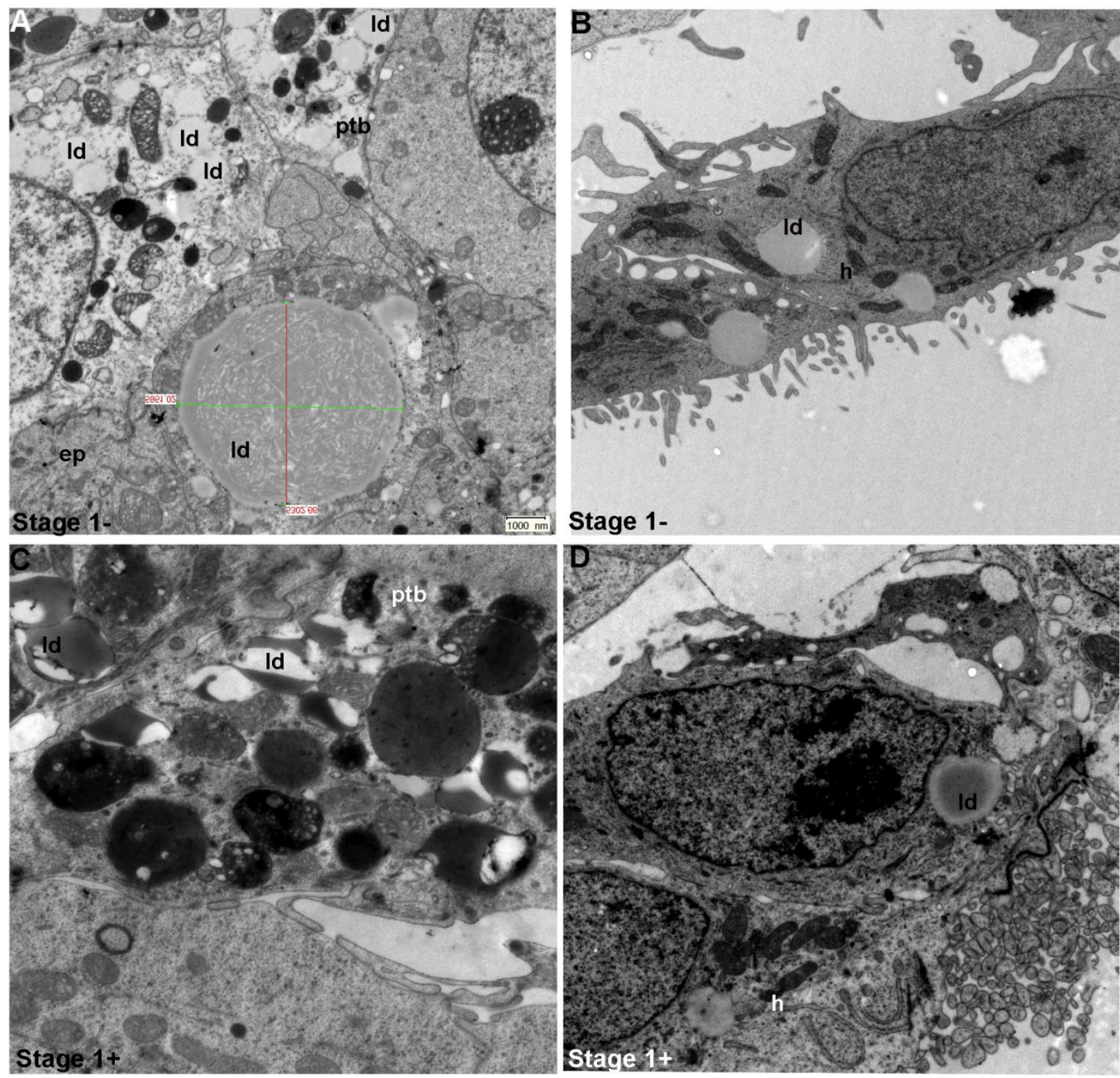

\section{Stage 1-}

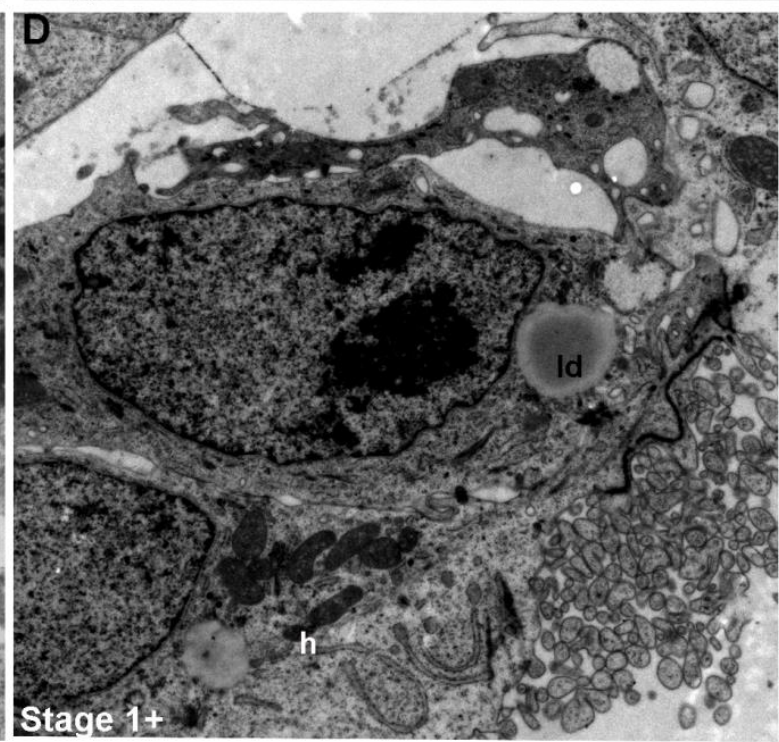

Fig. 2 Comparison of lipid droplets in polar trophoblast, epiblast and hypoblast at stages 1- and 1+. Huge lipid droplet with measurement in the cytoplasm of the epiblast cells near the embryonic disc borders and many smaller lipid droplets in the polar trophoblast at stage 1- (A). Few lipid droplets are found in hypoblast at stage 1- (B). At stage 1+, disintegration of lipid droplets in the polar trophoblast (C) and maintenance of the lipid droplets in the hypoblast (D); lp, lipid droplet; ep, epiblast; ptb, polar trophoblast; h, hypoblast. Scale bar: (A, B, D) $600 \mathrm{~nm}$, (C) $400 \mathrm{~nm}$. 

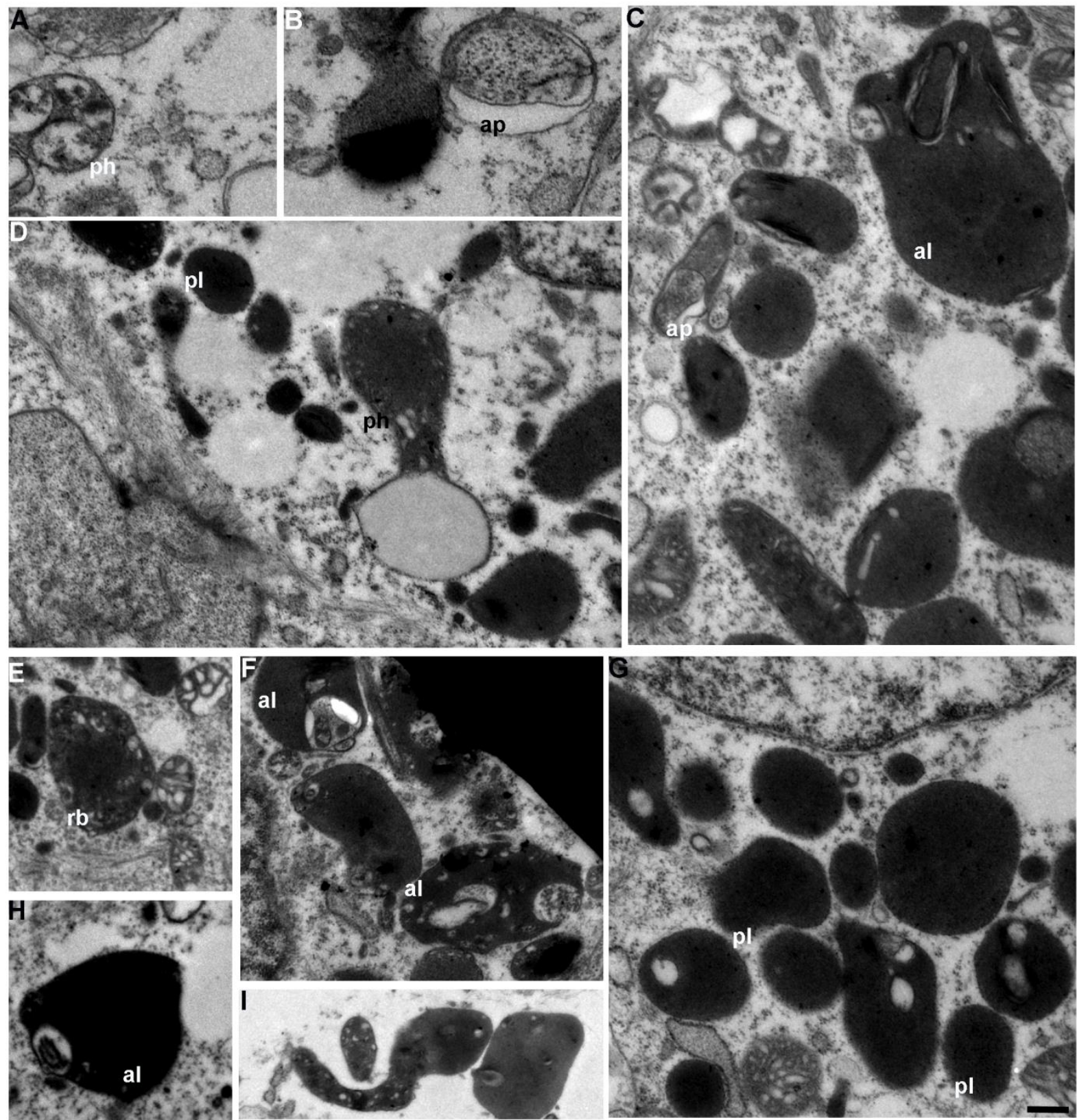

Fig. 3 Organelles during degeneration of polar trophoblast at stage 1+. Phagosome (A, D), double membrane autophagosome (in B and C), many dark spherical primary lysosome (in C, D and G), autolysosomes contain debris and remnants of lipid droplets (in C, F, H and I) and residual bodies (E); pl, primary lysosome; al, autolysosome; rb, residual body; ph, phagosome. Scale bar: (A-G) $200 \mathrm{~nm}$. 

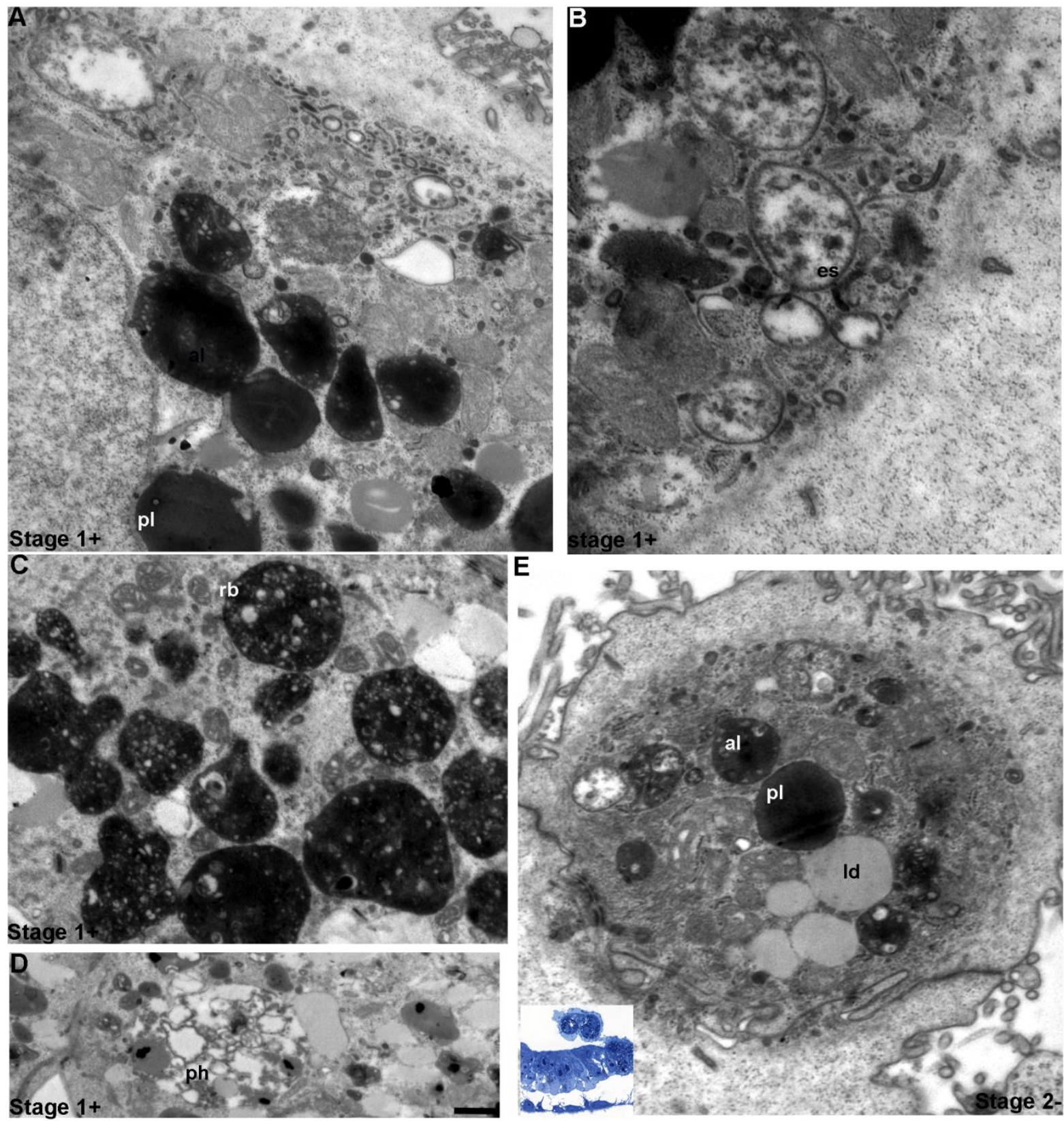

Fig. 4 Organelles in the remnants of polar trophoblast cells at late stage 1+ and 2-. At stage 1+ near the basal surface of the polar trophoblast blebs, there is increased number of autolysosomes (A), phagosome (D), endosomes (B) and residual bodies (C). Unattached remnant of polar trophoblast contains desmosomes, lipid droplets, autolysosomes and primary lysosome (E); ld, lipid droplet; pl, primary lysosome; al, autolysosome; es, endosome; rb, residual body; ph, phagosome. Scale bar: (A-D) $200 \mathrm{~nm}, € 450 \mathrm{~nm}$. 


\section{Tables}

Table 1. Comparison of embryonic stages prior to gastrulation with age

\begin{tabular}{|c|c|c|c|c|c|c|c|}
\hline \multirow{2}{*}{$\begin{array}{c}\text { Pig gestational age } \\
\text { (dpc) }\end{array}$} & $\begin{array}{c}\text { Total } \\
\text { number } \\
\text { of } \\
\text { embryos }\end{array}$ & \multicolumn{6}{|c|}{$\begin{array}{c}\text { Number of embryos at the four defined } \\
\text { pregastrulation Stages }\end{array}$} \\
\cline { 3 - 8 } & St 0 & St 1 & St $1^{+}$ & St 2- & St 2+ & St 4+ \\
\hline $8-9$ & 17 & 2 & 11 & 4 & - & - & - \\
\hline $9-10$ & 26 & - & 2 & 8 & 8 & 8 & - \\
\hline $11-12$ & 3 & - & - & - & - & & 3 \\
\hline
\end{tabular}


Table 2. Measurements $(\mathrm{nm})$ of the special desmosomes during the epithelialization of the epiblast cells.

\begin{tabular}{|l|l|l|l|l|l|}
\cline { 2 - 6 } \multicolumn{1}{c|}{} & Total length & $\begin{array}{l}\text { Length of } \\
\text { segments }\end{array}$ & $\begin{array}{l}\text { Width of } \\
\text { filament layer } \\
\text { ('felt') }\end{array}$ & $\begin{array}{l}\text { Length of } \\
\text { filament layer }\end{array}$ & $\begin{array}{l}\text { Intercellular } \\
\text { gap }\end{array}$ \\
\hline $\begin{array}{l}\text { Stage 1- } \\
\text { (8 dpc) }\end{array}$ & $324-890$ & & 84 & $17-20$ \\
\hline $\begin{array}{l}\text { Stage 1- } \\
\text { (9 dpc) }\end{array}$ & 783 & $181-194$ & 99 & 1127 & 15 \\
\hline $\begin{array}{l}\text { Stage 1+ } \\
\text { (9 dpc) }\end{array}$ & 579 & $162-233$ & 98 & 990 & 24 \\
\hline $\begin{array}{l}\text { Stage 2- } \\
\text { (10 dpc) }\end{array}$ & 1127 & $186-278$ & 85 & 1249 & 35 \\
\hline
\end{tabular}




\section{Curriculum Vitae}

\section{PERSONAL DETAILS}

Name

Date and Place of Birth

Nationality

\section{EDUCATION}

April 2015 - present

Apr. 20011

Apr 2009 - Jan 2011

Sep. 2000 - Sept. 2004

\author{
Braah Harmoush \\ January $3^{\text {rd }}, 1981$ in Jableh, Latakia, \\ Syrian
}

\section{Doctoral Candidate}

Georg-August University Göttingen, Germany

Institute of Anatomy and Embryology, University Medical

Center, Göttingen

Program: Biology, Georg-August University School of Science (GAUSS)

\author{
Diploma thesis Biology \\ Georg-August University Göttingen, Germany \\ Institute of Anatomy and Embryology, University Medical \\ Center, Göttingen \\ Program: Biology, Georg-August University
}

\section{MA Program Biology}

Georg-August University Göttingen, Germany

Faculty of Biology and Psychology,

as a scholarship holder of the Minister of Education and

Tishreen University, Syria

\section{Bachelor of Science in Biology and Biochemistry}

Tishreen University, Latakia, Syria

\section{PROFESSIONAL EXPERIENCE}

\section{TEACHING EXPERIENCE}

Oct $2018-\operatorname{Dec} 2018$

\section{Teaching Associate}

Georg-August University Göttingen, Germany Institute of Anatomy and Embryology, University Medical Center

Subjects (for Human Medicine, Dentistry, Molecular Medicine):

- General Histology

- Microscopic Anatomy of the Organs

Feb. 2005 - Jan. 2006

\section{Research Assistant}

Tishreen University, Latakia, Syria

Field of molecular embryology Faculty of Natural Sciences,

Department of Animal Biology

Teaching in the laboratories of the Faculty of Pharmacy and conducting experiments in the subject of "Biochemistry" 


\section{Conferences}

03/2009 Poster contribution, 18th Wissenschaftliche Tagung der Gesellschaft für Entwicklungsbiologie (GfE), Hannover, Germany

09/2016 Poster contribution „111th Annual Meeting of the Anatomische Gesellschaft, Göttingen, Germany

03/ 2017 Poster contribution Joint Meeting of the German and Japanese Societies of Developmental Biologists, Kiel, Germany

06/ 2019 Poster contribution 24th National Congress of the Bulgarian Anatomical Society, Stara Zagora, Bulgaria

\section{Manuscripts}

08/2021 Epiblast and trophoblast morphogenesis in the pre-gastrulation blastocyst of the pig. A light- and electron-microscopical study.

Manuscript in preparation: Organizer genes as early markers of the anterior-posterior axis differentiation in the pig blastocyst. Submission planned November 2021 